Review

\title{
Emissions estimation from satellite retrievals: A review of current capability
}

\author{
David G. Streets ${ }^{\mathrm{a}, *}$, Timothy Canty ${ }^{\mathrm{b}}$, Gregory R. Carmichael ${ }^{\mathrm{c}}$, Benjamin de Foy ${ }^{\mathrm{d}}$, \\ Russell R. Dickerson ${ }^{b}$, Bryan N. Duncan ${ }^{\text {, }}$, David P. Edwards ${ }^{f}$, John A. Haynes ${ }^{g}$, \\ Daven K. Henze ${ }^{\text {, }}$, Marc R. Houyoux ${ }^{i}$, Daniel J. Jacob ${ }^{j}$, Nickolay A. Krotkov ${ }^{\mathrm{e}}$, \\ Lok N. Lamsal ${ }^{\mathrm{e}}$, Yang Liu ${ }^{\mathrm{k}}$, Zifeng Lu ${ }^{\mathrm{a}}$, Randall V. Martin ${ }^{\text {, }}$, Gabriele G. Pfister ${ }^{\mathrm{f}}$, \\ Robert W. Pinder ${ }^{m}$, Ross J. Salawitch ${ }^{\mathrm{b}}$, Kevin J. Wecht ${ }^{\mathrm{j}}$
}

${ }^{a}$ Decision and Information Sciences Division, Argonne National Laboratory, Argonne, IL 60439, USA

${ }^{\mathrm{b}}$ Department of Atmospheric and Oceanic Science, The University of Maryland, College Park, MD 20742, USA

${ }^{c}$ Center for Global and Regional Environmental Research, The University of Iowa, Iowa City, IA 52242, USA

${ }^{\mathrm{d}}$ Department of Earth and Atmospheric Sciences, Saint Louis University, St. Louis, MO 63108, USA

e Atmospheric Chemistry and Dynamics Laboratory, NASA Goddard Space Flight Center, Greenbelt, MD 20771, USA

${ }^{\mathrm{f}}$ Atmospheric Chemistry Division, National Center for Atmospheric Research, Boulder, CO 80301, USA

${ }^{\mathrm{g}}$ Earth Science Division, National Aeronautics and Space Administration, Washington, DC 20546, USA

${ }^{\mathrm{h}}$ Department of Mechanical Engineering, University of Colorado, Boulder, CO 80309, USA

i Office of Air Quality Planning and Standards, U.S. Environmental Protection Agency, Research Triangle Park, NC 27711, USA

${ }^{\mathrm{j} S}$ School of Engineering and Applied Sciences, Harvard University, Cambridge, MA 02138, USA

${ }^{\mathrm{k}}$ Department of Environmental Health, Emory University, Atlanta, GA 30322, USA

${ }^{1}$ Department of Physics and Atmospheric Science, Dalhousie University, Halifax, NS B3H 4R2, Canada

${ }^{\mathrm{m}}$ Office of Research and Development, U.S. Environmental Protection Agency, Research Triangle Park, NC 2771, USA

\section{H I G H L I G H T S}

- Comprehensive review of studies of satellite data applied to emissions estimation.

- Overview of retrievals for eight major tropospheric air pollutants.

- Techniques to enhance the usefulness of satellite retrievals.

- Identification of target source categories for satellite data application.

- Recommendations on ways to improve the usability of satellite retrievals.

\section{A R T I C L E I N F O}

Article history:

Received 25 October 2012

Received in revised form

3 April 2013

Accepted 21 May 2013

\section{Keywords:}

Satellite retrievals

Emission inventories

Air quality management

Data assimilation

National Emission Inventory

\begin{abstract}
A B S T R A C T
Since the mid-1990s a new generation of Earth-observing satellites has been able to detect tropospheric air pollution at increasingly high spatial and temporal resolution. Most primary emitted species can be measured by one or more of the instruments. This review article addresses the question of how well we can relate the satellite measurements to quantification of primary emissions and what advances are needed to improve the usability of the measurements by U.S. air quality managers. Built on a comprehensive literature review and comprising input by both satellite experts and emission inventory specialists, the review identifies several targets that seem promising: large point sources of $\mathrm{NO}_{x}$ and $\mathrm{SO}_{2}$, species that are difficult to measure by other means $\left(\mathrm{NH}_{3}\right.$ and $\mathrm{CH}_{4}$, for example), area sources that cannot easily be quantified by traditional bottom-up methods (such as unconventional oil and gas extraction, shipping, biomass burning, and biogenic sources), and the temporal variation of emissions (seasonal, diurnal, episodic). Techniques that enhance the usefulness of current retrievals (data assimilation, oversampling, multi-species retrievals, improved vertical profiles, etc.) are discussed. Finally, we point out the value of having new geostationary satellites like GEO-CAPE and TEMPO over North America that could provide measurements at high spatial (few $\mathrm{km}$ ) and temporal (hourly) resolution.
\end{abstract}

(c) 2013 Elsevier Ltd. All rights reserved.

\footnotetext{
* Corresponding author. Tel.: +1 630252 3448; fax: +1 6302526500 .

E-mail address: dstreets@anl.gov (D.G. Streets).
} 


\section{Introduction}

In the past two decades major advances have occurred in the detection of atmospheric pollution from space. The generation of satellite instruments launched since 1995 has proved to be capable of observing a wide range of chemical species at increasingly high spatial and temporal resolution. In addition, the transformation of raw satellite retrievals to user-friendly, archived products has progressed considerably, such that the application of satellite observations to a wide range of atmospheric problems is no longer a daunting prospect. Previous review papers (Borrell et al., 2003; Martin, 2008; Palmer, 2008; Hoff and Christopher, 2009) have stressed the value of space-based observations for measuring tropospheric air pollution from space and have pointed out the potential to infer emission strengths. Satellite instruments measure the concentration of a chemical species in a vertical column of air; and, if transport and chemical conversion do not greatly interfere or can be compensated for, then the measurements can be used to estimate the emission rate of the species directly under that column of air.

In 2011 the U.S. National Aeronautics and Space Administration (NASA) Applied Sciences Program (ASP) created an Air Quality Applied Sciences Team (AQAST) to serve the needs of U.S. air quality managers through the use of Earth science satellite data, suborbital data, and models (NASA, 2013a). One component of the AQAST activity is an assessment of the applicability to U.S. air quality management of research that links satellite retrievals with emissions. We pose two questions: How can air quality managers make use of satellite retrievals to improve emission estimates? and What developments are needed to enhance the usefulness of those retrievals? It is not difficult to prepare a list of possible applications: verification of point-source compliance, quantification of uncertain area sources (including biogenic and other natural sources), estimation of neighboring emissions (say, in Canada and Mexico) and long-distance emissions (say, in China) that may influence U.S. air quality, the coordinated use of multiple-species retrievals, the detection of wildfires and other episodic events, etc. But in which of these areas does valuable capability lie?

In support of U.S. air quality management, EPA has developed the National Emissions Inventory (NEI), a compilation of emission estimates collected from state, local, and tribal (S/L/T) air agencies, supplemented with other resources (EPA, 2013a). The NEI is released on a triennial cycle, with the most recent version for 2008. Some satellite data products are already included in the NEI, mainly related to wildfires. However, there are many other areas in which satellite products could potentially augment the NEI in the future.

The purpose of this article is to review the literature and generate from it a U.S. perspective on what satellite observations can tell us about emissions. Because of this focus, the reader should not expect to find reference herein to the use of satellite data in studies of ambient concentrations of ozone or secondary aerosols or the movement of polluted air masses. Nor do we include studies outside North America unless they contribute significantly to relevant methods development or the novel treatment of emission sources that have the potential to be transferred to the U.S. context.

The article is organized in five main sections. First, we review 12 major satellite instruments that have the capability to detect and quantify emissions (Section 2). Next, we describe the derivation of retrievals from these instruments for eight important chemical species (Section 3). Methodological approaches to enhance source quantification are described in Section 4 , together with the primary application studies that have been published to date, organized by source type. In Section 5, we draw together the satellite capability and the characteristics of the NEI to highlight promising avenues for future applications, which are summarized in Section 6 .

\section{Satellites: platforms, instruments, and their characteristics}

In this section we briefly review the history of relevant satellite missions, highlighting those payload instruments that have helped to advance the study of tropospheric air pollution. We focus on modern instruments that have been widely used in the quantification of emissions or, at minimum, in the identification of source regions or the assessment of regional source strengths. We do not include older instruments or modern instruments that are of limited value for emissions estimation.

On the European side, the modern era of pollution-observing satellites began with the launch by the European Space Agency (ESA) of the second European Remote Sensing satellite ERS-2 on April 21, 1995, that carried the Global Ozone Monitoring Experiment (GOME) designed to measure $\mathrm{O}_{3}, \mathrm{NO}_{2}$, and related species (Burrows et al., 1999). GOME was fully functional until 2003, after which only limited data retrieval was possible until 2011. The successor to the ERS mission, ENVISAT, was launched on March 1, 2002, and carried the SCanning Imaging Absorption spectroMeter for Atmospheric CHartogaphY (SCIAMACHY) (Bovensmann et al., 1999), which has been extremely valuable for observing a wide range of trace gases in the troposphere. Sadly, the contributions of SCIAMACHY ended when contact with ENVISAT was lost on April 8, 2012. ESA and the European Organisation for the Exploitation of Meteorological Satellites (EUMETSAT) jointly initiated the MetOp mission for operational meteorology, and launched the MetOp-A satellite on October 19, 2006. Two instruments on MetOp-A are of relevance to this work: GOME-2 (Callies et al., 2000)-an update of the original ERS-2 instrument-and the Infrared Atmospheric Sounding Interferometer (IASI) (Clerbaux et al., 2009), which is capable of measuring $\mathrm{CO}, \mathrm{NH}_{3}, \mathrm{CH}_{4}$, and other species.

On the U.S. side, the modern era began on December 18, 1999, when NASA launched the Earth Observing System (EOS) satellite Terra, which featured three relevant onboard sensors: the Moderate Resolution Imaging Spectroradiometer (MODIS) (Barnes et al., 1998), the Multi-angle Imaging SpectroRadiometer (MISR) (Diner et al., 1998), and the Measurements Of Pollution In The Troposphere (MOPITT) instrument (Drummond, 1992). The first two of these instruments measure particulate matter (PM) and its optical effects, while the third specializes in the measurement of $\mathrm{CO}$. Two and a half years later, NASA launched Aqua on May 4, 2002. Aqua carried a second MODIS instrument as well as the Atmospheric Infrared Sounder (AIRS) (Aumann et al., 2003). On July 15, 2004, NASA launched the Aura satellite to improve our understanding of the changing chemistry of Earth's atmosphere. Two Aura instruments are particularly valuable in an air pollution context: the Ozone Monitoring Instrument (OMI) (Levelt et al., 2006) and the Tropospheric Emission Spectrometer (TES) (Beer et al., 2001). Aqua and Aura are both components of a constellation of satellites called the "A-train" that makes coordinated measurements of the same location as they pass over it, one at a time, within an eightminute period. Unfortunately, two subsequent satellites that would have further aided the investigation of tropospheric air pollution failed to reach orbit: the Orbiting Carbon Observatory (OCO) in February 2009 and Glory in March 2011. On January 23, 2009, the Japan Aerospace Exploration Agency (JAXA) and collaborating institutions launched the Greenhouse gases Observing SATellite (GOSAT) with the goal of measuring concentrations of $\mathrm{CO}_{2}$ and $\mathrm{CH}_{4}$ and their variability over time and space (Kuze et al., 2009). Table 1 provides an overview of the major satellite platforms, their key instruments, and their primary characteristics. It shows the major species that each instrument is capable of observing. Further details are provided in subsequent sections of this paper to the extent that they are relevant to emissions quantification. 


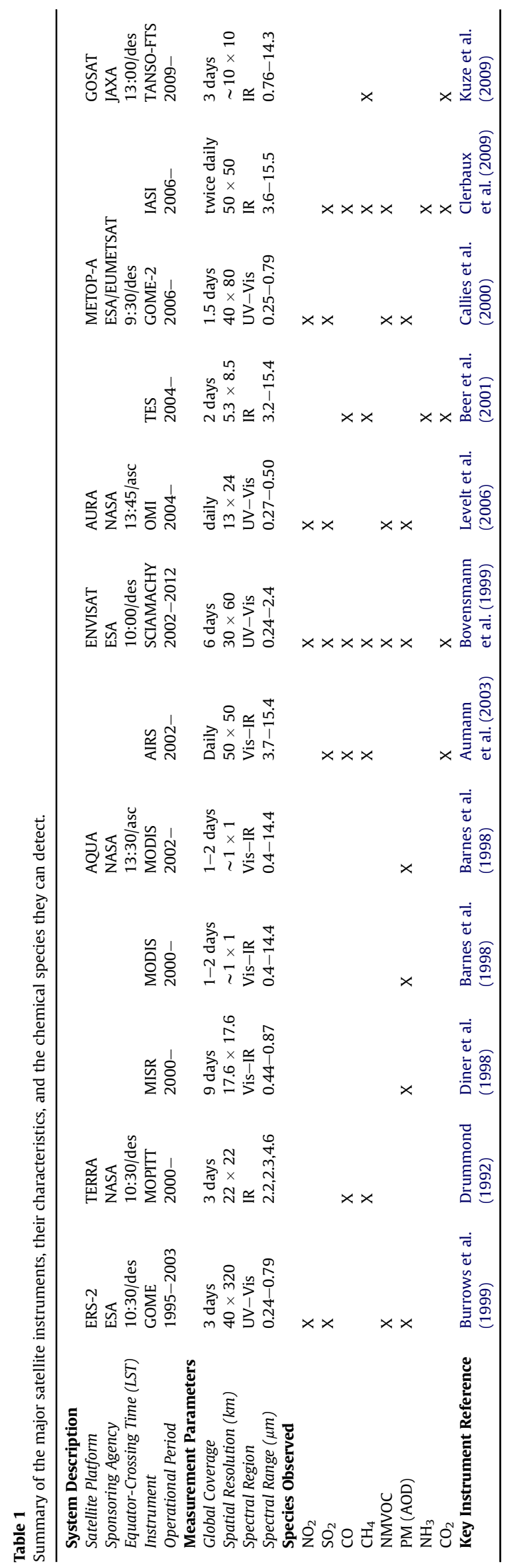

With no new launches of Earth-observing satellite instruments planned for the next few years, concern has been expressed that an interruption in the continuity of measurements could occur if present instruments were to fail. While this is undoubtedly true, prospects have improved in recent years with the approval of two new missions in the U.S. The next generation of Earth science satellite missions was planned as part of the National Research Council 2007 Decadal Survey. To study tropospheric trace gases and aerosols from geostationary orbit, the NASA Geostationary Coastal and Air Pollution Events (GEO-CAPE) mission was recommended for launch in the 2013-2016 time frame (Fishman et al., 2012), which would measure $\mathrm{SO}_{2}, \mathrm{NO}_{2}$, and other ozone/aerosol precursor species hourly over North America with the highest ground resolution of $4 \mathrm{~km} \times 4 \mathrm{~km}$. Due to budget constraints, the GEO-CAPE launch was subsequently delayed beyond 2020 , though refinements to the mission plan might bring this date forward somewhat. Then, in November 2012, a new mission called TEMPO (Tropospheric Emissions: Monitoring of Pollution) was selected under NASA's Earth Venture Instrument program with the specific goal of measuring tropospheric air pollutants $\mathrm{O}_{3}, \mathrm{NO}_{2}, \mathrm{SO}_{2}$, formaldehyde, glyoxal, and aerosols) over North America with high spatial and temporal resolution from geostationary orbit (NASA, 2013b). TEMPO is planned to be launched as a hosted payload on a commercial satellite before 2020. Depending on priorities and budgets, TEMPO could be a precursor or component of the larger GEO-CAPE suite of instruments.

For Europe, ESA is planning the Sentinel 4 and Sentinel 5 missions, carried on EUMETSAT meteorological satellites, to measure atmospheric composition. The Sentinel 5 Precursor mission is planned to launch in 2015 with a TROPOMI instrument, which will measure $\mathrm{NO}_{2}$ and $\mathrm{SO}_{2}$ with improved ground resolution $\left(\sim 50 \mathrm{~km}^{2}\right)$. Over Europe, the diurnal variations will be observed by the geostationary Sentinel 4 mission after 2018. Clerbaux and Crevoisier (2013) have expressed optimism about the future of IASI-type instruments for remote sensing in this timeframe. In addition, the Korea Aerospace Research Institute (KARI) is planning to launch an atmospheric chemistry satellite into geostationary orbit over East Asia in the 2018 time frame.

\section{Species observations}

This section describes the broad principles of satellite detection of atmospheric constituents, focusing on eight important emitted species that are observable from space at the present time. We review the conditions for measuring each species and some of the key studies undertaken to develop and apply the measurement methods. For the methods that are the furthest developed and the most used, we provide a little more detail on retrieval methods and archived products than for those that are primarily in research mode at the present time. The satellite instruments measure radiation over a wide region of the electromagnetic spectrum from the ultraviolet (UV) to the visible (Vis) in the range of $\sim 0.23-0.9 \mu \mathrm{m}$ and in the infrared (IR) from $\sim 4$ to $50 \mu \mathrm{m}$. Instruments can be classified into two types, those that observe solar backscatter radiation in the UV-Vis and those that observe thermal IR emission. Chemical species in the atmosphere are detected by the absorption, or attenuation, of radiation of specific wavelengths along the path that the radiation travels through the atmosphere. The inferred concentration of the chemical species, known as a retrieval, is determined by a complex set of spectral fitting and radiative transfer calculations, well described by Martin (2008). For the $\mathrm{NO}_{2}$ retrievals described in Section 3.1, which are the most fully developed and most widely used, we illustrate the process of deriving concentrations from radiation measurements in more detail, 
leading to the production of operational retrievals, i.e., fully processed data sets available for user applications.

\subsection{Nitrogen dioxide}

Nitrogen oxides $\left(\mathrm{NO}_{x}\right)$ are an important class of atmospheric species that are implicated in a number of environmental problems, including the formation of tropospheric ozone and aerosols, acidification, eutrophication, and human health effects. $\mathrm{NO}_{x}$ is primarily formed by combustion processes, and emission factors vary according to the fuel type and combustion conditions. For this reason, $\mathrm{NO}_{x}$ emissions can be quite uncertain, and there is potential for aiding the estimation of $\mathrm{NO}_{x}$ emissions using space-borne instruments. $\mathrm{NO}_{2}$ is the specific chemical form detected spectroscopically, so the relationship between $\mathrm{NO}_{x}$ emissions and $\mathrm{NO}_{2}$ concentrations must be taken into account (Lamsal et al., 2008, 2011). Daytime global $\mathrm{NO}_{2}$ datasets are produced daily using UVVis spectrometers aboard polar-orbiting, sun-synchronous satellites. OMI features the highest spatial resolution (13 km [along track] $\times 24 \mathrm{~km}$ [across track] at nadir) among this type of instrument and has been providing continuous global coverage since October 2004. The GOME-2 instrument has provided morning $\mathrm{NO}_{2}$ data since 2007. It is characterized by a spatial resolution of $40 \mathrm{~km} \times 80 \mathrm{~km}$ with global coverage in 1.5 days. In addition, the SCIAMACHY instrument produced $\mathrm{NO}_{2}$ data from its launch in 2002 until its demise in 2012. It was characterized by a spatial resolution of $30 \mathrm{~km} \times 60 \mathrm{~km}$ but had coverage gaps due to alternating limb and nadir modes of observation, so global coverage was achieved every six days at the equator. Their predecessor instrument, GOME, provided $\mathrm{NO}_{2}$ data from 1995 to 2003 at $40 \mathrm{~km} \times 320 \mathrm{~km}$ resolution, achieving global coverage every three days at the equator.

Processing of satellite measurements typically involves three or more steps or processing "levels". Calibrated Level 1 satellite data include high-resolution solar and earthshine spectra (typically better than $0.6 \mathrm{~nm}$ spectral resolution) for each individual measurement (pixel). Earthshine radiances are divided by a reference solar irradiance spectrum to linearize the $\mathrm{NO}_{2}$ retrieval problem. The reflectance spectra are fitted to laboratory-measured trace-gas spectra (e.g., Vandaele et al., 1998) convolved with an instrumental slit function, a reference Ring spectrum (e.g., Chance and Spurr, 1997), and a polynomial function that models the spectrally slowly varying scattering by clouds and aerosols and reflection by Earth's surface. The fitting algorithms use the Differential Optical Absorption Spectroscopy (DOAS) method, in which a continuous light source is used to send and receive light through the atmosphere and measure narrow-band UV-Vis absorption features associated with trace-gas species. These are applied to a preselected "fitting window" in the spectral range of $0.4-0.5 \mu \mathrm{m}$. The spectral fit yields a slant column density (SCD), which represents the measured total areal density of $\mathrm{NO}_{2}$ molecules along the effective optical path from the Sun through the atmosphere to the satellite. Additional processes include an air mass factor (AMF) calculation, which relates the trace gas abundance over the entire path length to the vertical column abundance, and partitioning of tropospheric and stratospheric components. Vertically resolved scattering weights (SW) or box air mass factors (box-AMF) describe the relationship between the slant column and the vertical column and are computed with a radiative transfer code that uses surface reflectivity, cloud fraction, cloud height, and surface topography. The profile-weighted average of SW provides the total stratospheric or tropospheric AMFs used to convert measured SCD to the inferred Level 2 vertical column density (VCD).

The overall error in the retrieval of tropospheric $\mathrm{NO}_{2}$ columns arises from errors in the SCD, the stratosphere-troposphere separation, and the AMF calculation. The uncertainty in SCD and the stratosphere-troposphere separation dominates the total retrieval error over the oceans and remote areas. Over continental source regions, AMF errors arising from incorrect assumptions about the $\mathrm{NO}_{2}$ vertical profile shape, surface reflectivity, cloud parameters, and aerosols dominate the overall retrieval errors. Estimated errors in the tropospheric $\mathrm{NO}_{2}$ columns are $\sim 30 \%$ under clear-sky conditions, but can reach up to $100 \%$ under certain conditions (Boersma et al., 2011; Bucsela et al., 2013). Instrument-specific artifacts, such as stripes in the OMI observations, may introduce additional errors (Celarier et al., 2008). The tropospheric $\mathrm{NO}_{2}$ retrievals and inferred emissions can benefit from the use of high spatial resolution information on surface reflectivity and $\mathrm{NO}_{2}$ vertical profile shape in the AMF calculation, as used in the Berkeley High-Resolution (BEHR) retrieval (Russell et al., 2011). The influence of spatial resolution on $\mathrm{NO}_{2}$ retrievals has been investigated by Valin et al. (2011) and Heckel et al. (2011).

Production of Level $3 \mathrm{NO}_{2}$ archived data typically includes regridding pixel data to a regular latitude-longitude grid, filtering the data, and time averaging to produce weekly-, monthly-, and seasonally-averaged data. Time averaging of the best-quality filtered data performed on a fine spatial grid (say, $1-5 \mathrm{~km}$ ) allows better characterization of stationary point sources such as power plants or smelters. Pixel-averaging techniques result in "superresolution" $\mathrm{NO}_{2}$ maps, greatly enhancing the satellite detection capability for weak point sources (see Section 4.2).

$\mathrm{NO}_{2}$ column retrievals have been the subject of a number of validation studies involving intercomparison with a variety of ground-based measurements, aircraft measurements, and model outputs. These studies contain great detail about the conditions (seasons, locations, weather conditions, etc.) under which the satellite retrievals can be expected to be the most reliable. These studies include Blond et al., 2007; Boersma et al., 2008a; Bucsela et al., 2008; Hains et al., 2010; Huijnen et al., 2010; Lamsal et al., 2008, 2010; and Martin et al., 2002, 2003. Different retrievals have been the subject of intercomparison (Boersma et al., 2008b; Lin et al., 2012). During the past decade, $\mathrm{NO}_{2}$ retrieval algorithms have matured considerably, such that different algorithms now have good consistency (Boersma et al., 2011; Bucsela et al., 2013).

\subsection{Sulfur dioxide}

Sulfur dioxide $\left(\mathrm{SO}_{2}\right)$ is an atmospheric constituent that is linked to adverse respiratory effects and can also form secondary sulfate particles through chemical reactions in the atmosphere. Acid deposition is another detrimental effect of $\mathrm{SO}_{2}$. Satellite measurements that are sufficiently sensitive to anthropogenic $\mathrm{SO}_{2}$ emissions are spectroscopically possible by measuring backscattered solar radiation in the UV. Measurements of anthropogenic $\mathrm{SO}_{2}$ have been demonstrated using several of the instruments described in Section 2, including GOME (Eisinger and Burrows, 1998), GOME-2 (Nowlan et al., 2011), SCIAMACHY (Lee et al., 2008b, 2009), and OMI (Krotkov et al., 2006, 2008; Yang et al., 2007). Currently, $\mathrm{SO}_{2}$ data from the OMI instrument are available in NASA Goddard public archives, such as GES-DISC and AVDC.

Different algorithms have been developed to retrieve $\mathrm{SO}_{2}$ from satellite data. DOAS $\mathrm{SO}_{2}$ algorithms have to use spectral fitting windows at longer UV wavelengths ( $>315 \mathrm{~nm}$ ), where $\mathrm{O}_{3}$ and $\mathrm{SO}_{2}$ absorptions are weak (Lee et al., 2008b, 2009). Alternatively, the operational $\mathrm{OMI} \mathrm{SO}_{2}$ band residual difference (BRD) algorithm (Krotkov et al., 2006) uses shorter wavelengths between $310.8 \mathrm{~nm}$ and $315 \mathrm{~nm}$ that are most sensitive to $\mathrm{SO}_{2}$, explicitly accounting for the strong $\mathrm{O}_{3}$ absorption in this spectral region. In the absence of information concerning the vertical distribution of $\mathrm{SO}_{2}$, a constant AMF value of 0.36 is assumed in the Level $2 \mathrm{OMSO} 2 \mathrm{PBL}$ product. This value is based on an average summertime $\mathrm{SO}_{2}$ profile measured by 
aircraft over the U.S. Mid-Atlantic region (Taubman et al., 2006). Although advanced $\mathrm{SO}_{2}$ algorithms such as optimal estimation (Nowlan et al., 2011) and direct spectral fitting (Yang et al., 2010) have been demonstrated, they are not yet used operationally.

Several factors influence the quality of the satellite-retrieved $\mathrm{SO}_{2}$ product. The sensitivity of satellite retrievals to $\mathrm{SO}_{2}$ in the boundary layer is low, due to enhanced Rayleigh scattering, large $\mathrm{O}_{3}$ absorption, and low surface albedo $(0.01-0.03$, except for snow-covered surfaces). Level 1 radiance spectra $(<320 \mathrm{~nm})$ have lower signalto-noise ratio and higher stray light compared to measurements at longer UV-Vis wavelengths (van den Oord et al., 2006). As a result, the noise of the $\mathrm{SO}_{2}$ retrieval is high (one standard deviation $=1-$ 2 DU) even under optimal viewing conditions (i.e., no clouds, near nadir, low solar zenith angle, mid- to low-latitudes). Spatial averaging of pixel data reduces the noise, although not as effectively as would be expected for random noise (Krotkov et al., 2008). In the OMI Level 2 OMSO2 data, there is no correction for clouds, so cloud screening and other filters (e.g., high solar zenith angle, snow cover, row anomaly, etc.) - as well as various adjustments such as corrections for the Pacific sector and local AMF (Lee et al., 2009, 2011a) and local bias (Fioletov et al., 2011)-are recommended for users. All necessary filters and corrections are currently applied in OMI Level 3 processing, and users are encouraged to use the Level 3 daily gridded $\left(0.25^{\circ} \times 0.25^{\circ}\right) \mathrm{SO}_{2}$ product (OMSO2e).

Despite these limitations, the operational $\mathrm{OMI} \mathrm{SO}_{2}$ data have been utilized in a wide range of studies (Krueger et al., 2009), in combination with aircraft MAX-DOAS measurements (Walter et al., 2012), in situ measurements (Dickerson et al., 2007; Lee et al., 2011b), and chemical transport modeling (CTM) (Lee et al., 2011a). Topics studied include the transport and transformation of emitted $\mathrm{SO}_{2}$ (Dickerson et al., 2007; Lee et al., 2008a; Li et al., 2010a; de Foy et al., 2009), top-down constraints on emissions and lifetime (Lee et al., 2008a, 2011a); spatiotemporal variations (McLinden et al., 2012; Jiang et al., 2012), and the impacts of anthropogenic emission controls on air pollution (Witte et al., 2009; Li et al., 2010b; Fioletov et al., 2011). Temporal averaging over a month or longer can effectively reduce the uncertainties in the daily $\mathrm{SO}_{2}$ operational data, which are estimated at $\sim 100 \%$ (Krotkov et al., 2008) and considered to be too large for most air quality applications. Using pixel averaging and spatial filtration techniques, moderate point sources of $\mathrm{SO}_{2}$ can be quantified (see Section 4.2).

Spectroscopic detection of $\mathrm{SO}_{2}$ in the infrared is also possible, though sensitivity is hindered by the strong absorption by water vapor in the same spectral region (Clarisse et al., 2008). Detection of ground-level $\mathrm{SO}_{2}$ by IASI has been demonstrated in principle, but presently the sensitivity is greatest at higher altitudes and for strong sources. Retrievals have been described by Clarisse et al. (2008) in the context of observations of the $\mathrm{SO}_{2}$ plume from the 2007 eruption of the Jebel at Tair volcano in the Red Sea.

\subsection{Carbon monoxide}

CO retrievals have unique value for observing anthropogenic activity, evaluating emissions, and determining the transport and influence of these emissions downwind of sources. For these reasons, it has been one of the few mission-critical measurements in all aircraft campaigns of the NASA Global Tropospheric Chemistry Program (Fisher et al., 2010). CO is a U.S. EPA criteria pollutant, the sources of which fall into two main classes: secondary chemical production and incomplete combustion. Chemical production results from hydrocarbon oxidation, while combustion sources include urban/industrial fossil-fuel burning, biofuel use, wildfires, and tropical biomass burning. $\mathrm{CO}$ is the dominant sink for the hydroxyl radical $(\mathrm{OH})$, and as such plays a critical role in controlling $\mathrm{OH}$ levels with implications for a wide range of atmospheric gases.
$\mathrm{CO}$ is also a major precursor for tropospheric $\mathrm{O}_{3}$ on a global scale. The $\mathrm{CO}$ global average lifetime against $\mathrm{OH}$ oxidation is about two months, providing sufficient time for $\mathrm{CO}$ to be an effective tracer of long-range pollution transport, yet sufficiently short for it to show large contrasts between polluted air masses and the background atmosphere (Edwards et al., 2004).

Two CO spectral bands, the thermal infrared (TIR) fundamental at $4.6 \mu \mathrm{m}$ and the near infrared (NIR) overtone band at $2.3 \mu \mathrm{m}$, can be used for passive remote sensing (Edwards et al., 1999). Instruments on each of NASA's EOS platforms make nadir measurements of CO at $4.6 \mu \mathrm{m}$ from low Earth orbit: MOPITT (Deeter et al., 2003), AIRS (McMillan et al., 2005), and TES (Rinsland et al., 2006b). CO observations are also made by IASI on the MetOp-A satellite (George et al., 2009). These measurements are generally most sensitive to $\mathrm{CO}$ in the middle troposphere, with limited vertical profile information available only under favorable conditions (e.g., Deeter et al., 2004). Using solar reflection at $2.3 \mu \mathrm{m}$ allows for retrieval of the total $\mathrm{CO}$ column with measurement sensitivity to all altitudes, including the lowermost troposphere. These have been made by SCIAMACHY (Buchwitz et al., 2006) and by MOPITT (Deeter et al., 2009).

Currently, MOPITT is the only satellite instrument to demonstrate the instantaneous multispectral retrievals necessary for an independent measurement of a trace-gas concentration in the lowermost troposphere (Worden et al., 2010). Retrieving CO from combined TIR and NIR radiances allows increased discrimination of vertical structure and upwards of three pieces of independent information, as characterized by the degrees of freedom of signal (DFS) (Rodgers, 2000). The fact that significant information about CO concentration in the lowest $2 \mathrm{~km}$ is often available should improve emission estimates of not only $\mathrm{CO}$, but also other combustion products for which emission ratios with $\mathrm{CO}$ can be developed. Accurate emission inventories for $\mathrm{CO}$ are important for air quality management; yet, past atmospheric observations have often yielded results that were significantly at odds with emission inventories (Parrish, 2006; Hudman et al., 2008; Miller et al., 2008; Kopacz et al., 2010). Further results from CO satellite observations are presented in Section 4.5 on anthropogenic area sources, the source category where the strongest potential applications exist.

\subsection{Methane}

Methane $\left(\mathrm{CH}_{4}\right)$ is the second most important anthropogenic greenhouse gas after $\mathrm{CO}_{2}$, and, as a short-lived climate forcing agent with a lifetime of $\sim 10$ years, it provides a lever for slowing near-term climate change. Emission controls also have co-benefits for improving air quality (Fiore et al., 2002). Efforts to reduce $\mathrm{CH}_{4}$ emissions around the globe are undertaken against the backdrop of poor quantitative understanding of $\mathrm{CH}_{4}$ sources (Heimann, 2011). Major anthropogenic sources include natural gas extraction and use, coal mining, landfills, livestock, rice cultivation, and biomass burning. Wetlands are the largest natural source. Bloom et al. (2010) were able to estimate worldwide $\mathrm{CH}_{4}$ emissions from wetlands and rice paddies using SCIAMACHY coupled with other measurements. Present-day global emissions of $\mathrm{CH}_{4}$ are $580 \pm 100 \mathrm{Tg} \mathrm{yr}^{-1}$, constrained by knowledge of the main global sink (reaction with the $\mathrm{OH}$ radical) from the methylchloroform budget (IPCC, 2007). However, the allocation of global emissions to source types and source regions is highly uncertain (Dlugokencky et al., 2011). To cite just one contemporary example, U.S. natural gas production has boomed in recent years as a result of new drilling techniques to unlock fuel trapped in shale formations. There is poor understanding of the associated $\mathrm{CH}_{4}$ emissions, and the shifting nature of oil/gas exploration complicates their accounting in standard inventories. 
Satellite observations provide a unique resource for constraining $\mathrm{CH}_{4}$ emissions through inverse modeling, because of the dense and continuous data they provide. Methane can be retrieved from space-based measurements of solar backscatter in the shortwave infrared (SWIR) and of terrestrial radiation in the thermal infrared (TIR). SWIR retrievals are available from SCIAMACHY for 20032012 (Frankenberg et al., 2005, 2011), though pixel degradation in the detector reduced data quality after 2005, and from GOSAT for 2009-present (Yokota et al., 2009; Butz et al., 2011; Parker et al., 2011). The retrievals are sensitive to the entire tropospheric column, but their dependence on reflected sunlight precludes observations at night, over most ocean surfaces, and over most cloudy targets. TIR retrievals are available from AIRS for 2002-present
(Xiong et al., 2009, 2010), TES for 2004-present (Worden et al., 2012b), and IASI for 2007-present (Crevoisier et al., 2009; Razavi et al., 2009); they have limited sensitivity to the lower troposphere but can be performed at night, over land and ocean, and for cloudy scenes.

SCIAMACHY data have been used in global and continental inverse modeling studies of $\mathrm{CH}_{4}$ emissions (Bergamaschi et al., 2007, 2009; Meirink et al., 2006, 2008), although the early studies were affected by retrieval biases propagating through the inversion (Bergamaschi et al., 2009). Fig. 1 compares SCIAMACHY observations for June-August 2004 to concurrent boundary layer observations from the NASA INTEX-A aircraft campaign, as well as to GEOS-Chem model results using a state-of-science emission
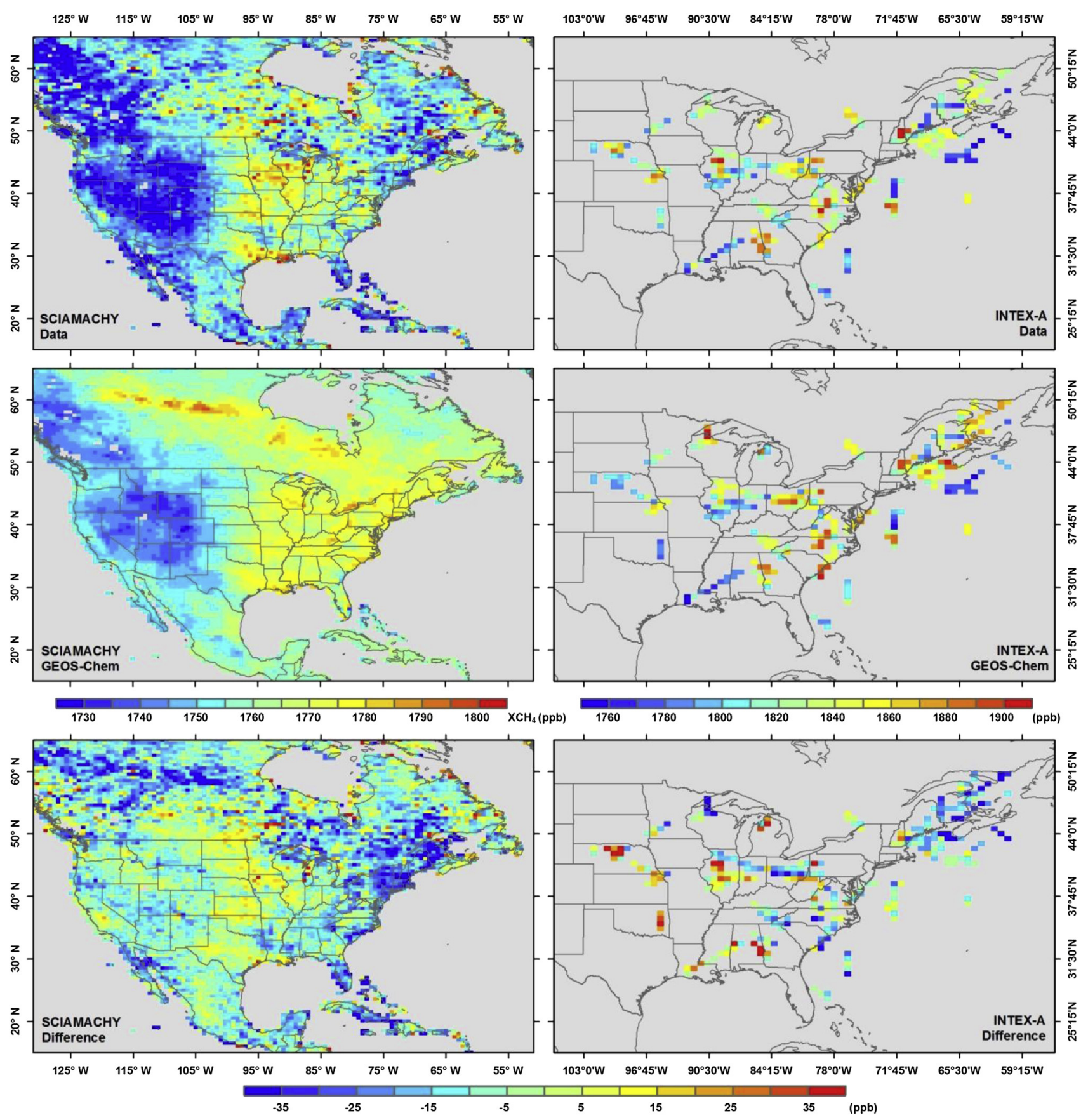

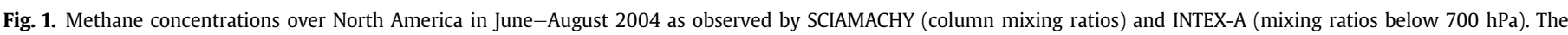
middle panels show the corresponding GEOS-Chem model values, and the bottom panels show the observed-model differences. 
inventory as the a priori (Pickett-Heaps et al., 2011). There is excellent correlation between SCIAMACHY and INTEX-A vertical profile data $(r=0.93$, regression slope $=0.96)$. Comparison with GEOS-Chem shows patterns of model underestimation in the central U.S. and overestimation along the east coast. Placing these discrepancies in the context of the a priori emissions suggests that livestock emissions are underestimated, while landfill and wetland emissions may be overestimated. But we also see that major sources in the south-central U.S. (likely from oil/gas recovery) appear to be missing from the emission inventory. Formal source attribution of the model overestimates and underestimates must be achieved through inverse modeling. Adjoint inverse modeling, as demonstrated by Meirink et al. $(2006,2008)$ and Bergamaschi et al. (2009), allows for emission estimates at the native resolution of the model. Specific source-type attribution needs to be derived by comparing the high-resolution inverse emission estimates with detailed bottom-up information.

The ability to validate satellite observations for $\mathrm{CH}_{4}$ has greatly expanded in recent years with the increased availability of aircraft vertical profiles and of ground-based column observations from the Total Carbon Column Observing Network (TCCON). Wecht et al. (2012) used the extensive vertical profiles from the HIAPER Poleto-Pole Observation (HIPPO) program over the Pacific to successfully validate the new TES v5 retrieval, including information in the lower troposphere. Validation of GOSAT with TCCON data, including over North America, shows that it can capture column changes of a few tenths of a percent, providing strong constraints for inverse modeling (Butz et al., 2011; Parker et al., 2011). GOSAT is likely to be an important source for space-based observation of $\mathrm{CH}_{4}$ emissions in the future.

The complementary vertical sensitivities of SWIR and TIR retrievals can be combined to improve emission estimates by constraining lower tropospheric $\mathrm{CH}_{4}$ concentrations. Kuai et al. (2013) have demonstrated the utility of this approach using $\mathrm{CO}_{2}$ retrievals from TES and TCCON, but to our knowledge no similar study has been done combining satellite-based $\mathrm{CH}_{4}$ retrievals. Fig. 2 shows the flight paths of the CalNex aircraft campaign in April-June 2010 and the locations of TES and GOSAT observations during this period. This figure is a good illustration of the relative spatial coverage of satellite and aircraft measurements that frame the intercomparison. By performing a set of inversions using combinations of CalNex, TES, and GOSAT data during the CalNex period, it is possible to evaluate the utility of each instrument or combination of instruments for constraining California $\mathrm{CH}_{4}$ emissions.

\subsection{Nonmethane volatile organic compounds}

Nonmethane volatile organic compounds (NMVOC) in the atmosphere have important implications for air quality and climate through their effects on atmospheric chemistry. They serve as precursors of organic aerosol, organic nitrates, and tropospheric $\mathrm{O}_{3}$, and can either enhance or deplete $\mathrm{OH}$ concentrations. Ability to observe NMVOC from space is mainly limited to $C_{1-3}$ molecules, because larger molecules do not have the fine band structure necessary for detection. Solar backscatter measurements of atmospheric columns require strong absorption features in the UV-Vis region and have been limited so far to formaldehyde ( $\mathrm{HCHO}$ ) (Chance et al., 2000) and glyoxal (CHOCHO) (Wittrock et al., 2006). Absorption bands in the IR enable the measurement of many other species by solar occultation or terrestrial emission, including methanol $\left(\mathrm{CH}_{3} \mathrm{OH}\right)$, formic acid $(\mathrm{HCOOH})$, hydrogen cyanide $(\mathrm{HCN})$, ethane $\left(\mathrm{C}_{2} \mathrm{H}_{6}\right)$, ethylene $\left(\mathrm{C}_{2} \mathrm{H}_{4}\right)$, acetylene $\left(\mathrm{C}_{2} \mathrm{H}_{2}\right)$, acetonitrile $\left(\mathrm{CH}_{3} \mathrm{CN}\right)$, peroxyacetylnitrate ( $\left.\mathrm{PAN}, \mathrm{CH}_{3} \mathrm{C}(\mathrm{O}) \mathrm{OONO}_{2}\right)$, and acetone $\left(\mathrm{CH}_{3} \mathrm{C}(\mathrm{O}) \mathrm{CH}_{3}\right)$. However, sensitivity for these measurements is limited to the middle or upper troposphere.

Satellite observations of HCHO columns by solar backscatter are available from GOME, SCIAMACHY, OMI, and GOME-2. These instruments provide a long and continuous record of observations (De Smedt et al., 2008; Stavrakou et al., 2009b). The detection limit is a few ppb in the boundary layer. HCHO is a high-yield product of NMVOC oxidation and has a lifetime of only a few hours against photolysis and oxidation. Satellite observations show large $\mathrm{HCHO}$ enhancements over vegetated and biomass burning regions, reflecting fast production from short-lived NMVOC. Urban areas are

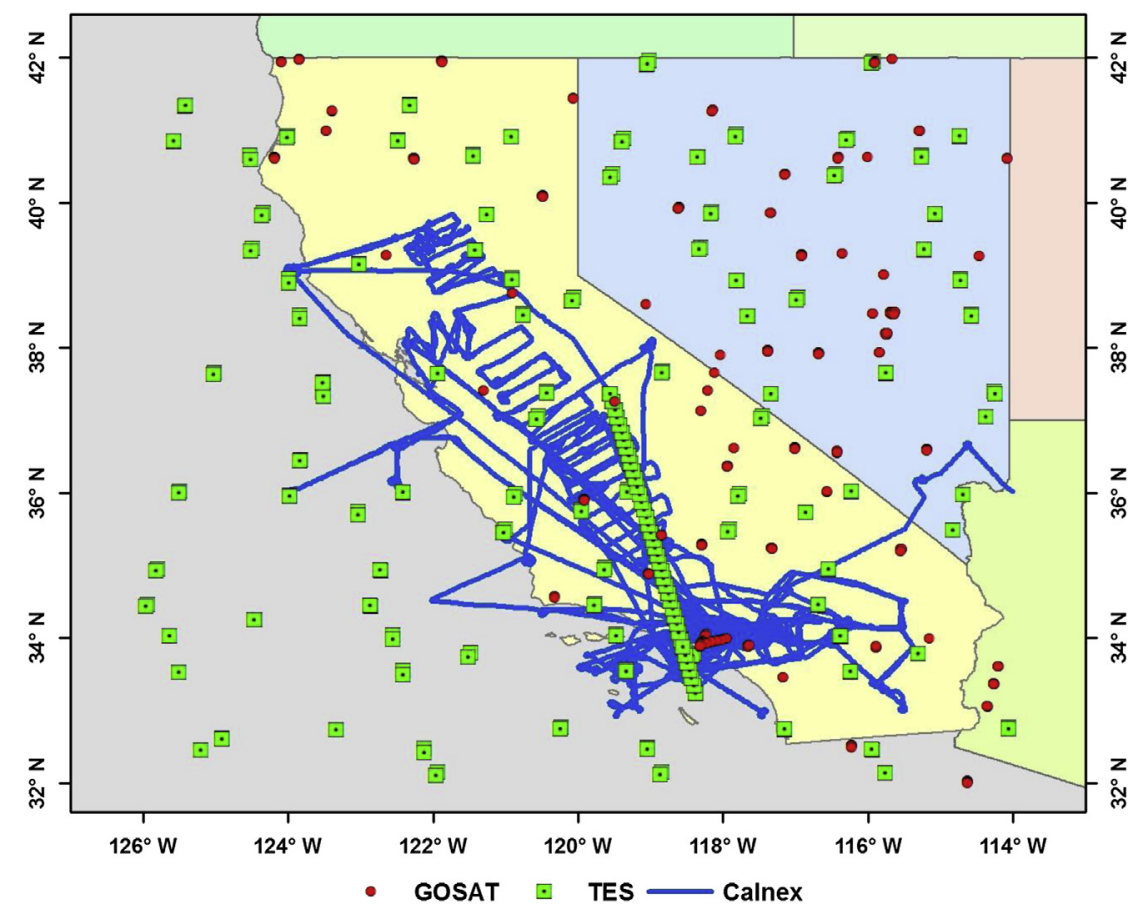

Fig. 2. Flight paths of the CalNex aircraft campaign in California in April-June 2010 and the locations of TES and GOSAT satellite observations during this period. 
detectable only under very polluted conditions, reflecting the relatively small fluxes of short-lived anthropogenic NMVOC (Shim et al., 2005; Fu et al., 2007; Millet et al., 2008; Curci et al., 2010). Palmer et al. (2003) and Millet et al. (2006) have shown that HCHO in non-combustion regions is mainly a tracer of isoprene emissions because of its large flux, its short lifetime against oxidation by $\mathrm{OH}$, and its prompt yield of $\mathrm{HCHO}$ as a first-generation product.

A number of studies have demonstrated the value of $\mathrm{HCHO}$ columns from space to infer isoprene emissions in different parts of the world, using $\mathrm{HCHO}-$ isoprene relationships derived from a CTM (Palmer et al., 2003, 2006; Barkley et al., 2008; Millet et al., 2008; Marais et al., 2012). Although isoprene chemistry under low- $\mathrm{NO}_{\mathrm{x}}$ conditions is not well known, this appears to have little effect on HCHO yields (Palmer et al., 2006; Marais et al., 2012). The largest source of error appears to be the "smearing" associated with the time delay between isoprene emission and $\mathrm{HCHO}$ formation (Marais et al., 2012). This smearing error can be addressed with a formal inverse analysis using the adjoint of a CTM (Stavrakou et al., 2009c). However, the results are then sensitive to the coupling between chemistry and transport on the time scales of boundary layer mixing.

Glyoxal is measurable from space by solar backscatter in its 420-460 nm absorption bands (Wittrock et al., 2006; Vrekoussis et al., 2009, 2010). Operational products are available from SCIAMACHY and GOME-2. Like HCHO, it is produced in the atmosphere from the oxidation of NMVOC, and it has a lifetime of a few hours against photolysis and oxidation by $\mathrm{OH}$. However, it has very different yields from $\mathrm{HCHO}$, depending on the precursor. There is evidence for fast production of $\mathrm{CHOCHO}$ from the oxidation of isoprene, but the mechanism involved is not well understood. $\mathrm{CHOCHO}$ data from SCIAMACHY show prominent signatures from pyrogenic, biogenic, and anthropogenic sources, but also elevated concentrations over tropical oceans that suggest a marine biogenic source (Wittrock et al., 2006). Vrekoussis et al. (2009) examined the $\mathrm{CHOCHO} / \mathrm{HCHO}$ column ratios observed by SCIAMACHY for 12 continental source regions and found significant variability, reflecting different source signature mixes of precursor NMVOC.

Several global model studies have focused on better defining the atmospheric budget of $\mathrm{CHOCHO}$, including evaluation with in situ and SCIAMACHY observations (Fu et al., 2008; Myriokefalitakis et al., 2008; Stavrakou et al., 2009a). Models are unable to reproduce the high values observed over tropical oceans and are also generally too low over land. Stavrakou et al. (2009a) argued that the latter underestimate could reflect a missing secondary biogenic source of $\mathrm{CHOCHO}$ accounting for $50 \%$ of the global $\mathrm{CHOCHO}$ source. Liu et al. (2012b) inferred a large missing source of $\mathrm{CHOCHO}$ over China from SCIAMACHY measurements, which they attributed to an underestimate of anthropogenic emissions of aromatics. Overall, the SCIAMACHY data imply shortcomings in our current understanding of $\mathrm{CHOCHO}$ sources, with potentially important implications for NMVOC emissions and organic aerosol formation.

IR observations of NMVOC are available from the ACE-FTS (2003-) solar occultation instrument, the MIPAS (2002-) limb thermal emission instrument, and the TES (2004-) and IASI (2006-) nadir thermal emission instruments. Solar occultation and limb measurements are restricted to the upper troposphere. ACEFTS data have been reported for $\mathrm{CH}_{3} \mathrm{OH}$ (Dufour et al., 2006), $\mathrm{HCOOH}$ (Rinsland et al., 2006a), $\mathrm{C}_{2} \mathrm{H}_{4}$ (Herbin et al., 2009), HCN (Rinsland et al., 2005), and $\mathrm{C}_{2} \mathrm{H}_{6}$ and $\mathrm{C}_{2} \mathrm{H}_{2}$ (Rinsland et al., 2005; González Abad et al., 2011). MIPAS data have been reported for $\mathrm{C}_{2} \mathrm{H}_{6}$ (Clarmann et al., 2007; Glatthor et al., 2009), HCN (Glatthor et al., 2009), $\mathrm{HCOOH}$ (Grutter et al., 2010), $\mathrm{C}_{2} \mathrm{H}_{2}$ (Parker et al., 2011), $\mathrm{CH}_{3} \mathrm{C}(\mathrm{O}) \mathrm{CH}_{3}$ (Moore et al., 2012), and PAN (Wiegele et al., 2012). The ACE-FTS and MIPAS data provide climatological distributions and seasonal cycles in the upper troposphere, as well as correlations among species, that are of great value for testing global CTMs (Dufour et al., 2007; González Abad et al., 2011). Their value for testing emission inventories is more limited at present because of the convolution with vertical transport and chemistry and because upper tropospheric observations integrate emissions information over a large domain. Nevertheless, because of the difficulties in compiling bottom-up emission inventories of speciated NMVOC emissions from many source categories and in many parts of the world, the contribution of satellite observations of individual chemical species may ultimately prove to be of value. For example, Rinsland et al. (2007) used ACE-FTS data in freshly convected biomass burning plumes to infer emission ratios.

Nadir IR observations from TES and IASI have higher horizontal resolution and are sensitive to lower altitudes, thus providing better constraints to relate observed concentrations to sources and to test emission inventories. TES has been used to detect large urban enhancements of $\mathrm{CH}_{3} \mathrm{OH}$ (Beer et al., 2008) and to test current inventories of global biogenic $\mathrm{CH}_{3} \mathrm{OH}$ emissions (Wells et al., 2012). A new retrieval algorithm for TES observations of $\mathrm{CH}_{3} \mathrm{OH}$ presents seasonal and spatial variability (Cady-Pereira et al., 2012). IASI has provided data for $\mathrm{CH}_{3} \mathrm{OH}, \mathrm{HCOOH}$, PAN, $\mathrm{C}_{2} \mathrm{H}_{4}, \mathrm{C}_{3} \mathrm{H}_{6}$, and furan $\left(\mathrm{C}_{4} \mathrm{H}_{4} \mathrm{O}\right)$ (Clarisse et al., 2011b). Detection of most of these species requires large enhancements from a point source such as a large fire (Clerbaux et al., 2009; Coheur et al., 2009). However, high-quality global data sets have been produced for $\mathrm{CH}_{3} \mathrm{OH}$ and $\mathrm{HCOOH}$ (Razavi et al., 2011), and these have been used in inverse analyses to constrain emissions and secondary sources (Stavrakou et al., 2011a,b).

\subsection{Ammonia}

Ammonia $\left(\mathrm{NH}_{3}\right)$ plays an important role in atmospheric chemistry and biogeochemical cycles of reactive nitrogen (Galloway et al., 2003). By contributing to the transport and deposition of reactive nitrogen, $\mathrm{NH}_{3}$ poses a hazard to sensitive ecosystems. The formation of ammonium sulfate and ammonium nitrate aerosol impacts human health, visibility, and climate. However, routine monitoring of surface-level $\mathrm{NH}_{3}$ concentrations is sparse, as it is a difficult substance to measure in situ (von Bobrutzki et al., 2010). The potential for space-based observations of $\mathrm{NH}_{3}$ is thus especially appealing. Profiles of atmospheric $\mathrm{NH}_{3}$ have been retrieved from two instruments: TES (Beer et al., 2008; Shephard et al., 2011) and IASI (Clarisse et al., 2009, 2010), both of which measure thermal IR in the range of $940-969 \mathrm{~cm}^{-1}$ twice daily.

The biggest challenges in remotely observing $\mathrm{NH}_{3}$ are that much of the $\mathrm{NH}_{3}$ is close to the surface, which makes it difficult to detect from space, and the horizontal distribution of $\mathrm{NH}_{3}$ can have strong spatial gradients. Under conditions with significant thermal contrast near Earth's surface and a large enough signal-to-noise ratio, both instruments can be sensitive to boundary-layer $\mathrm{NH}_{3}$ concentrations (Clarisse et al., 2010). The shape of the profiles retrieved by these instruments is strongly influenced by the retrieval a priori information, as the retrievals themselves typically contain less than one degree of freedom for signal. Typical retrieval sensitivities peak near $800-600 \mathrm{hPa}$. Compared to IASI, TES has a higher spectral resolution (0.06 vs $0.5 \mathrm{~cm}^{-1}$ ) and is thus more frequently sensitive to $\mathrm{NH}_{3}$ in the boundary layer. Theoretical analysis indicates that the lower detection limit of the TES instrument for $\mathrm{NH}_{3}$ is $\sim 1 \mathrm{ppb}$ (Shephard et al., 2011); it is likely $2-5 \mathrm{ppb}$ for IASI (Clarisse et al., 2010). However, while TES has a smaller footprint (viewing area of approximately $5.3 \mathrm{~km} \times 8.3 \mathrm{~km}$ ), the observations are spaced far apart, which makes mapping difficult. On the other hand, IASI has much higher spatial coverage, providing global coverage twice daily with a $12 \mathrm{~km} \times 12 \mathrm{~km}$ footprint, which is important because $\mathrm{NH}_{3}$ has high spatial variability. 
Given the paucity of existing surface measurements of $\mathrm{NH}_{3}$, there is significant potential for enhancing our understanding of $\mathrm{NH}_{3}$ using remote-sensing observations. It has been shown that TES is able to resolve spatial and temporal gradients in surface $\mathrm{NH}_{3}$ concentrations (Pinder et al., 2011). Heald et al. (2012) used IASI measurements to study $\mathrm{NH}_{3}$ concentrations over the U.S., finding underestimation of emissions in California and in the springtime in the Midwest. Zhu et al. (2013) have shown that TES observations of $\mathrm{NH}_{3}$ can be used to constrain monthly average emissions. Model optimization for the U.S. improves the representation of measured $\mathrm{NH}_{3}$ in April and October. Overall, remote-sensing constraints suggest that the $\mathrm{NH}_{3}$ emission inventory is broadly underestimated in many parts of the U.S., particularly in the West.

\subsection{Particulate matter}

Aerosol data products from a subset of satellite sensors have been explored to estimate ground-level particle characteristics over land. MODIS and MISR measure particle abundance and composition with nearly global coverage at moderate spatial resolutions, even over complex land surfaces. One of the most robust aerosol parameters that MISR and MODIS can retrieve is aerosol optical depth (AOD), also known as aerosol optical thickness (AOT). AOD is defined as the integral of aerosol extinction coefficients along the vertical atmospheric column from Earth's surface to the top of the atmosphere. There are MODIS instruments aboard both the Terra (equator crossing time 10:30 am) and Aqua (equator crossing time 1:30 pm) satellites. A comparison of early-version Terra MODIS and Aqua MODIS AOD values indicated that differences vary by region without consistent patterns (Ichoku et al., 2005).

The MODIS operational "Dense Dark Vegetation" (DDV) retrieval algorithm is designed to infer clear-sky aerosol properties over land surfaces that have low surface reflectance. This algorithm removes the surface impact by using the $2.1 \mu \mathrm{m}$ band to estimate the surface reflectance, assuming a relationship of surface reflectance between this band and the blue $(440 \mathrm{~nm})$ and red $(670 \mathrm{~nm})$ bands as a function of both NDVI and scattering angle (Remer et al., 2005). AOD can then be derived by searching precomputed lookup tables corresponding to different aerosol models. The MODIS operational algorithm has developed considerably over the last several years, with Collection 6 being recently described (Levy et al., 2013).

The DDV algorithm is not performed over bright surfaces (i.e., when the $2.1 \mu \mathrm{m}$ surface reflectance is above 0.15). The MODIS Deep Blue (DB) algorithm alleviates the bright-surface problem by employing radiance measurements from the blue channels to infer the properties of aerosols (Hsu et al., 2004). A maximum-likelihood method is used to match the appropriate values of AOD and SSA from a lookup table to the measured radiances. Studies over the Sahara Desert and nearby Arabian Peninsula, as well as the Gobi Desert, indicate that this algorithm is particularly sensitive to mineral dust over their bright source regions (Hsu et al., 2006; Fischer et al., 2009). Currently, MODIS DDV and DB AOD data (Collection 5.1) are reported as separate parameters in the Level 2 data products (MOD04 and MYD04) at $10 \mathrm{~km} \times 10 \mathrm{~km}$ nominal spatial resolution.

MISR employs a unique multiangle design that allows it to observe the atmosphere through different effective path lengths, leading to a very different aerosol retrieval algorithm (Martonchik et al., 1998). To effectively separate surface-leaving light reflection from atmosphere-leaving light reflection over land, MISR uses the presence of spatial contrasts within a $17.6 \mathrm{~km} \times 17.6 \mathrm{~km}$ retrieval region to derive an empirical orthogonal function (EOF) representative of the region-averaged, surface-leaving light reflection. MISR defines a set of aerosol mixtures to represent aerosol types globally, which carry information about aerosol size distribution, shape, refractive index, and scale height. As a research instrument, MISR provides a rich aerosol dataset to study long-term spatial and temporal trends of particle mass, composition, and other information. MISR-retrieved AOD is reported in its Level 2 aerosol data product (MIL2ASAE) on a $17.6 \mathrm{~km} \times 17.6 \mathrm{~km}$ grid.

The stereoscopic nature of MISR data also enables it to retrieve the top heights of distinct plumes through a stereo-matching technique. Due to its narrow swath $(\sim 400 \mathrm{~km})$, however, preliminary studies have shown that MISR only observes approximately $10 \%$ of large wildfire smoke plumes (Kahn et al., 2008). Plume recognition is more likely to succeed close to the sources of fires, dust storms, volcanic eruptions, etc. The MISR plume-top height information is reported in the Level 2 cloud product (MIL2TCSP) on a $1.1 \mathrm{~km} \times 1.1 \mathrm{~km}$ grid.

MODIS and MISR AOD data provide the possibility for largescale air pollution monitoring over land. Since the launch of MODIS and MISR, numerous studies have explored the relationship between satellite-retrieved aerosol parameters and ground-level air pollution measurements (e.g., Chu et al., 2003; Liu et al., 2005, 2007; Wang and Christopher, 2003). Most studies have focused on the relationship between AOD and surface $\mathrm{PM}_{2.5}$, although a few have considered $\mathrm{PM}_{10}$ as well, since measurements of $\mathrm{PM}_{2.5}$ outside North America and Western Europe are rare. The analytical methods have evolved from semi-quantitative descriptions of air pollution patterns, through correlation and simple linear regression, to more sophisticated multivariate spatial and temporal models (van Donkelaar et al., 2010; Kloog et al., 2011; Lee et al., 2011c; Liu et al., 2012a).

Both PM and AOD can be observed using visible imagery from geostationary orbit, offering high spatial (30 $\mathrm{min} \times 30 \mathrm{~min}$ ) resolution. Examples of geostationary platforms with AOD products include the U.S. Geostationary Orbiting Earth Satellite (GOES) series, the Japanese GMS and MTSAT, and the European SEVIRI. These AOD retrievals typically use only one or two visible channels (Prados et al., 2007). The geostationary AOD products offer higher observation frequency but have larger errors than MODIS or MISR (Paciorek et al., 2008). The Suomi-NPP VIIRS instrument was launched in October 2011 and has similar capabilities to MODIS but with higher resolution ( $6 \mathrm{~km}$ at nadir). The retrieval algorithm is developing rapidly and offers exciting possibilities to understand aerosol sources.

\subsection{Carbon dioxide}

Observing $\mathrm{CO}_{2}$ concentrations from space is not difficult. In fact, many of the space-borne instruments have the capability to measure $\mathrm{CO}_{2}$ columns, either by detecting the attenuation or emission of infrared radiation. The problem is to separate the $\mathrm{CO}_{2}$ flux arising from natural sources from the flux due to human activity. Natural carbon fluxes are on the order of $300 \mathrm{GtC} \mathrm{yr}^{-1}$, while the anthropogenic contribution is only about $2 \%$ of this value, or $\sim 6 \mathrm{GtC} \mathrm{yr}^{-1}$. This presents a great challenge to the measurement instrumentation and the design of satellite platforms. Global measurements with an accuracy of $\sim 1 \mathrm{ppm} \mathrm{CO}_{2}$ are needed at high spatial and temporal resolution in order to be able to detect anthropogenic $\mathrm{CO}_{2}$ in a useful way. Measurements of $\mathrm{CO}_{2}$ concentrations using SCIAMACHY, AIRS, and TES have all been reported, as well as from the dedicated greenhouse-gas satellite GOSAT. It is generally held that satellite observations alone are at present unable to provide the required observational power for detecting point-source emissions, but that the coupling of satellite data with a ground-based sensor array and accurate meteorological data might be able to succeed (JASON, 2011).

Specification of the necessary attributes of a space-borne global $\mathrm{CO}_{2}$ observational platform that could detect anthropogenic 
emissions began more than a decade ago. These were established with the design, development, and operation of the OCO and GOSAT platforms in mind. A number of inversion and precision analyses have been conducted to quantify how well $\mathrm{CO}_{2}$ column measurements would be able to estimate surface sources and sinks of $\mathrm{CO}_{2}$ (e.g., Chevallier et al., 2007, 2009; Miller et al., 2007; Baker et al., 2010; Pillai et al., 2010). Houweling et al. (2004) first confirmed that rather precise satellite measurements ( $\sim 1-2 \mathrm{ppm})$ would be needed to constrain sub-continental carbon fluxes. Lauvaux et al. (2009) focused on the effects of transport uncertainty on inversion modeling of sources and sinks. All these studies pointed out both the opportunities and the great challenges ahead.

Buchwitz et al. (2007) first reported direct observations of atmospheric $\mathrm{CO}_{2}$ concentrations between 2003 and 2005 from SCIAMACHY. Good agreement with CarbonTracker data was found, and the analysis was able to detect the $\mathrm{CO}_{2}$ seasonal cycle and, for the first time, the year-to-year increase of $\mathrm{CO}_{2}$, which agreed with the CarbonTracker increase to within $1 \mathrm{ppm} \mathrm{yr}^{-1}$. Subsequent work compared a new SCIAMACHY column $\mathrm{CO}_{2}$ retrieval with four TCCON sites and CarbonTracker data (Reuter et al., 2011). Systematic differences were in the range of $0.2-0.8 \mathrm{ppm}$ with a singlemeasurement precision of $2.5 \mathrm{ppm}$. The validation confirmed the potential of SCIAMACHY to provide information about column $\mathrm{CO}_{2}$ in regions with few in situ measurements. Observations of $\mathrm{CO}_{2}$ from TES have been reported (Kulawik et al., 2010; Nassar et al., 2011). Kulawik et al. (2010) demonstrated good agreement with a variety of observational datasets, including CONTRAIL aircraft data, surface sites, AIRS data, and CarbonTracker. Nassar et al. (2011) inferred $\mathrm{CO}_{2}$ fluxes using inverse modeling of the satellite and surface measurements jointly with GEOS-Chem; the quantification of global fluxes from oceans and the terrestrial biosphere was in good agreement with other studies.

The first results from GOSAT were reported in 2009 by the Japanese team (Yokota et al., 2009) using SWIR reflected light at $1.6 \mu \mathrm{m}$. Pending further instrument calibration and validation, Yokota et al. (2009) were able to observe inter-hemisphere differences in $\mathrm{CO}_{2}$ concentrations, but with an underestimation of absolute concentration values. Subsequently, GOSAT retrievals of column-average $\mathrm{CO}_{2}$ during its first year of operation (April 2009-July 2010) were compared with TCCON and showed very close correlation (Butz et al., 2011). The seasonal $\mathrm{CO}_{2}$ cycle and general source/sink patterns were evident. Further validation of GOSAT retrievals against TCCON data by Oshchepkov et al. (2012) and against TCCON and GEOS-Chem model calculations by Cogan et al. (2012) have also showed close correlation after removal of observations contaminated by cloud and aerosol. Global maps of $\mathrm{CO}_{2}$ distributions from GOSAT have now been released as a Level 3 product (Hammerling et al., 2012), generally in agreement with carbon modeling work, except for South America in July and August, which may point to inaccuracies in flux estimates due to the sparseness of in situ measurements there.

A prime objective of space-based observations of $\mathrm{CO}_{2}$ is to be able to detect emissions from individual point sources, which has yet to be fulfilled. Bovensmann et al. (2010) derived requirements for detecting the $\mathrm{CO}_{2}$ emissions from a typical power plant. Minimum requirements of a spatial resolution of $2 \mathrm{~km} \times 2 \mathrm{~km}$, a wide swath width $(\sim 500 \mathrm{~km})$, and a precision of $2 \mathrm{ppm}$ could, they assert, be achieved with existing technology. The statistical uncertainty of the retrieval was found to be in the range of $12-36 \%$ of the emissions of a mid-sized power plant, with wind speed and aerosol concentration being the main interferences. The concept developed by Bovensmann et al. (2010), which they termed CarbonSat, could detect and quantify $\mathrm{CO}_{2}$ emissions from large point sources and would therefore have the potential to provide independent verification of emission reductions under a future global agreement.

Kort et al. (2012) demonstrated the potential to quantify $\mathrm{CO}_{2}$ concentration enhancements due to human activity at the scale of megacities, using GOSAT observations over Los Angeles $(3.2 \pm 1.5 \mathrm{ppm})$ and Mumbai $(2.4 \pm 1.2 \mathrm{ppm})$. They estimate that changes as small as $0.7 \mathrm{ppm}$ could be detected (in Los Angeles) from GOSAT observations at 95\% confidence level. McKain et al. (2012) demonstrated the capability to determine changes in $\mathrm{CO}_{2}$ emissions from an urban area (Salt Lake City) with a ground-based monitoring network and a CTM. Changes in emissions of $\pm 15 \%$ could be detected at 95\% confidence level. It was argued that integrated $\mathrm{CO}_{2}$ column measurements, of the kind that could be provided by space-borne instruments, would greatly enhance the detection of $\mathrm{CO}_{2}$ emissions from source regions. Using SCIAMACHY data, Schneising et al. (2013) estimated an enhancement of $1.1 \pm 0.5 \mathrm{ppm}$ for the U.S. east coast.

With the limitations of current satellites to detect $\mathrm{CO}_{2}$ emissions at the required level of detail and the failure of OCO in 2009, eyes turn to future satellite capability. The second version of the Orbiting Carbon Observatory (OCO-2) is presently under development with a scheduled launch date still to be determined, but possibly 2014/ 2015; it would provide the capability needed to characterize sources and sinks of $\mathrm{CO}_{2}$ at high resolution, when combined with ground-based measurements and related observations. $\mathrm{A} \mathrm{CO}_{2}$ measurement platform in geosynchronous orbit would have many benefits, including the ability to revisit individual source locations on a time scale of hours rather than the 15-20 days of current low Earth orbit satellites (JASON, 2011).

\section{Methods for emissions estimation and examples of applications}

In this section, we first review analytical methods for constraining emission estimates from remote sensing observations (4.1). This is followed by discussion of how more-detailed information about sources can be obtained by increasing the resolution of the satellite retrievals (4.2) and by the use of satellite data as a proxy for emissions trends (4.3). Then we discuss the potential to gain quantitative information about different kinds of sources from space-borne observations by highlighting results from applications related to anthropogenic point sources (4.4), anthropogenic area sources (4.5), natural point sources (4.6), and natural area sources (4.7). We discuss synergy with field campaigns in a final sub-section (4.8).

\subsection{Inverse modeling techniques}

The most straightforward approach to developing "top-down" constraints on emissions directly attributes changes in observed concentrations to changes in emissions. This is commonly done for evaluating point sources (Sections 4.2 and 4.4) or for estimating long-term trends (Section 4.3). Such estimates can be based on observations alone. For assessment of area sources or point sources for which the signals are not distinct, because of transport, chemistry, or the atmospheric lifetime of the species in question, more formal inverse methods are used.

Inverse modeling seeks to formally develop constraints on emissions by combining three types of information: a set of observations such as satellite measurements $(\boldsymbol{y})$, an estimate of the distribution of sources of the species in question $\left(\boldsymbol{x}_{\mathrm{a}}\right.$, referred to as the a priori, prior, initial, or background), and a modeled simulation of the observed quantity using an estimate of the emissions $(H(\mathbf{x}))$ all with associated error estimates (see, e.g., Sandu and Chai, 2011). Many of the approaches to constraining emissions stem from Bayes theory, which describes how to determine the distribution of a set 
of parameters (in this case, emissions) consistent with estimates of the remotely observed quantity that are closest to the distribution of these observations, while simultaneously accounting for prior information regarding reasonable values of these parameters. In general, solving for this probability distribution in full is computationally prohibitive. In the following sections we review common methods for inverse modeling that approximate the Bayesian approach at varying levels of detail. The methods are distinguished by the ways in which the models are used, how the desired spatial and temporal scales of the analysis warrant various levels of complexity, and how errors in the inversion inputs are determined and propagated throughout the analysis.

A common method for constraining emissions of short-lived species using remote sensing data is to average a set of satellite measurements over a particular location and derive top-down constraints on surface emissions using a mass balance approach. Model simulations based on an a priori emissions estimate are used to simulate atmospheric column or profile concentrations. The ratio of the simulated to the observed concentration, weighted according to estimates of the error in the observations and simulations, is then used to directly adjust the model emissions (e.g., Martin et al., 2003). In this approach, the influences of atmospheric transport and chemistry on the relationship between emissions in one grid cell and concentrations in another grid cell are assumed to be negligible, presuming that the short chemical lifetime of the species translates to a smearing length scale less than the width of the model grid cell (see, e.g., Palmer et al., 2003). These assumptions are most suitable for short-lived species (e.g., $\mathrm{NO}_{x}$ ) and for relatively coarse $\left(>1^{\circ}\right)$ model simulations. However, even for shortlived species, the influence of emissions in a coarse air-quality model may extend beyond the column directly overhead (Turner et al., 2012). Kernels, or smoothing representations of the emission field, have been used to account for the influence of adjacent cells (Toenges-Schuller et al., 2006; Boersma et al., 2008a). The procedure can be iterated to account for nonlinear relationships between emissions and column concentrations or profiles, or transport from neighboring grid cells (e.g., Zhao and Wang, 2009; Ghude et al., 2013). Differences in concentrations from multiple observations at different times can also be used to constrain the mass balance (Lin et al., 2010b).

For longer-lived species or finer model resolutions, more explicit treatment of chemistry and transport becomes necessary. Formally, these approaches seek to minimize a cost function, $J(\boldsymbol{x})$, which is a scalar measure of the misfit of the model $(H(\boldsymbol{x}))$ compared to observations $(\boldsymbol{y})$, weighted by the observational error covariance matrix (R), plus the departure of the emissions from their a priori estimates $\left(\boldsymbol{x}_{b}\right)$, also weighted by the a priori error covariance matrix (B):

$J(\mathbf{x})=1 / 2(H(\mathbf{x})-\mathbf{y})^{\mathrm{T}} \mathbf{R}^{-1}(H(\mathbf{x})-\mathbf{y})+1 / 2\left(\mathbf{x}-\mathbf{x}_{\mathrm{b}}\right)^{\mathrm{T}} \mathbf{B}^{-1}\left(\mathbf{x}-\mathbf{x}_{\mathrm{b}}\right)$

Approaches taken to finding the set of emissions that minimize this cost function depends upon several factors. The direct (or analytical) solution, which leads to the best linear unbiased estimate of emissions for linear systems, can be directly found as:

$\mathbf{x}=\mathbf{x}_{\mathrm{b}}+\mathbf{K}(\mathbf{y}-H(\mathbf{x}))$

where $\mathbf{K}$ is the gain matrix,

$$
\mathbf{K}=\mathbf{B H}^{\mathrm{T}}\left(\mathbf{H B} \mathbf{H}^{\mathrm{T}}+\mathbf{R}\right)^{-1}
$$

and $\mathbf{H}$ is a Jacobian matrix that relates changes in emissions to changes in model estimates of observations determined from a (linearized) sensitivity analysis of the atmospheric chemistry and transport model $H$. This equation can be evaluated in a single step for all observations (direct or analytic inversion) or broken up into sequential steps (Kalman Filter) to update $\boldsymbol{x}, \boldsymbol{x}_{\mathrm{b}}$, and $\mathbf{B}$, as a function of time.

One of the main challenges with either approach is determining the Jacobian matrix. For a large number of emission values, or a large number of observations, this can simply become computationally intractable. A common practice is to consider emissions aggregated at large spatial scales and then directly evaluate the Jacobian through successive forward model calculations (e.g., Heald et al., 2004; Stavrakou and Müller, 2006; Kopacz et al., 2009). A drawback with this approach is the subjective lumping of emissions across broad regions, i.e., aggregation error. To define the Jacobian at finer scales, several approaches can be considered. Moreefficient sensitivity techniques, such as direct decoupled or adjoint methods, may also be used to evaluate the Jacobian (e.g., Napelenok et al., 2008). Konovalov et al. (2006) define the relationship between emissions and concentrations through Monte Carlo sampling of linear statistical relationships. Mijling and van der A (2012) introduced a Kalman-filter algorithm specifically designed for rapid inversion of short-lived atmospheric constituents at a spatial scale of $\sim 25 \mathrm{~km} \times 25 \mathrm{~km}$, by approximating the Jacobian matrix through 2D trajectory analysis.

An alternative approach is the ensemble Kalman filter method (Evensen, 1994). This does not require specification of Jacobian matrices; instead, the influence of emissions and their uncertainties on the model estimates is assessed through analysis of the spread of ensembles (typically 20-40) of forward model evaluations. For example, Miyazaki et al. (2012a) use the ensemble Kalman filter approach to constrain $\mathrm{NO}_{x}$ emissions with $\mathrm{OMI}$ observations. Such approaches, becoming increasingly common in weather forecasting systems, have become attractive in recent years given their scalability on parallel computing systems.

Lastly, the minimum of the cost function may be sought iteratively using gradient-based optimization techniques. This method, referred to in the context of air quality forecasting as 4D-Var, is based on the calculus of variation, wherein a perturbation in a scalar, receptor-based metric is propagated backward in time through a set of equations that are auxiliary (adjoint) to the locally linearized system. This affords calculation of the gradient with respect to numerous parameters simultaneously. These gradients are then used in conjunction with an optimization scheme to minimize the cost equation. The 4D-Var method was first used to constrain emissions in an Eulerian air-quality model of chemically active species in the troposphere by Elbern et al. (2000). Effectively, this method affords constraints on model emissions at the native model resolution (e.g., Kopacz et al., 2009; Jiang et al., 2011; Hooghiemstra et al., 2012), which minimizes the aggregation error incurred when solving Equation (2) directly for a vector or emissions defined across broad areas. The approach does, however, require the existence of an adjoint model, and estimating the uncertainty in the resulting emissions requires additional effort.

Within the frameworks for developing top-down emissions constraints described above, there are several challenges related to the use of new remote sensing constraints, applications to new inverse modeling objectives, and ascertaining the uncertainties in the resulting inventories. One issue at the forefront of inverse modeling is to use measurements from multiple species, or from multiple platforms. Data assimilation techniques have typically focused on the recovery of emissions of a single species. For example, Dubovik et al. (2008) used MODIS AOD to estimate fineand coarse-mode aerosol emissions. More recently, Huneeus et al. (2012) demonstrated the simultaneous estimate of global emissions of multiple gaseous and aerosol species (dust, sea salt, BC, OC, 
and $\mathrm{SO}_{2}$ ) using a 4D-Var approach assimilating MODIS total and fine-mode AOD. Miyazaki et al. (2012b) have used the same data assimilation system to combine observations of four interrelated species- $\mathrm{NO}_{2}, \mathrm{O}_{3}, \mathrm{CO}$, and $\mathrm{HNO}_{3}$ - from four satellites-OMI, TES, MOPITT, and MLS - with additional aircraft and ozonesonde data. More work is needed on top down-estimates for multiple species (such as $\mathrm{NO}_{2}$ and $\mathrm{VOC}$ or $\mathrm{NO}_{2}$ and $\mathrm{O}_{3}$ ). Early attempts (Zhang et al., 2008; Carmichael et al., 2008) produced mixed results, where in some regions the assimilation was pulled in opposite directions by the different data sets.

There are also issues with trying to assimilate a single parameter from multiple retrievals. For example, Jones et al. (2009) compared an analytic inversion, Equation (2), of MOPITT and TES in the tropics in November 2004. While, in general, the a posteriori emissions showed some consistency, over North America-where in boreal fall emissions make only a small contribution to total CO abundance-MOPITT and TES adjusted initial estimates in opposite directions. Fortems-Cheiney et al. (2009) presented a first comparison of inversions using IASI and MOPITT data and found that the regional totals were broadly consistent. George et al. (2009) compared IASI CO retrievals with MOPITT, AIRS, and TES (see Fig. 3) and found, on average, total column discrepancies of $\sim 7 \%$ in the Northern Hemisphere and in the equatorial region. All the studies concluded that there was a need for better characterization of biases among data sets.

Model errors also pose a significant limitation on the accuracy of top-down emission estimates. Arellano and Hess (2006), in an inter-model comparison, showed that the results of inversions are particularly sensitive to the model treatment of convection and to transport out of the boundary layer. A linearization error is introduced when the chemical loss of $\mathrm{CO}$ is accounted for by specified $\mathrm{OH}$ abundances (Müller and Stavrakou, 2005), an approach commonly used to minimize the computation cost of the inversion. Differences between inversions based on remote sensing observations of column concentrations compared to surface observations can also be used to identify components of model transport error that impact the emissions constraints (Jiang et al., 2013).

The selection of source types to be constrained also impacts the inversion solution. For example, since CO observations mainly constrain total emissions, an increase in one source category may be compensated for by a decrease in another. A careful characterization of the state vector using the spatiotemporal resolution and precision of observations rather than geographical boundaries is required. Accounting for the $\mathrm{CO}$ contribution that is not directly emitted adds another level of uncertainty. In most studies (e.g., Palmer et al., 2003; Heald et al., 2004; Arellano and Hess, 2006; Jones et al., 2009; Kopacz et al., 2009), the biogenic NMVOC source, representing a main source for $\mathrm{CO}$ precursors, is aggregated into a background global chemical source of CO. Stavrakou and Müller (2006) and Jiang et al. (2011) explicitly solved for the biogenic NMVOC source at the same spatial resolution at which the combustion $\mathrm{CO}$ emissions were constrained and showed that aggregating the biogenic NMVOC source into the global background could result in significant over-adjustment of the $a$
IASI

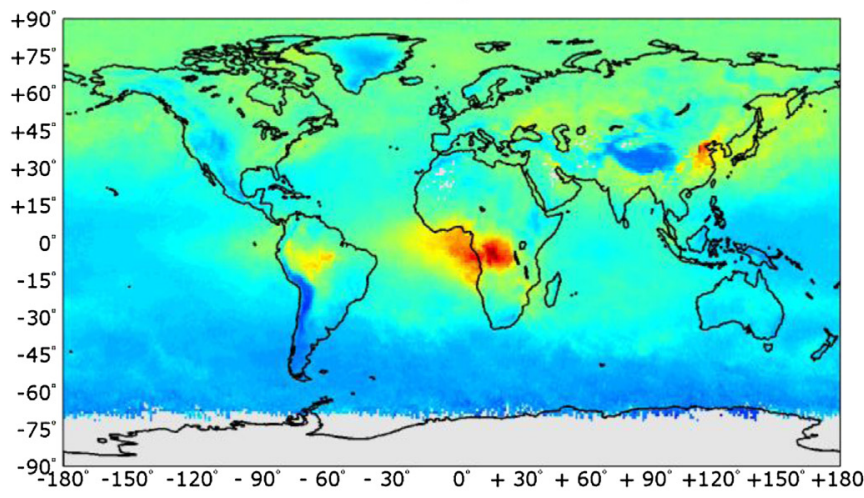

AIRS

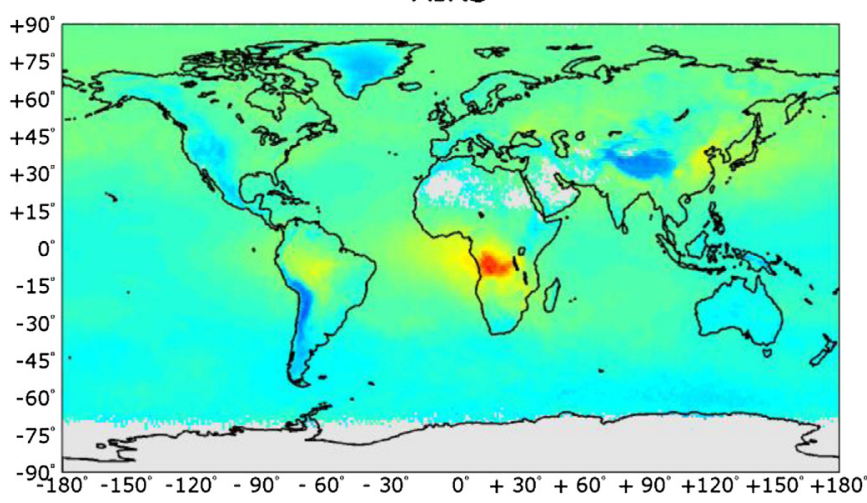

MOPITT

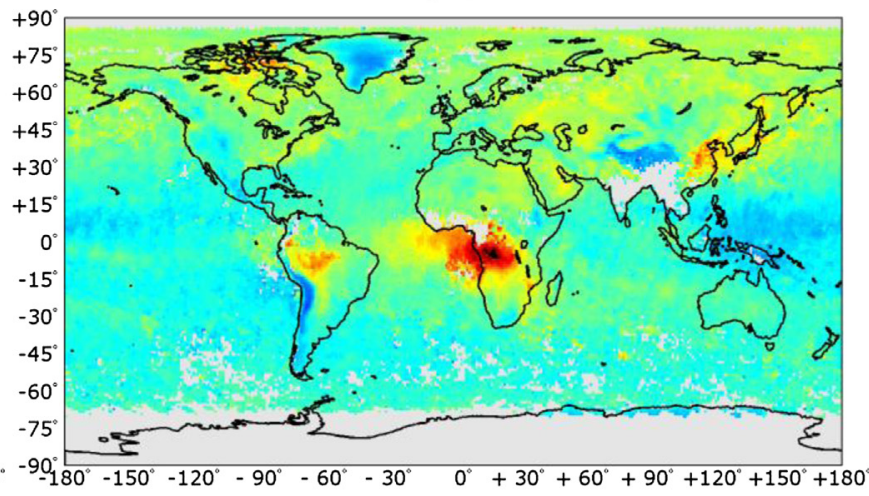

TES

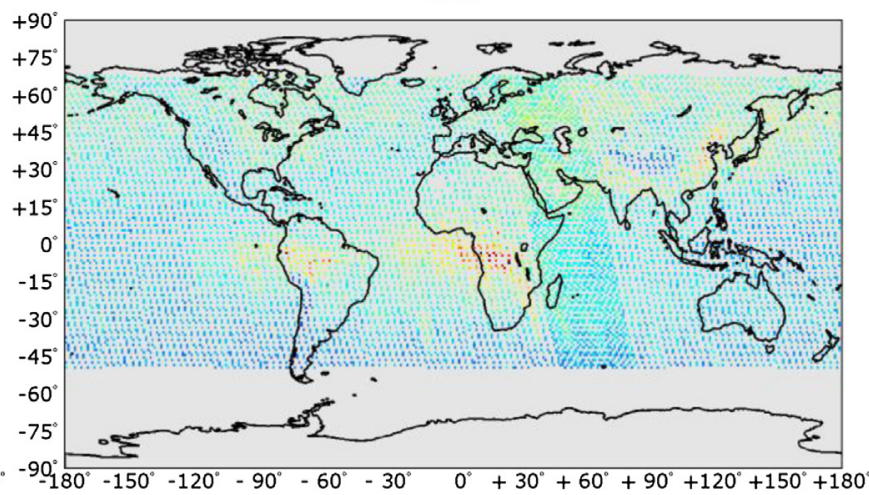

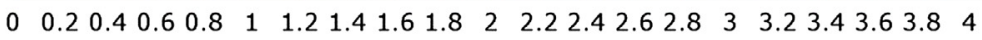

Total Column CO $\times 10^{18}$ molecules $/ \mathrm{cm}^{2}$

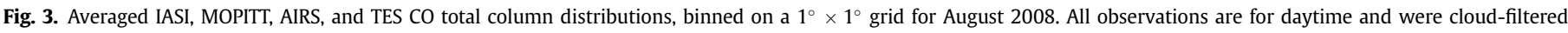
following the recommendations provided by each retrieval team (adapted from George et al., 2009). 
posteriori $\mathrm{CO}$ emissions. The range of solutions from different inversions was shown to be much larger than the a posteriori errors, indicating that the solution is more sensitive to modifications to the inverse system than a posteriori errors suggest. Without a reasonable model error estimate, the results of inverse analyses will be sensitive to the choice of the observation domain and the proximity of observations to the source location of interest.

\subsection{Oversampling/spatial smoothing}

Some species have well-defined plumes that tend to be smoothed out during spatial averaging. It is possible to improve the definition of these plumes by oversampling the original swath data to a higher resolution. Oversampling is a powerful tool, because higher resolution data are produced from coarse observations and noise is reduced, thereby enhancing weak signals. This technique has been widely used for $\mathrm{NO}_{2}$ (e.g., Martin et al., 2003; Beirle et al., 2004b; Lamsal et al., 2008) and was recently applied to high-quality $\mathrm{SO}_{2}$ pixels from the OMI sensor to a resolution of $3 \mathrm{~km} \times 3 \mathrm{~km}$ for retrievals above Mexico City (de Foy et al., 2009). Using this technique, the separate plumes and dispersion patterns of an industrial complex and a passively degassing volcano became clearly visible. By averaging OMI $\mathrm{NO}_{2}$ columns to a grid resolution of $0.025^{\circ} \times 0.025^{\circ}$ over California, Russell et al. (2010) were able to identify spatial patterns in the weekday-weekend concentrations in the Los Angeles basin.

Fioletov et al. (2011) used a similar technique to evaluate the strengths of large point sources of $\mathrm{SO}_{2}$ in the U.S. on a $2 \mathrm{~km} \times 2 \mathrm{~km}$ grid. Because the elevated $\mathrm{SO}_{2}$ values associated with a point source generally become insignificant beyond $\sim 50 \mathrm{~km}$, they averaged all OMI pixels within a $12 \mathrm{~km}$ radius of the source. At the highest spatial resolution currently available from OMI $\left(>300 \mathrm{~km}^{2}\right)$ the $\mathrm{SO}_{2}$ detection limit is $0.1-0.3 \mathrm{DU}$, which corresponds to annual emissions larger than $\sim 70 \mathrm{Gg} \mathrm{SO}_{2} \mathrm{yr}^{-1}$. Currently, there are about 40 point sources in North America (smelters and coal-fired power plants in Canada, the U.S., and Mexico) that exceed this source strength. Fioletov et al. (2011) also observed reductions of column $\mathrm{SO}_{2}$ of $\sim 40 \%$ that were consistent with reported decreases in emissions between 2005-2007 and 2008-2010. Fig. 4 shows the high-resolution $\mathrm{SO}_{2}$ retrievals reported in Fioletov et al. (2011). Applying the same method to Alberta, Canada, McLinden et al. (2012) showed annual increases in $\mathrm{NO}_{2}$ columns between 2005 and 2010 due to the development of oil sands (see Section 4.5). These techniques have generated higher-resolution emissions distributions that significantly improve our ability to detect and quantify emission sources.

\subsection{Timely updates to emission trends and other temporal variations}

The bottom-up approach of compiling emission inventories by aggregating activity data and emission factors provides the most comprehensive treatment of emissions, but this approach is a major undertaking that can require time to complete. For example, at the time of writing (2013) the current NEI from the U.S. EPA is for the year 2008, though estimates for more recent years are available in other products (see below). More timely information could improve the accuracy of model simulations for time periods after the release of the inventory. Satellite observations offer near-realtime information on a range of species, as discussed above, and the trends in the satellite measurements can be used to update bottom-up emission trends, pending the gathering of source information to construct a new bottom-up inventory.

Lamsal et al. (2011) demonstrated that satellite observations of $\mathrm{NO}_{2}$ provide timely information about changes in anthropogenic $\mathrm{NO}_{x}$ emissions, when combined with model information on the relationship between changes in tropospheric $\mathrm{NO}_{2}$ columns and changes in $\mathrm{NO}_{x}$ emissions. Fig. 5 shows the spatial variation of anthropogenic $\mathrm{NO}_{x}$ emissions for 2005 from a bottom-up inventory and a predicted $\mathrm{NO}_{x}$ inventory for 2010 from OMI measurements. The predicted $\mathrm{NO}_{x}$ inventory $\left(24.8 \mathrm{Tg} \mathrm{N} \mathrm{yr}^{-1}\right.$ ) is $2.5 \%$ higher than the bottom-up inventory (24.2 $\mathrm{Tg} \mathrm{N} \mathrm{yr}^{-1}$ ) for regions dominated by anthropogenic $\mathrm{NO}_{x}$ emissions. The difference between the predicted inventory for 2010 and the bottom-up inventory for 2005 presented in Fig. 5 (bottom frame) shows significant reductions over the eastern U.S., Japan, and parts of Europe, and increases over eastern China. Changes in anthropogenic $\mathrm{NO}_{x}$ emissions during 2005-2010 indicate a decrease of $22.7 \%$ and $13.7 \%$ over the U.S. and
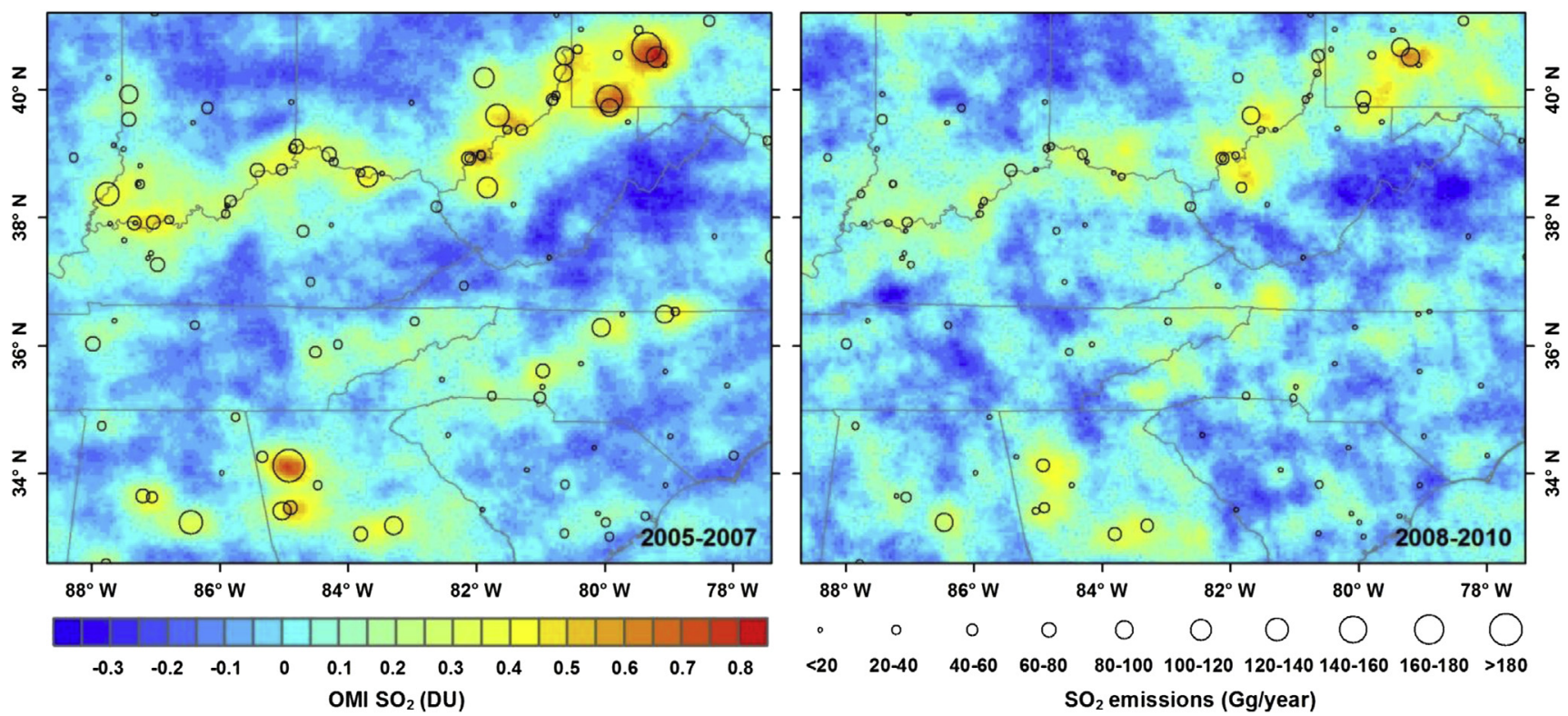

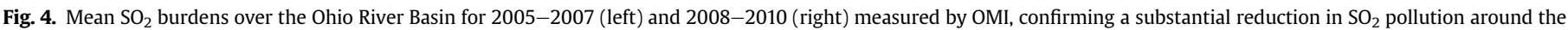

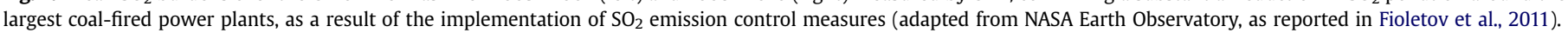



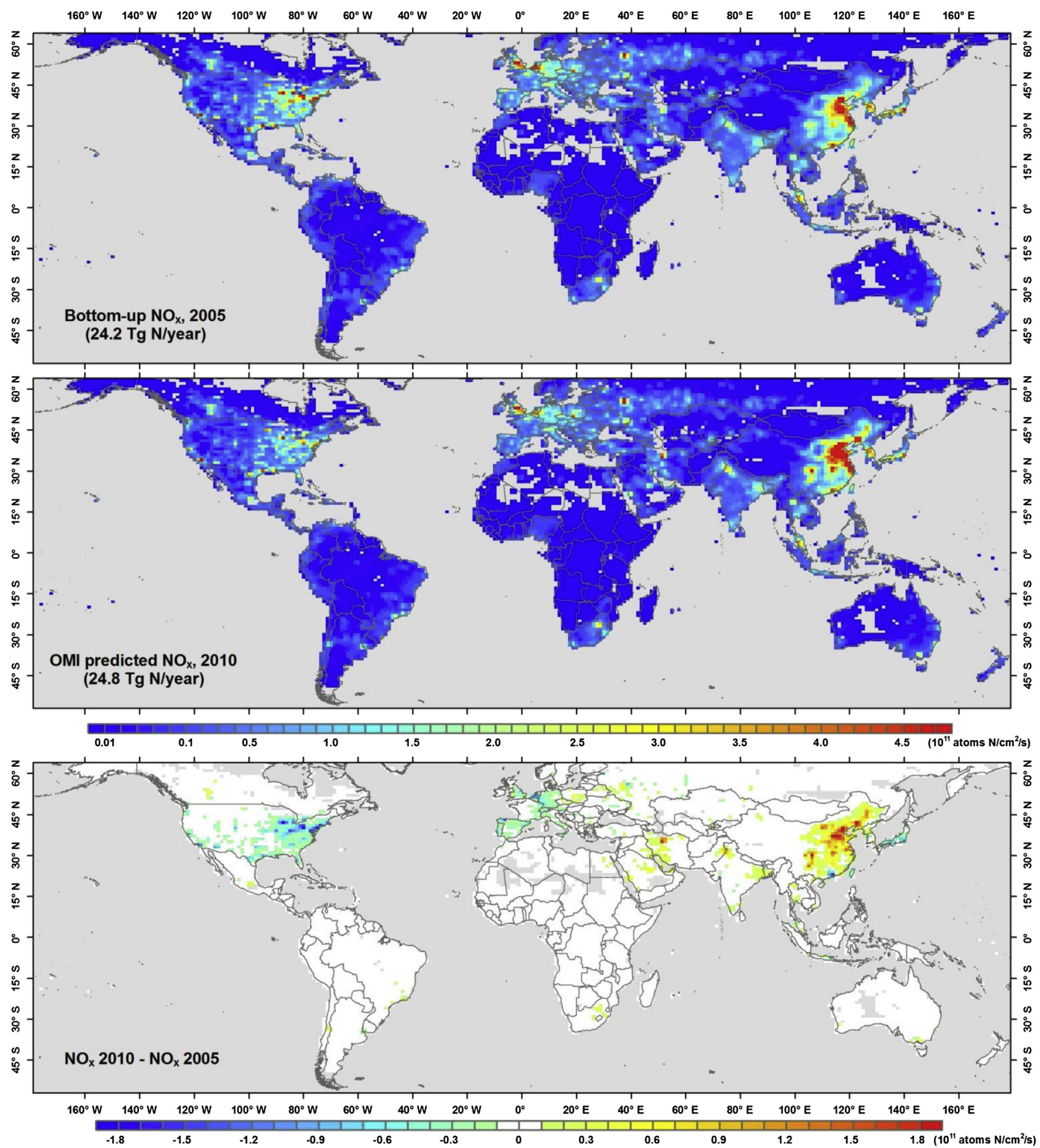

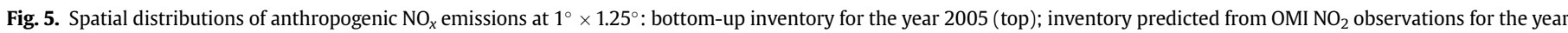

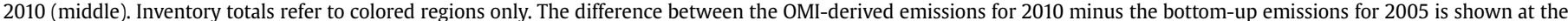
bottom (adapted from Lamsal et al., 2011).

OECD Europe, respectively, and an increase of 24.9\% in East Asia, with a 26.8\% growth in Chinese $\mathrm{NO}_{x}$ emissions. The predicted decrease of $22.7 \%$ for the U.S. is very similar to the decrease calculated from U.S. EPA trends data for 2005 and the unreleased $2010 \mathrm{NEI}$, providing confirmation of the updating approach.

A similar approach may be applicable to other species such as $\mathrm{CO}$ and $\mathrm{NH}_{3}$ to monitor emission changes over time (e.g., Worden et al., 2013). Fortems-Cheiney et al. (2011) conducted an inversion of the 10-year time series of MOPITT CO and interpreted interannual changes in terms of variability due to biomass burning, climate, and socioeconomic factors. However, this study used MOPITT v4 data, which did not account for instrument drift that has resulted in a $0.8 \pm 0.2 \% \mathrm{yr}^{-1}$ increase in the retrieved column (Deeter et al., 2010). Recent MOPITT v5 data (Deeter et al., 2012) 
account for this drift and compare well with temporal trends from other satellite data, as shown in Fig. 6, which is from a study by Worden et al. (2013). This study did not analyze changes in emissions directly, but compared trends in retrieved CO columns from MOPITT, AIRS, TES and IASI for 2000-2011. They found a modest decreasing trend $\left(\sim-1 \% \mathrm{yr}^{-1}\right)$ in total column CO over the Northern Hemisphere and a less significant, but still decreasing trend in the Southern Hemisphere. The decreasing trend over Europe and the U.S. has been reported in other studies and is related to reductions in anthropogenic emissions (Zellweger et al., 2009; Angelbratt et al., 2011; EPA, 2013b).

Not only can time series of satellite retrievals help to extend and interpret long-term trends in emissions in various parts of the world (e.g., van der A et al., 2008; Lin et al., 2010a; Schneider and van der A, 2012), but the effects of short-term changes in emissions (days to weeks to a year)-due to deliberate human intervention or to autonomous forces-can be observed. This suggests significant capability to improve the sensitivity of emission inventories by convolving satellite-derived temporal variability.

Anomalies in annual trends have been reported in a number of studies, both in the U.S. and other parts of the world. Russell et al. (2012) noted from examination of $\mathrm{NO}_{2}$ retrievals in California that there had been a decrease in diesel truck activity attributed to the economic recession (Russell et al., 2012). Castellanos and Boersma (2012) observed similar $\mathrm{NO}_{2}$ reductions over Europe during
2008-2009, though in both California and western Europe the continued implementation of $\mathrm{NO}_{x}$ emission controls makes it difficult to assign causation unequivocally. Satellite-detected effects of the economic recession on $\mathrm{NO}_{x}$ emissions have also been reported for China (Lin and McElroy, 2011), Greece (Vrekoussis et al., 2013), and international shipping (de Ruyter de Wildt et al., 2012). And in a related shorter-term study of economic impact, Yoshida et al. (2010) showed that the effects of Hurricanes Katrina and Rita in 2005 could be detected in the form of reduced OMI $\mathrm{NO}_{2}$ signals around the Gulf of Mexico, associated with disruptions to oil and gas production, oil refining, and power generation.

Changes in emission levels on the scale of days to months due to particular policy interventions or other driving forces have been observed. The first reported example of this was the change in $\mathrm{NO}_{x}$ emissions in Beijing at the time of the Sino-African Summit in November 2006 (Wang et al., 2007). Beijing municipal authorities instituted policy measures to limit traffic in Beijing during a six-day period, with an estimated $30 \%$ reduction in the numbers of vehicles on the road. OMI observed a reduction in column densities of about a factor of two during the period of the Summit. In some ways, this event was a dress rehearsal for the 2008 Beijing Olympic Games, in anticipation of which even more drastic emission reductions were implemented, covering both mobile and stationary sources, and extending from Beijing itself to several surrounding provinces. This unprecedented intervention to reduce emissions over roughly a
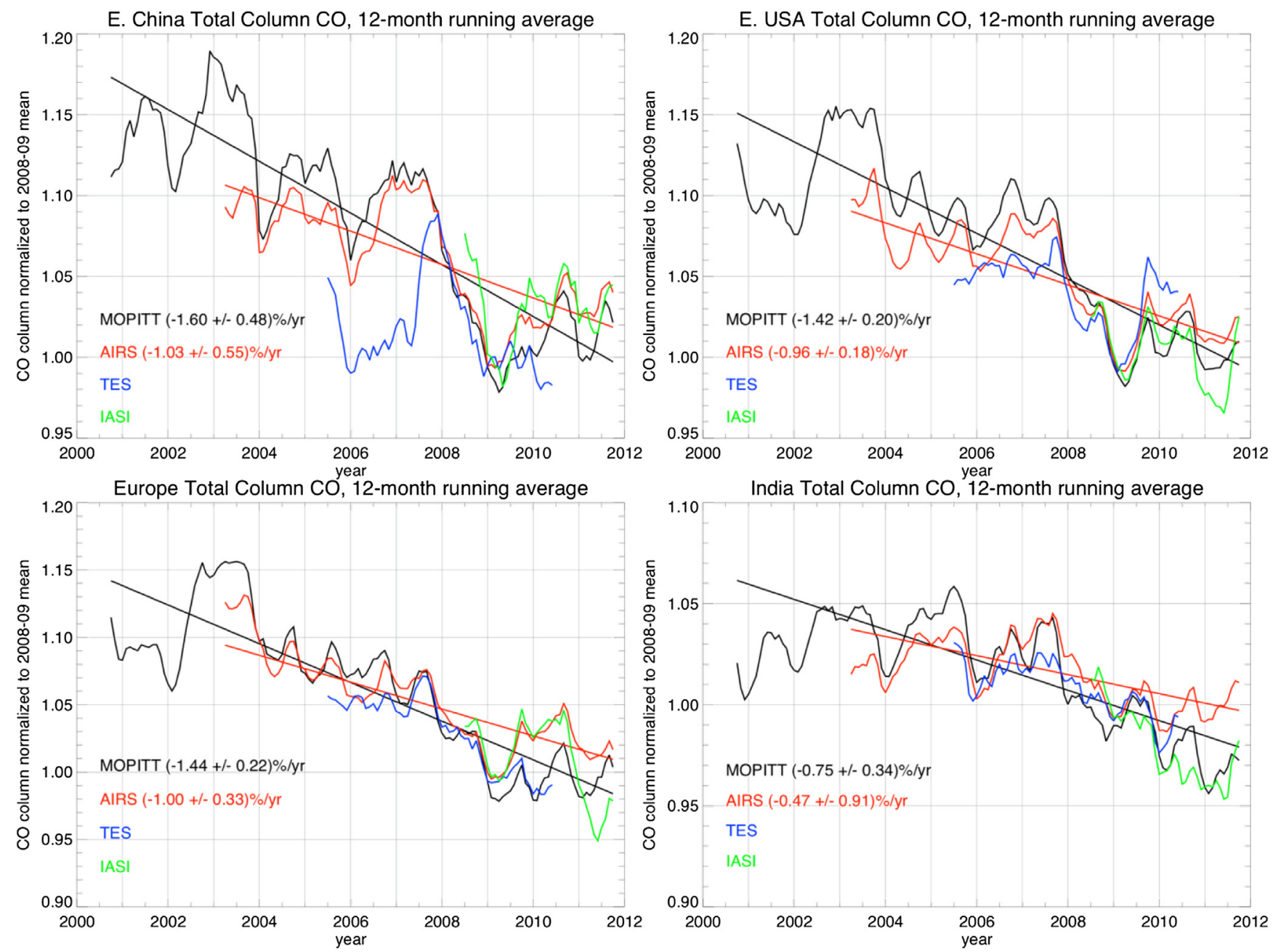

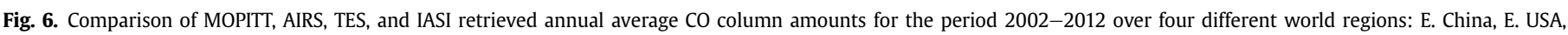
Europe, and India (adapted from Worden et al., 2013). 
two-month period stimulated many research studies utilizing ground-based measurements, satellite observations, and emission inventories: $\mathrm{NO}_{2}$ from GOME-2 and OMI (Mijling et al., 2009), $\mathrm{NO}_{2}$ and $\mathrm{SO}_{2}$ from OMI and CO from MOPITT (Witte et al., 2009), aerosols from MODIS (Cermak and Knutti, 2009; Liu et al., 2012a), aerosols from MODIS and $\mathrm{NO}_{2}$ from OMI (Zhang et al., 2009b), and CO from MOPITT (Worden et al., 2012a). In all cases, the satellite measurements confirmed the emission reductions that were reported to have been implemented. A return to pre-existing emission levels after the conclusion of the Olympic Games was in some cases masked by the onset of an economic recession in the fall of 2008. The experience of the Beijing Olympic Games was revisited during the 2010 World Expo in Shanghai, when Hao et al. (2011) reported significant $(8-14 \%)$ emission reductions of $\mathrm{NO}_{2}, \mathrm{CO}$, and aerosols during the six-month period of the Expo.

Because of the daily coverage provided by some of the satellites, it is possible to investigate even finer temporal cycles of emissions. In the first study of its kind, Beirle et al. (2003) were able to discern different weekly cycles of $\mathrm{NO}_{x}$ emissions in different parts of the world from GOME $\mathrm{NO}_{2}$ columns. In countries with a largely Christian tradition, there was a distinct reduction in emissions on Sundays and a slight reduction on Saturdays. In Israel the minimum occurred on Saturdays, and in Islamic cities of the Middle East there was a slight reduction on Fridays. In China, no weekly effect was observed, possibly due to the fact that emissions are dominated by power plants and industrial plants that operate seven days a week. Kaynak et al. (2009) extended the work of Beirle et al. (2003) by using SCIAMACHY retrievals during the period 2003-2005 over rural, urban, and power-plant areas of the continental U.S. A distinct weekly pattern was observed in cities, with a minimum on Sundays and a smaller reduction on Saturdays, as found by Beirle et al. (2003). Rural areas showed no clear weekly pattern. Areas dominated by power plants showed only a small Sunday reduction. It was possible to infer the relative contributions of mobile sources to total emissions from these weekly patterns, with results differing somewhat from what would be obtained from bottom-up inventories, suggesting a possible application of the satellite data to refine day-to-day variability of emissions over urban areas. Russell et al. (2010) examined the situation over California from OMI data and confirmed that weekday emissions are higher than weekend emissions. They observed that transportation studies have ascribed much of the difference to the absence of heavy-duty diesel trucks on weekends. Similar weekly cycles were reported over Europe by Zhou et al. (2012). Even observations of AOD have revealed weekly cycles over the U.S., central Europe, India, and the Middle East (Xia et al., 2008).

Since each $\mathrm{NO}_{x}$ source has specific characteristics that determine the seasonal variation of the tropospheric $\mathrm{NO}_{2}$ columns, the seasonality of $\mathrm{NO}_{2}$ satellite observations can be used to identify the dominant sources of emissions (van der A et al., 2006, 2008; Ghude et al., 2010; Zhang et al., 2012). The idea builds on seasonal characteristics that have been exploited in earlier studies to understand sources. For example, regions that are dominated by anthropogenic emissions have a seasonal $\mathrm{NO}_{2}$ maximum in the winter (Martin et al., 2003); biomass burning of forests and savanna usually takes place during the dry season such as early spring; and soil emissions can result in enhanced $\mathrm{NO}_{2}$ signals in summertime (Jaeglé et al., 2004). Using these characteristics, van der A et al. (2008) first identified the dominant sources of $\mathrm{NO}_{x}$ emissions on a global scale at a resolution of $1^{\circ} \times 1^{\circ}$ on the basis of GOME and SCIAMACHY measurements. On a regional scale, they found that eastern and western China are dominated by anthropogenic and natural emissions, respectively. Recently, Zhang et al. (2012) applied a similar methodology to a multiyear analysis from 1996 to 2010 . They observed that the highly polluted regions (areas dominated by anthropogenic emissions) in China have expanded from the east to the central and the west, and new highly polluted regions have formed throughout the nation in the past 15 years. This technique shows the potential for determining changes over time in the spatial extent of different area sources having different emitting patterns that can then be fed back into bottom-up inventories.

\subsection{Anthropogenic point sources}

Emissions from large, man-made point sources are clearly one of the major targets for measurement from space, both because they represent a strong signal that should be within the detection limits of available instruments and also because they are potentially large polluters that command the attention of environmental regulatory bodies. The ability to detect changing emissions from these types of sources has the potential to aid in the verification of region-wide pollution control policies and in determining the compliance of individual point sources with emission control requirements. Consequently, anthropogenic point sources, particularly of $\mathrm{NO}_{x}$ and $\mathrm{SO}_{2}$, have been the subject of many research studies. For application to U.S. air quality management, the interplay between observed emissions and regulatory policy is a key component of such work.

During the era of measuring air quality from space $(\sim$ mid1990 s to present), there have been several important environmental efforts in the U.S. directed at reducing the emissions of $\mathrm{NO}_{x}$ and $\mathrm{SO}_{2}$ from coal-burning power plants. For example, EPA issued the $1998 \mathrm{NO}_{x}$ State Implementation Plan (SIP) Call with the intent to reduce $\mathrm{NO}_{x}$ emissions during the summer season and thereby to reduce ground-level $\mathrm{O}_{3}$ concentrations. And in $2005 \mathrm{EPA}$ issued the Clean Air Interstate Rule (CAIR) with the goal of decreasing $\mathrm{NO}_{x}$ and $\mathrm{SO}_{2}$ emissions even further. Both the SIP Call and CAIR apply to the eastern U.S., where emissions in an upwind state can significantly impact air quality in another, downwind state.

There are a number of methods for significantly reducing emissions of $\mathrm{NO}_{x}$ and $\mathrm{SO}_{2}$ from the effluent of stationary sources, most importantly Selective Catalytic Reduction (SCR) for $\mathrm{NO}_{x}$ and flue-gas desulfurization (FGD) for $\mathrm{SO}_{2}$. SCR and FGD units can effectively remove up to $90 \%$ of $\mathrm{NO}_{x}$ and $\mathrm{SO}_{2}$, respectively, from the effluent stream. Application of these systems on a number of power plants, coupled with other strategies to limit emissions from polluting plants, has caused $\mathrm{NO}_{x}$ and $\mathrm{SO}_{2}$ emissions from power plants to decrease substantially from 1999, when about onequarter of total $\mathrm{NO}_{x}$ emissions and almost all $\mathrm{SO}_{2}$ emissions in the U.S. were associated with power generation. Given the short lifetimes of $\mathrm{NO}_{x}$ and $\mathrm{SO}_{2}$, data collected from space can be used to confirm reductions reported by individual power plants, particularly those not impacted by large area sources such as cities. Inferring emissions or changes in emissions from point sources using satellite data requires careful attention, however, as the estimate depends on the assumed lifetimes for $\mathrm{SO}_{2}$ and $\mathrm{NO}_{2}$, which can be highly variable due to weather and other factors (see, e.g., Beirle et al., 2011; Walter et al., 2012; Zhou et al., 2012).

The first work on U.S. power plants was reported by Kim et al. (2006), who used GOME and SCIAMACHY data to examine the long-term evolution of $\mathrm{NO}_{2}$ columns in the eastern U.S. from 1997 to 2005, with the intention of assessing regional changes in $\mathrm{NO}_{x}$ emissions associated with the $1998 \mathrm{NO}_{x}$ SIP Call. They inferred that $\mathrm{NO}_{x}$ emissions from power plants in the Ohio River Valley had decreased by about $35 \%$ over this period, which was in line with reported measured emission changes from Continuous Emissions Monitoring Systems (CEMS). This result was in contrast to the Northeast urban corridor, where there was no clear trend in emissions. In subsequent work Kim et al. (2009) reported an analysis of $2005 \mathrm{NO}_{2}$ satellite data for 13 individual power plants in 
the western U.S. Agreement with WRF-Chem modeled columns was found to be excellent for three retrievals: SCIAMACHY $(r=0.93)$; the University of Bremen OMI $(r=0.97)$, and NASA OMI $(r=0.95)$. These plants are considerably more remote from other sources than plants in the eastern U.S., making the signals from their plumes more distinctive. Russell et al. (2012) used $\mathrm{NO}_{2}$ column data from the OMI BEHR retrieval algorithm to infer that $\mathrm{NO}_{x}$ emission changes from 23 large power plants throughout the U.S. were variable because of region-specific regulations, decreasing on average by $26 \pm 12 \%$ from 2005 to 2011 .

China and India are excellent test beds for the study of point sources. Both countries contain large coal-fired power plants that are relatively poorly controlled and therefore have high emission rates. Not only that, the boom period of the mid-2000s saw the construction of many new plants of this kind, meaning that we have the luxury of being able to observe the satellite responses before and after the sources of emissions came into existence. This is rarely possible in the developed world these days. The close relationship between $\mathrm{NO}_{2}$ columns and the locations of large coalfired power plants in China and India is shown in Fig. 7.

The potential for investigating emissions from power plants in China was triggered by the groundbreaking paper of Richter et al. (2005), which reported the large growth $(\sim 50 \%)$ in $\mathrm{NO}_{x}$ emissions in China inferred from GOME and SCIAMACHY measurements during the period 1996-2004. This was confirmed by a combined bottom-up and top-down examination of China's $\mathrm{NO}_{x}$ emission trends over the same period (Zhang et al., 2007). Subsequently, Zhang et al. (2009a) studied the $\mathrm{NO}_{x}$ emissions from new power plants built in the period 2005-2007 in Inner Mongolia, China, where the power plants are relatively far removed from large urban areas. OMI summertime $\mathrm{NO}_{2}$ columns were found to be closely correlated with emissions from the new large sources of pollution. Quantitative agreement (rates of increase) were very good in cases where new sources were added to already-developed regions $\left(R^{2}=0.94\right)$, but not so good in remote regions, due to uncertainty in the background $\mathrm{NO}_{x}\left(R^{2}=0.73\right.$ for all plant locations). This work was subsequently expanded to a wider set of Chinese power plants with similar results (Wang et al., 2010, 2012).

Li et al. (2010b) extended the study of Chinese power plants to $\mathrm{SO}_{2}$, with the aim of demonstrating that OMI could detect the presence or absence of $\mathrm{SO}_{2}$ emission control equipment and possibly even quantify its efficiency. Following Zhang et al. (2009a), the $\mathrm{SO}_{2} / \mathrm{NO}_{2}$ column ratios were determined for a number of power plants in Inner Mongolia in 2005-2008, during which period the plants were scheduled to install FGD equipment. Dramatic declines in $\mathrm{SO}_{2}$ were observed at some plants-implying the implementation of pollution controls-while the $\mathrm{NO}_{2}$ signal remained relatively constant-implying steady electricity generation over the time period. Li et al. (2010b) clearly demonstrated that there is great potential to verify the effectiveness of pollution measures

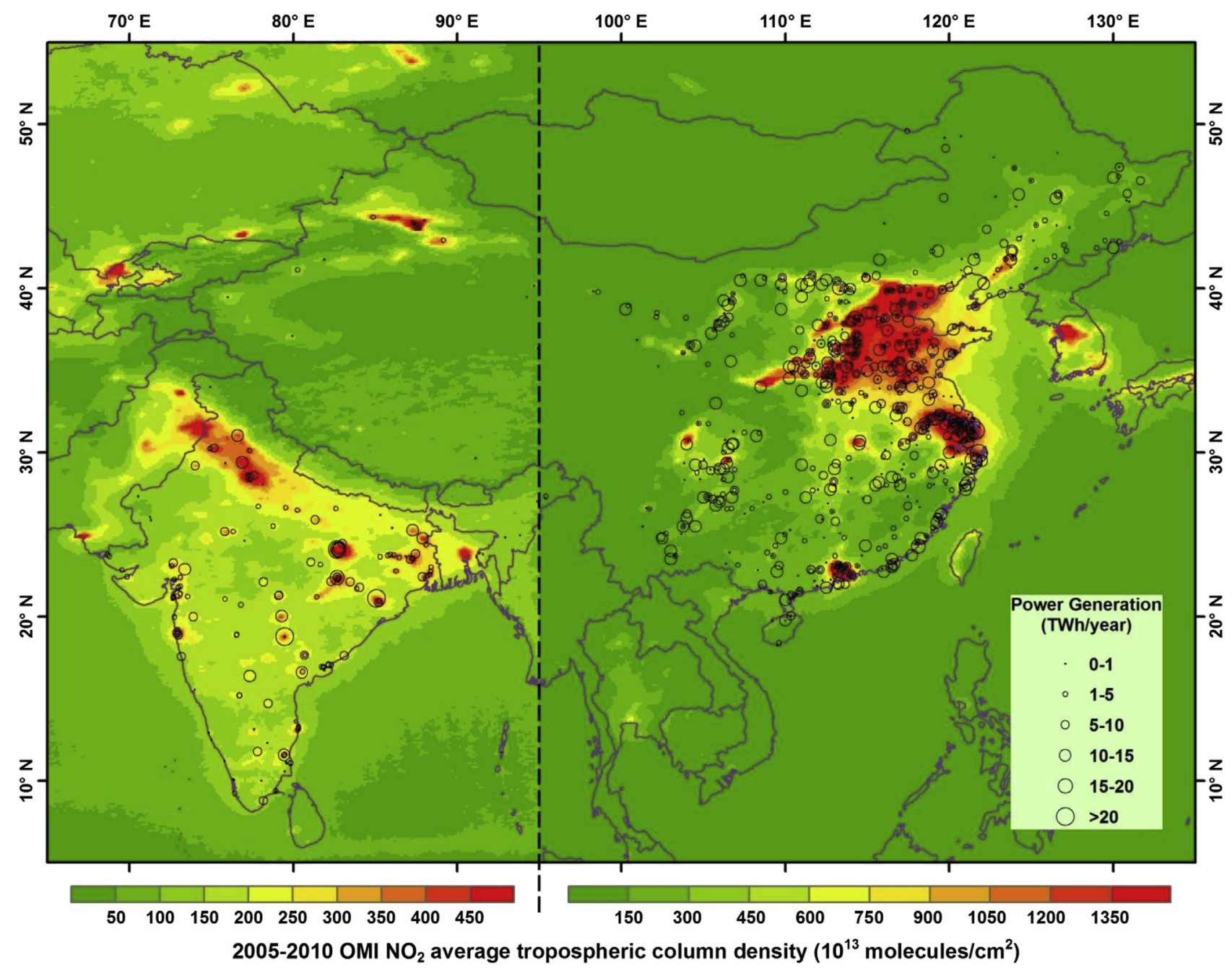

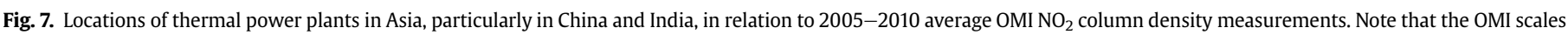
are different in the two parts of this image. 
from space, which was bolstered by the high level of interest in this work expressed by China's Ministry of Environmental Protection.

There have been fewer papers devoted to power plants in India, though the situation is similar to China in that many new coalfired plants with relatively poor controls were built after the availability of high-performance satellite measurements. In many ways India is a more desirable target than China because of shorter $\mathrm{NO}_{2}$ lifetimes in hotter conditions, smaller solar zenith angle, weaker seasonality, and lower area emissions around power plants (Lu and Streets, 2012). GOME and SCIAMACHY trends over India for 1996-2006 have been used to identify major hotspots of $\mathrm{NO}_{x}$ emissions, some of which were power plants (Ghude et al., 2008). Prasad et al. (2012) used OMI data to study power plants in India over the period 2005-2007. Lu and Streets (2012) combined results from four satellite instruments, GOME, SCIAMACHY, OMI, and GOME-2 to quantify the growth in $\mathrm{NO}_{x}$ emissions from Indian power plants.

Overall, it can be concluded that emissions of $\mathrm{NO}_{x}$ and $\mathrm{SO}_{2}$ from coal-fired power plants represent promising targets for application of satellite observations. The China and India experience needs to be transferred to the North American context with detailed, unitspecific comparison of space-based emission estimates with CEMS measurements under a variety of location, seasonal, and meteorological conditions. An inter-comparison of derived relationships between, for example, power-plant $\mathrm{NO}_{x}$ emission rates and $\mathrm{NO}_{2}$ column concentrations from different studies in different parts of the world would also be a step forward.

Metal smelters are the largest anthropogenic point sources of $\mathrm{SO}_{2}$ and have therefore been targets of study to test the capability of space-borne instruments. Carn et al. (2007) first reported the detection of $\mathrm{SO}_{2}$ emissions from two copper smelters in Peru using OMI. Annual $\mathrm{SO}_{2}$ emissions from the larger of the two smelters, Ilo, were estimated at $0.3(0.2-0.5) \mathrm{Tg}$. Interestingly, the emission rate appeared to decrease by about $40 \%$ between late 2004 and early 2005 , which the authors of the paper speculate may have been caused by modernization of the plant and an increase in the $\mathrm{SO}_{2}$ capture rate. This mirrors the work on $\mathrm{SO}_{2}$ capture by power plants in China ( $\mathrm{Li}$ et al., 2010b). Khokhar et al. (2008) analyzed $\mathrm{SO}_{2}$ emissions from the same two smelters in Peru and the large smelter complex at Norilsk in Russia, using a seven-year time series of GOME data. They estimated annual $\mathrm{SO}_{2}$ emissions from the Ilo smelter at $1.095 \pm 0.2 \mathrm{Tg}$, larger than the value obtained by Carn et al. (2007). Uncertainties related to the assumed $\mathrm{SO}_{2}$ lifetime and AMF are cited as possible reasons for discrepancies.

The copper and nickel smelters at Norilsk in Russia are acknowledged to be the largest anthropogenic point sources of $\mathrm{SO}_{2}$ in the world. Khokhar et al. (2008) estimated their annual emissions to be $1.685 \pm 0.3 \mathrm{Tg}$ from GOME data. Walter et al. (2012) were able to reassess Norilsk emissions using the DOAS system on board the CARIBIC aircraft, yielding an estimate of annual $\mathrm{SO}_{2}$ emissions of $0.92 \pm 0.5 \mathrm{Tg}$. The estimate derived from closely synchronized OMI measurements was $0.7(0.6-0.9) \mathrm{Tg}$. Walter et al. (2012) report on several bottom-up estimates from such sources as the EDGAR inventory and the Norilsk Nickel Company itself, which suggest that emissions "ought" to be higher than the satellite observed

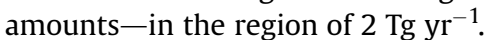

In a similar study Carn et al. (2004) observed the $\mathrm{SO}_{2}$ that was released from a month-long fire at the Al-Mishraq State Sulfur plant in Iraq in 2003. Using TOMS data they estimated a release of $\sim 0.6 \mathrm{Tg}$ of $\mathrm{SO}_{2}$ in total-roughly consistent with the reported inventory loss of sulfur-which made it the largest non-volcanic $\mathrm{SO}_{2}$ emission event observed to date. Kearney et al. (2009) subsequently resampled the MODIS data to the spatial resolution of TOMS and reanalyzed the plume $\mathrm{SO}_{2}$ for a single day, 29 June 2003, finding good agreement between the two data sets. Large anthropogenic $\mathrm{SO}_{2}$ point sources like these are clearly visible in the satellite retrievals, but, fortunately, they are few and far between.

\subsection{Anthropogenic area sources}

Anthropogenic area sources are a natural target of opportunity for space-based emissions estimation, as they are individually small in size, spatially dispersed, and difficult to accurately represent in emission inventories. Unconventional energy extraction processes are such an area source. The important work of McLinden et al. (2012) examined emissions of $\mathrm{NO}_{x}$ and $\mathrm{SO}_{2}$ from oil/tar sands operations in the Canadian province of Alberta, using the highresolution $(\sim 30 \mathrm{~km} \times 50 \mathrm{~km})$ retrievals previously discussed in the context of Fioletov et al. (2011) and Boersma et al. (2011). Increases in $\mathrm{NO}_{2}$ columns between 2005 and 2010 were estimated to be a remarkable $10.4 \pm 3.5 \% \mathrm{yr}^{-1}$, reflecting the dramatic growth in exploitation of this resource both in intensity and spatial extent. Similar applications to such activities as oil and gas extraction in the Colorado Northern Front Range and other locations are likely to follow.

Shipping emissions represent an area source category that has posed problems for bottom-up inventories due to the wide variety of source types and poor statistics on numbers of vessels and emission factors. The first remote detection of ship tracks was reported by Beirle et al. (2004a) along the international shipping lane from Sri Lanka to the Strait of Malacca across the Indian Ocean. They used a 6-year (1996-2001) composite of GOME $\mathrm{NO}_{2}$ data. Seasonal differences in wind direction were used to derive a mean lifetime of $\mathrm{NO}_{x}$ in ship exhaust of 3.7 (1.9-6.0) hours. Using this result, Beirle et al. (2004a) derived an estimate for annual shipping emissions in the Indian Ocean domain of $23(10-73) \mathrm{Gg} \mathrm{N}$, in good agreement with inventory estimates. In that same year, Richter et al. (2004) reported SCIAMACHY measurements of $\mathrm{NO}_{2}$ associated with shipping not only in the Indian Ocean, but also in the Red Sea and the South China Sea. Reasonable agreement with shipping emission inventories was obtained, though in some locations uncertainty was high. Better knowledge of the $\mathrm{NO}_{2}$ lifetime was needed-they used a value of $5.6 \mathrm{~h}$, longer than Beirle et al. (2004a)-in order to more accurately characterize the horizontal and vertical dispersion of the plumes and $\mathrm{NO}_{x}$ removal.

This work was later extended by Franke et al. (2009) using both SCIAMACHY and GOME-2 to obtain monthly information about shipping emissions, though springtime biomass burning over India and autumn burning over Indonesia interfered with the analysis. They concluded that an annual emission estimate of $90 \mathrm{Gg} \mathrm{N}$ was reasonable, increasing at a rapid rate that could account for differences between GOME and SCIAMACHY measurements over the period 1996-2007. Marbach et al. (2009) detected HCHO from shipping in the Indian Ocean using GOME data. The HCHO is not emitted directly from the ships but is thought to be formed by some unknown photochemical mechanism in or close to the ship plumes. Most recently, de Ruyter de Wildt et al. (2012) used data from four space-borne instruments to observe $\mathrm{NO}_{2}$ columns from shipping activity in a region stretching from the Mediterranean Sea to the South China Sea. SCIAMACHY detected four major shipping lanes: the Mediterranean Sea between Italy and Tunisia, the Red Sea, the Indian Ocean (as reported by Beirle et al., 2004a), and the South China Sea leading northeast from Singapore to Chinese ports. They developed time trends in $\mathrm{NO}_{2}$ column density from 1996 to 2010 and compared them with trends in shipping cargo volume and international trade volume.

One major potential application for satellite observations is to estimate the emissions in a large metropolitan area, where there may be very many small sources of different types that in aggregate represent a large emissions contribution spread over a wide 
domain. In the U.S., $\mathrm{NO}_{2}$ urban signatures and their weekly cycles were first reported for five cities (New York, Los Angeles, Chicago, Dallas, and Detroit) using GOME measurements (Beirle et al., 2003). Later work addressed 14 western cities (Kim et al., 2009), including annual trends and weekly cycles. Similar work was then performed for several cities located across the U.S. (Kaynak et al., 2009) and cities in California (Russell et al., 2010). Satellite observations show that $\mathrm{NO}_{2}$ columns in U.S. cities have generally been declining during the observational record, which is consistent with the implementation of the requirements of the Tier 1 and 2 vehicle standards and the gradual turnover of the fleet of light-duty vehicles. Russell et al. (2012) used the BEHR OMI NO 2 retrieval data to estimate an average total reduction of $32 \pm 7 \%$ for U.S. cities from 2005 to 2011 with a $34 \%$ decrease in $\mathrm{NO}_{2}$ from mobile sources. U.S. EPA trends data show a reduction of 31\% between 2005 and 2011. Russell et al. (2012) attributed part of the observed decline in $\mathrm{OMI} \mathrm{NO}_{2}$ columns to the turnover in the mobile source fleet and part to the economic recession that began in 2008. Specifically, they reported that $\mathrm{NO}_{2}$ columns decreased by $6 \pm 5 \% \mathrm{yr}^{-1}$ before the recession and $8 \pm 5 \%$ $\mathrm{yr}^{-1}$ during the recession.

Developing a bottom-up emission inventory for a megacity in the developing world is an even more daunting task. Conventional techniques for doing so are confounded by influxes of migrant workers and unconventional vehicles from the countryside, neverending construction activities with their ubiquitous diesel engines, unregistered vehicles, small industrial operations, household burning of solid fuels, etc. These difficulties can, to a certain extent, be by-passed by a satellite observation, which sees only the integrated product of multifarious small sources. Indeed, the potential of satellite $\mathrm{NO}_{2}$ observations to yield information about the size, shape, land use, and dynamics of an urban area has prompted a new breed of demographic/socioeconomic studies, exemplified by Bechle et al. (2011) and Novotny et al. (2011). For urban studies outside North America, the reader can consult satellite analyses of cities worldwide (Clerbaux et al., 2008; Kar et al., 2010), in Europe and the Middle East (Konovalov et al., 2010), in the eastern Mediterranean (Kanakidou et al., 2011), and in southeastern Europe (Zyrichidou et al., 2009). Beirle et al. (2011) used OMI measurements over eight large urban agglomerations to probe the lifetime of $\mathrm{NO}_{x}$, with an eye to elucidating the formation of urban $\mathrm{O}_{3}$. A good relationship was obtained between urban $\mathrm{NO}_{x}$ emissions derived from OMI columns with EDGAR bottom-up inventory estimates. In the Saudi Arabian city of Riyadh a strong dependency of the $\mathrm{NO}_{2}$ column density on wind direction was observed, with the maximum concentration shifted by $\sim 10-40 \mathrm{~km}$ downwind from the city center. Across all the cities, the $\mathrm{NO}_{x}$ lifetimes were in the range of $2.3-6.4 \mathrm{~h}$, reflecting the oxidizing capacity of the freshly emitted plumes.

As indicated earlier, it is possible that U.S. air quality studies could be improved by the use of satellite data to augment uncertain emission inventories for neighboring countries, of which Mexico is the prime example. Some satellite studies have already shed light on emission estimates in Mexico. The emissions inventory of $\mathrm{NO}_{x}$ was evaluated during the Megacity Initiative: Local And Global Research Observations (MILAGRO/INTEX-B) campaign with a combination of in situ aircraft measurements, satellite retrievals, and numerical modeling (Boersma et al., 2008a, 2008b; Molina et al., 2010). OMI top-down emission estimates have been compared with the official Mexican National Emissions Inventory of 1999. Large sources of $\mathrm{SO}_{2}$ were identified on either side of Mexico City during the same campaign (de Foy et al., 2009), using the oversampling technique described in Section 4.2. Source strengths were compared with surface measurements using mesoscale simulations, improving the confidence in prior emissions estimates. Shim et al. (2009) used $\mathrm{O}_{3}$ and $\mathrm{CO}$ data from TES to study pollution outflow from Mexico City, also as part of the
MILAGRO/INTEX-B campaign. Retrieval issues prevented measurements directly over the metropolitan area. Generally, TES enhancement ratios of $\mathrm{O}_{3}$ to $\mathrm{CO}$ were overestimated compared to in situ measurements, prompting a call for further examination of the data sets.

\subsection{Natural point sources}

Volcanoes are the only natural point sources of large magnitude, but they can be so large that they can dwarf the emissions of $\mathrm{SO}_{2}$, $\mathrm{PM}$, and other gases from anthropogenic point sources during eruptive and even degassing periods. Sizeable eruptive events can release several $\mathrm{Tg}$ of $\mathrm{SO}_{2}$ in a day or two, as compared with about $1 \mathrm{Tg}$ per year from large anthropogenic point sources like the copper and nickel smelters at Norilsk (see, e.g., Walter et al., 2012). The history of observations of volcanic emissions from space has been reviewed by Thomas and Watson (2010), and the reader is referred to that source for more information. One clear advantage that satellites have over ground measurements is the ability to monitor emissions from a source that may be very remote and inaccessible, as well as being expensive and hazardous for humans to monitor in situ. Because the volcanic source strength is great, the $\mathrm{SO}_{2}$ signal is readily detectable by several instruments and more easily converted to an estimate of emissions than the $\mathrm{SO}_{2}$ released by anthropogenic sources.

Satellite observations of $\mathrm{SO}_{2}$ releases from volcanoes trace back to the late 1970s and are perhaps best exemplified by the observation by TOMS of the eruption of the El Chichón volcano in southern Mexico in 1982 (Krueger, 1983). It was estimated from the UV absorption properties of the released cloud that $\sim 3.3 \mathrm{Tg}$ of $\mathrm{SO}_{2}$ were injected into the stratosphere over a two-day period. One of the first comprehensive reports of satellite observations of $\mathrm{SO}_{2}$ emissions from volcanoes was by Khokhar et al. (2005), who studied both eruptions and degassing at about 20 volcanoes around the world during the period 1996-2002, using GOME data. Despite the coarse spatial resolution of GOME and the relatively large uncertainties for individual observations, it was felt at that time that there was potential for being able to derive rough estimates of $\mathrm{SO}_{2}$ emissions from satellite retrievals. Uncertainties could be reduced if additional information on plume height, cloud cover, aerosol loading, and $\mathrm{SO}_{2}$ lifetime were available.

As the next generation of satellites came into operation, having greater spatial resolution, it became possible to develop additional information about volcanic releases of $\mathrm{SO}_{2}$. For example, Loyola et al. (2008) studied four volcanic eruptions in Central and South America with a combination of GOME, SCIAMACHY, and GOME-2 instruments. By combining the retrievals with a trajectory model, they were able to determine the effective plume heights. They also proposed the development of a near-real-time $\mathrm{SO}_{2}$ data delivery service to warn of aviation hazards arising from volcanic ash clouds. Using OMI and other retrievals, Carn and Prata (2010) reported on the numerous episodes of explosive $\mathrm{SO}_{2}$ emissions on the Caribbean island of Montserrat during the period 1995-2009 and particularly in 2003 and 2006. The largest single emission was $\sim 2 \mathrm{Tg}$ in 2006 that was injected into the lower stratosphere and tracked halfway around the world. They suggested that spacebased routine monitoring of gaseous releases from volcanoes might be capable of warning of impending eruptions.

The August 2008 eruption of the Kasatochi volcano on the Aleutian Islands of Alaska, released similar amounts of $\mathrm{SO}_{2}$, estimated at $\sim 1.5-2.5 \mathrm{Tg}$. Krotkov et al. (2010) combined OMI satellite data with a trajectory model to analyze the dispersion of the $\mathrm{SO}_{2}$ cloud. The OMI data were able to constrain the $\mathrm{SO}_{2}$ plume height and eruption times and initialize the transport model. The OMI $\mathrm{SO}_{2}$ burden was integrated over the Northern Hemisphere and 
extrapolated back to yield an initial erupted mass of $\sim 2.2 \mathrm{Tg}$, twice as large as the measured mass on the day. In addition, instruments on the CARIBIC flying observatory detected remnants of the Kasatochi $\mathrm{SO}_{2}$ plume in central Europe, and comparisons with GOME-2 satellite observations were possible within just a few hours, yielding a robust correlation (Heue et al., 2010). Clarisse et al. (2011a) were able to observe $\mathrm{H}_{2} \mathrm{~S}$ in the Kasatochi plume from IASI observations, though $\mathrm{H}_{2} \mathrm{~S}$ is spectroscopically difficult to detect and it oxidizes to $\mathrm{SO}_{2}$ in the atmosphere within a few days.

The eruption of the Icelandic volcano Eyjafjallajökull in 2010 enabled Carboni et al. (2012) to develop a new scheme to utilize IASI retrievals to track the $\mathrm{SO}_{2}$ plume in the presence of cloud and volcanic ash. Rix et al. (2012) were able to study $\mathrm{SO}_{2}$ and $\mathrm{BrO}$ columns in the eruption from this volcano using GOME-2 data, as well as to determine the $\mathrm{SO}_{2}$ plume height. Finally, Martínez-Alonso et al. (2012) reported the first observation of CO emissions from a volcano using MOPITT data.

\subsection{Natural area sources}

There are several types of natural area sources that are important to characterize from the perspectives of assessing the contribution of anthropogenic emissions to total emissions, understanding atmospheric chemistry and the production of secondary species, and assembling complete emissions datasets to run CTMs and other atmospheric models. Such source types include open biomass burning, soils, lightning, and biogenic sources. Biogenic NMVOC were described in Section 3.5 and are not discussed further here.

Satellite estimates of open biomass burning have become routine, and their resulting emissions are now reported on a regular basis, e.g., the Global Fire Emissions Database, GFED (van der Werf et al., 2010), the Fire INventory from NCAR, FINN (Wiedinmyer et al., 2011), and the Wildland Fire Emission Inventory, WFEI (Urbanski et al., 2011). The literature related to biomass burning detection from space is vast and beyond the scope of this article. Given the large uncertainty in bottom-up estimates of CO emissions, inversion analyses using CO satellite observations offer considerable promise for constraining this important source (e.g., Pétron et al., 2004) and separating anthropogenic and biomass burning components.

Lightning $\mathrm{NO}_{x}$ has been studied by a number of research groups using satellite products. A typical approach to this problem is to measure the SCD of lightning-related $\mathrm{NO}_{x}$ and then develop a formalism to relate SCD to VCD. Cloud-resolving models are useful to calculate the appropriate AMF. A further complication is that most of the gas exists in the upper troposphere in the form of NO, which is not directly measurable. Beirle et al. (2009) identified the uncertainties and sensitivities involved in using satellite observations to study lightning $\mathrm{NO}_{x}$. The analytical process involves generating an estimate of production efficiency (number of molecules produced per flash) and then multiplying that by an estimate of the number of flashes in a given time period over a given area to yield an estimate of the $\mathrm{NO}_{x}$ produced.

Perhaps the most widely accepted estimate of annual $\mathrm{NO}_{x}$ produced from lightning worldwide developed by a method that does not involve satellite observations is $\sim 5 \mathrm{Tg} \mathrm{N}$ in the range of 2$8 \mathrm{Tg} \mathrm{N}$ (Schumann and Huntrieser, 2007). There have been a number of satellite-based studies that have attempted to constrain the global magnitude of lightning $\mathrm{NO}_{x}$ generated, and we touch on just a few of them here. Though uncertainties are still large, central estimates agree quite well. More than a decade ago, Bond et al. (2002) used satellite imagery from the Lightning Image Sensor (LIS) on board the Tropical Rainfall Measuring Mission (TRMM) satellite to obtain an emission estimate of $6.3 \mathrm{Tg} \mathrm{N} \mathrm{yr}^{-1}$ in the tropics. Beirle et al. (2004c) combined the LIS data on lightning activity with GOME $\mathrm{NO}_{2}$ measurements for a statistical case study over central Australia, where other $\mathrm{NO}_{x}$ sources are very few. Extrapolation of the results yielded a global production estimate of $2.8(0.8-14) \mathrm{Tg} \mathrm{N} \mathrm{yr}^{-1}$ Boersma et al. (2005) also used GOME measurements to estimate an annual global $\mathrm{NO}_{x}$ production rate of 1.1-6.4 TgN in 1997.

Martin et al. (2007) used observations from four satellite instruments to constrain the estimate of NO production by lightning: $\mathrm{NO}_{2}$ columns from SCIAMACHY, $\mathrm{O}_{3}$ columns from OMI and MLS, and upper tropospheric $\mathrm{HNO}_{3}$ from ACE-FTS. Supplementing these observations with GEOS-Chem model predictions of the times and places of lightning occurrences, a global estimate of $6 \pm 2 \mathrm{Tg} \mathrm{N} \mathrm{yr}^{-1}$ was obtained. When Beirle et al. (2010) studied SCIAMACHY measurements of lightning $\mathrm{NO}_{x}$ over the eastern U.S., they often found poor spatial correlation between fresh flashes and enhanced column densities, inferring that aged lightning $\mathrm{NO}_{x}$ or anthropogenic $\mathrm{NO}_{x}$ was interfering. Production efficiency was often lower than expected, equivalent to a global source strength of $\sim 1 \mathrm{Tg} \mathrm{N} \mathrm{yr}^{-1}$ Bucsela et al. (2010) were able to develop customized OMI retrievals for lightning $\mathrm{NO}_{x}$ during the NASA $\mathrm{TC}^{4}$ campaign, which were supported by aircraft observations. Combining CMAQ with OMI observations, an estimate of $500 \mathrm{~mol} \mathrm{NO}$ per flash provided reasonable $(-5$ to $+13 \%)$ model/measurement agreement for the mean summertime tropospheric $\mathrm{NO}_{2}$ column (Allen et al., 2012).

Soil $\mathrm{NO}_{x}$ emissions have also been estimated from satellite observations. It is difficult to estimate soil $\mathrm{NO}_{x}$ emissions by bottomup methods, due to high spatial and temporal variability, as well as the sensitivity of the emission rates to climatic variables, soil characteristics, and anthropogenic influences such as cultivation and fertilizer application. Soil $\mathrm{NO}_{x}$ emissions might therefore be a prime candidate for measurement from space, where spatial coverage is high and daily observation is possible. As with lightning, NO is the primary emitted species and the rate of oxidation to other nitrogen species is an issue. Jaeglé et al. (2004) first demonstrated the ability of satellites to observe soil $\mathrm{NO}_{x}$ emission processes. Bertram et al. (2005) studied an agricultural area of two million hectares in Montana using SCIAMACHY data and observed pulses of $\mathrm{NO}_{x}$ associated with application of fertilizer and precipitation. They were able to use the satellite data to refine mechanistic parameters in a conventional model of soil $\mathrm{NO}_{x}$. Hudman et al. (2010) used OMI data to study soil $\mathrm{NO}_{x}$ emissions in the Great Plains. They also used a case study of a region of soybean and corn production in South Dakota to demonstrate rain-induced pulses of $\mathrm{NO}_{x}$, as well as associations with fertilizer application. Large interannual variation in the emission rate was observed during the period of measurement (2005-2008), and differences between model simulations and satellite retrievals were noted. Overall, the soil $\mathrm{NO}_{x}$ emissions resulted in an increase of $\sim 3 \mathrm{ppbv}$ in 8-h $\mathrm{O}_{3}$ concentrations over the agricultural Great Plains region. Subsequently, Hudman et al. (2012) were able to develop a mechanistic model of global soil NO emissions using OMI satellite data to constrain the parameterization.

\subsection{Field campaigns: observing transport and transformation}

Satellite observations are becoming an increasingly integral part of field campaigns aimed at understanding air quality and source contributions. Although evaluating and improving space-based measurement of tropospheric composition is a nearly universal goal of such field experiments, satellite products can be part of the planning process and can contribute to analysis of the results. Consider INTEX-A (Intercontinental Chemical Transport Experiment-North America) with the objective of studying pollution plumes over the U.S. and export from North America, and INTEX-B 
(Intercontinental Chemical Transport Experiment-Phase B) with the objective of quantifying the outflow of pollution from Mexico and East Asia. These projects integrated satellite products along with model forecasts into the flight planning process. In TexAQS II (The Second Texas Air Quality Study) satellites provided the regional context for urban measurements of trace gases (McMillan et al., 2005) and aerosols (Winker et al., 2007).

In several recent, large-scale field campaigns, satellite observations have been a core component. EAST-AIRE (East Asian Study of Tropospheric Aerosols: An International Regional Experiment), RAMMPP (Regional Atmospheric Measurement, Modeling and Prediction Program) and DISCOVER-AQ (Deriving Information on Surface conditions from Column and Vertically Resolved Observations Relevant to Air Quality) offer illustrative examples. For these projects, satellite observations were incorporated into the experimental plan as one of the tools to understand atmospheric processes. EAST-AIRE (and its successor EAST-AIRC) were focused on aerosol emissions, transport, distributions, optical and chemical properties, and their subsequent impact on direct radiative forcing, air quality, ecosystems, and regional climate, as summarized in $\mathrm{Li}$ et al. (2007, 2011). A 2008 experiment employed a combination of aircraft and satellite observations to constrain the $S$ budget over China and to estimate the lifetime and export (He et al., 2012). The combination of aircraft and satellite observations allowed the plume to be tracked for several days, resulting in an estimate of the gas-to-particle conversion rate (Dickerson et al., 2007; Krotkov et al., 2008; Li et al., 2010a).
RAMMPP is a long-standing program to provide policy-relevant science to the nonattainment areas of the Mid-Atlantic states (Castellanos et al., 2011: Hains et al., 2008; Lee et al., 2011a; Loughner et al., 2011; Marufu et al., 2004; Taubman et al., 2006). The rate of emission of $\mathrm{SO}_{2}$ over the U.S. is reasonably well known, because many large sources are monitored with CEMS. The lifetime of the $\mathrm{SO}_{2}$, however, depends on concentrations of the oxidants $\mathrm{OH}$ and $\mathrm{H}_{2} \mathrm{O}_{2}$ as well as cloud cover, variables that are hard to model accurately with CMAQ (Loughner et al., 2011). Because $\mathrm{SO}_{2}$ is the major precursor of sulfate particles, the rate of conversion must be understood in compliance modeling for $\mathrm{PM}_{2.5}$. Both in situ and remotely sensed data have been used to estimate the overall rate of loss of $\mathrm{SO}_{2}$ from the atmosphere and by implication the rate of formation of sulfate (Lee et al., 2011a). Both RAMMPP and INTEX-A (Hennigan et al., 2006) show a nearly exponential decrease in mixing ratio with altitude with the bulk of the $\mathrm{SO}_{2}$ located below $2000 \mathrm{~m}$. A mass balance approach indicates an $\mathrm{SO}_{2}$ lifetime of 17 $( \pm 7) \mathrm{hr}$ for summer conditions. Lee et al. (2011a) expanded these observations to the global scale using GEOS-Chem and column contents for OMI and SCIAMACHY. The results (Fig. 8) show the seasonal cycle and latitudinal dependence expected for photochemical oxidation processes, with maximal lifetimes in the winter and at high latitudes.

A major challenge for Earth-observing satellites is to distinguish between pollution high in the atmosphere and pollution near the surface that has a direct connection to emissions and a direct relevance to human health (Lin and McElroy, 2010). In summer
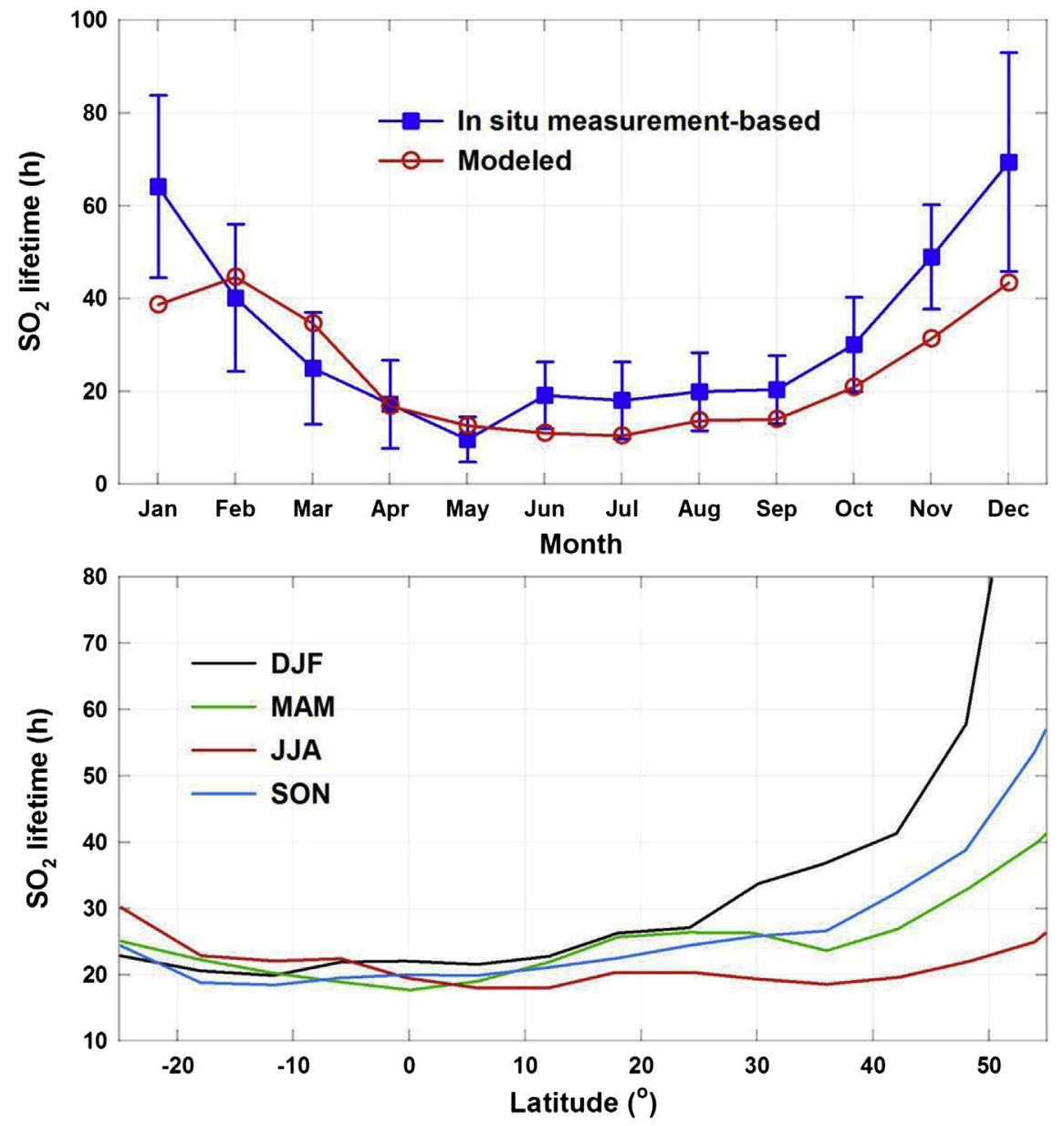

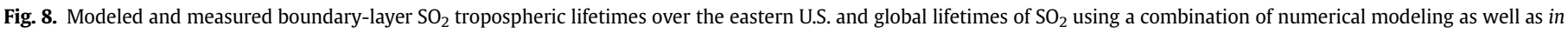
situ and remote observations (adapted from Lee et al., 2011a). This material is reproduced with permission of John Wiley \& Sons, Inc. 
2011, the DISCOVER-AQ program began a multi-year airborne field campaign to tackle this challenge. The first experiments were performed over the urban area encompassing Baltimore, MD and Washington, DC. Results indicate that there is a strong correlation between column content and surface concentration, but $\mathrm{O}_{3}$ located above the PBL can interfere, especially on days with poor air quality. The main precursor of $\mathrm{O}_{3}$ formation over the eastern U.S. is $\mathrm{NO}_{2}$. Preliminary results indicate that the bulk of $\mathrm{NO}_{2}$ lies near the surface, both in the morning and afternoon. If $\mathrm{NO}_{2}$ is generally confined to the surface, then satellite observations should be expected to correlate well with surface observations. The similarities of $\mathrm{NO}_{x}$ both upwind of the Baltimore/Washington area (morning measurements) and downwind (afternoon measurements) indicate that $\mathrm{O}_{3}$ is formed over a broad area. This shows that emissions controls can yield benefits hundreds of kilometers from the source. Results from OMI (Fig. 9) indicate high concentrations of $\mathrm{NO}_{2}$ near sources such as New York City, but substantial concentrations over rural areas as well. CMAQ captures the major source areas seen by OMI. The ratio of urban to rural $\mathrm{NO}_{2}$ column content, however, is higher in CMAQ than in OMI or the in situ data (Allen et al., 2012). Current work involves verifying these differences and exploring how the dynamics and chemistry of the CMAQ model could be improved. Satellites can provide coverage unavailable from even the most ambitious in situ measurements and when compared appropriately to numerical simulations can provide guidance on model improvement. Because plans for compliance with air quality standards rely on simulated emission reductions, such models must be able to reliably reproduce the temporal and spatial characteristics of pollution events.

\section{The National Emissions Inventory (NEI)}

It is clear from the content of Section 4 that there has been a tremendous amount of work undertaken in the past decade to interpret satellite retrievals with the purpose of gaining new information about the spatial and temporal aspects of emissions of a variety of species from many types of sources. The value that these studies have depends partly on what the perceived needs are for the regulatory community and the degree of confidence that we have in bottom-up inventory methods. At the end of the day, the capability of the satellite instruments must be weighed against the established inventory methods currently in use. Only then can we judge the merits of focusing on particular sources and species and deciding what resources should be invested in pushing the application of satellite methods into the emissions estimating arena.

The U.S. National Emissions Inventory (NEI) is a national compilation of emissions sources collected from state, local, and tribal $(\mathrm{S} / \mathrm{L} / \mathrm{T})$ air agencies specifically for the NEI, as well as from other EPA emissions programs, including the Toxics Release Inventory (TRI), emissions trading programs such as the Acid Rain Program, and data collected as part of EPA regulatory development for reducing emissions of air toxics. The NEI development efforts include assembling component datasets, blending data from multiple sources, and performing quality assurance steps that further enhance and augment the compiled data. The NEI is produced by EPA on a triennial cycle, with the most recently released NEI for the calendar year 2008 .

The species included in the NEI are those related to implementation of the National Ambient Air Quality Standards (NAAQS) - known as criteria air pollutants (CAPs), other precursors of ozone and PM, as well as hazardous air pollutants (HAPs) associated with EPA's Air Toxics Program. The CAPs and their precursors include lead $(\mathrm{Pb}), \mathrm{CO}, \mathrm{NO}_{x}, \mathrm{VOC}, \mathrm{SO}_{2}, \mathrm{NH}_{3}, \mathrm{PM}$ of diameter $2.5 \mu \mathrm{m}$ or less $\left(\mathrm{PM}_{2.5}\right)$, and PM of diameter $10 \mu \mathrm{m}$ or less $\left(\mathrm{PM}_{10}\right)$. The HAPs include the 187 remaining HAPs from the original 188 listed in Section 112(b) of the 1990 Clean Air Act Amendments. Key HAP emissions species include mercury $(\mathrm{Hg})$, hydrochloric acid $(\mathrm{HCl})$ and other acid gases, heavy metals such as nickel and cadmium, and hazardous organic compounds such as benzene, formaldehyde, and acetaldehyde.

While the NAAQS program is the basis on which EPA collects CAP emissions from the state, local, and tribal air agencies, it does not require collection of HAP emissions. For this reason, the HAP reporting requirements are voluntary. Nevertheless, the HAP emissions are an essential part of the NEI program. These emissions estimates allow EPA to assess progress in meeting HAP reduction goals described in the Clean Air Act amendments of 1990. These reductions seek to reduce the negative impacts to people of HAP emissions in the environment, and the NEI allows EPA to assess how much emissions have been reduced since 1990. With the exception of a few organic compounds like formaldehyde, HAP species are not at present able to be detected by satellite instruments, but that may change in the future.

The Air Emissions Reporting Rule (AERR) is the rule that requires states to submit estimates of CAP emissions and provides the framework for voluntary submission of HAP emissions. The AERR
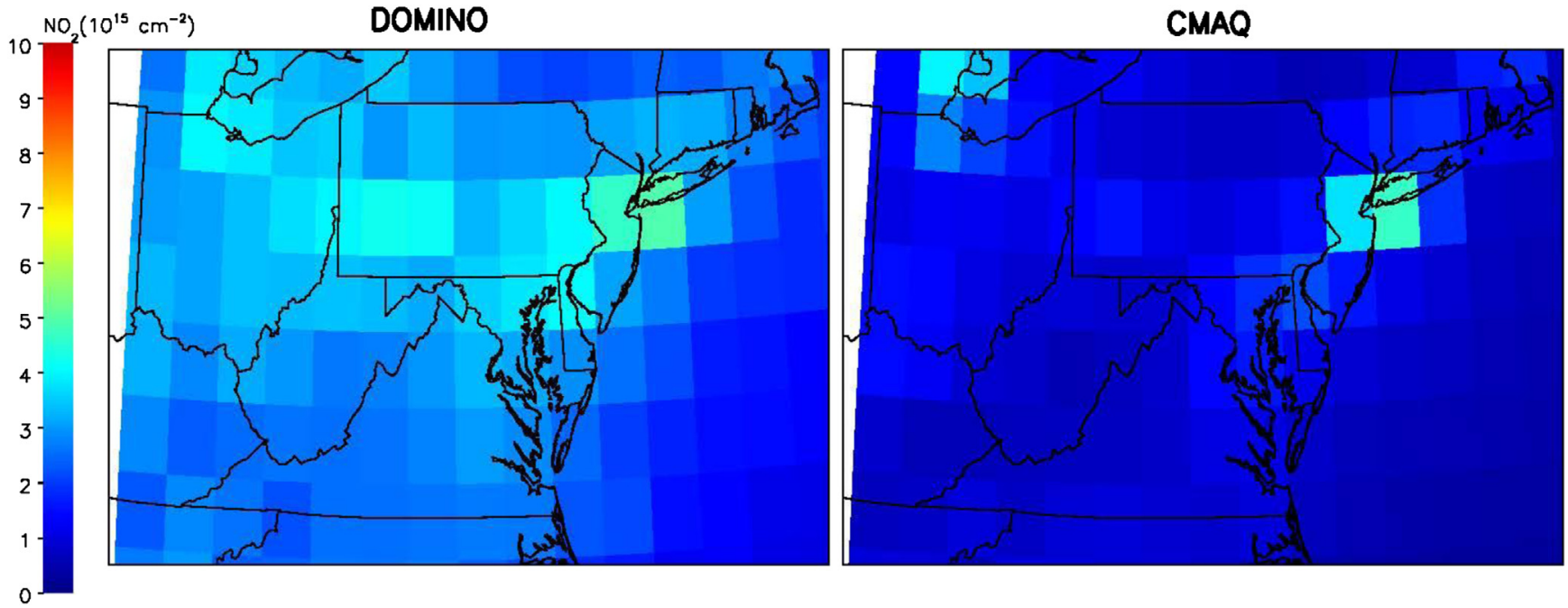

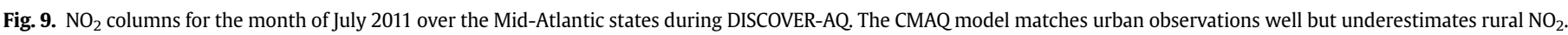
Increasing the photolysis rate of alkyl nitrates in CB05 improves model-measurement agreement. 
has emissions thresholds that determine whether an S/L/T agency must report stationary source emissions as point sources or whether the emissions can be lumped together into a county total as nonpoint sources. Based on the AERR requirements, S/L/T agencies submit emissions of point, nonpoint, on-road mobile, nonroad mobile, and fires emissions sources. These submissions are sent to the Emission Inventory System (EIS) that EPA then uses to review and assemble the data from the $\mathrm{S} / \mathrm{L} / \mathrm{T}$ agencies.

While the basis of the NEI is an S/L/T agency reporting program, EPA compiles data for use by these agencies, including data that are derived, or could be derived, from satellite-based information. While initial resource investments are generally needed for updating emissions methods to use satellite data, there can be longterm benefits of the resultant improved data, such as making better regulatory or other decisions.

Some uses of satellite data already exist in the NEI. A satellitebased emissions method is the use of fire detect data from satellites in the SMARTFIRE version 2 system as described in EPA (2013a). While the satellite data are useful for compiling reasonable location and temporal information, the data are best used for emissions estimation when accompanied by ground-based observational information to augment the spatial extent of the fires as well as the fuel consumption estimates derived from other models. In addition, satellite images are routinely used by $\mathrm{S} / \mathrm{L} / \mathrm{T}$ agencies and EPA to verify location information for point-source facilities.

Other satellite data may be able to be used in the future for the NEI to compile other types of activity data. For example, satellite images could conceivably be used to develop or augment traffic count data, the size and location of animal feedlots and waste lagoons, the locations of residential and non-residential construction, and the characterization of "urban" or "rural" that is a part of some methods such as residential wood combustion. Depending on the frequency of availability, satellite images could also be used to help assess the timing of activities such as agricultural tilling and asphalt paving, where the timing relative to meteorological events can determine whether the activity actually occurs and what the emissions will be.

A summary of the construction and the components of the 2008 NEI by sector, key species, and sources of data is presented in Table 2, with notes regarding uncertainties associated with the various sectors. The strengths and weaknesses of the NEI vary from year to year as changes are made to the creation processes and as resources for the program vary. It is impossible to generalize about the strengths and weaknesses since data are compiled from so many sources. Since the most recent NEI was released for calendar year 2008, this summary reflects only on that inventory. EPA estimates emissions from many source categories and then uses those data when states do not submit it; thus, the quality and origin of the data can vary from state to state. As a general matter, the primary sources of uncertainty are: (1) uncertainty in emission rates; (2) uncertainty in the activities generating emissions; and (3) the temporal and spatial variability of both emission rates and activities.

\section{Promising applications and future needs}

Organizations that develop emission inventories can profit from the vast amount of spatial and temporal data delivered from satellites; however, much of this opportunity has yet to be realized. One challenge is that emission inventories consist of a series of data-intensive calculations, while the results from most inverse modeling studies consist of two-dimensional maps of emission adjustments. Progress on the use of satellite data to inform emission inventories depends on connecting these emission adjustments to the real building blocks of emission inventories, namely activity levels and emission factors. This is possible with further collaboration between emission inventory developers and the satellite research communities. In this final section we review some ways in which the gap between promise and fulfillment of satellite applications for emissions estimation might be narrowed.

Identification of the practical problems faced routinely by emission inventory developers can be used to guide further interaction between the communities. For example, the acquisition of temporal information from satellites to help adjust day-of-week emission allocations that are needed for Eulerian grid models would be beneficial for many types of area sources, including onroad mobile, nonroad mobile, and shipping. A number of unconventional area sources, e.g., evaporation ponds from oil and gas development activities, are desperately short of data. Often there is industry and state resistance to monitoring such sources. If the detection limit for such emissions could be improved, there is great potential to enhance the conventional bottom-up inventory methods. State regulators have expressed a need for help in identifying small but significant hotspots of emissions of species such as $\mathrm{SO}_{2}$. Monitors are sparse in many areas and expensive to maintain. This means that some sources may elude detection by the ground monitoring network. To be able to get uniform coverage over a very wide area could be extremely valuable and cost-effective.

Ammonia is difficult to measure in situ and measurements are sparse; but reduced $\mathrm{N}$ species are becoming an increasingly important component of reactive $\mathrm{N}$ deposition and are steadily leading to adverse environmental effects. Detection of agricultural emissions of $\mathrm{NH}_{3}$ from space would be an ideal opportunity to improve inventories and identify hotspots. Observations could be used to help ground-truth the results that will come from the updated $\mathrm{NH}_{3}$ emission rate information provided by the National Air Emissions Monitoring Study (NAEMS). And there is a continued need in the regulatory community for satellite products that allow estimation of biomass burning activities using software such as SMARTFIRE to support a nationally consistent approach that brings together the best of the satellite and on-the-ground information for a robust inventory.

Using ratios of trace gases as an indication of emission amounts and characteristics also shows great promise, but these require colocation of observations. For example, biomass burning and other inherently inefficient combustion processes have elevated $\mathrm{CO} / \mathrm{CO}_{2}$ and $\mathrm{CH}_{4} / \mathrm{CO}_{2}$ ratios, while modern, efficient power plants have very low ratios. Unregulated or under-regulated internal combustion engines can produce elevated $\mathrm{NO}_{2} / \mathrm{CO}_{2}$ ratios. Such information can help to improve emission inventories and help policy makers target the most important sources.

The temporal and spatial characteristics of natural emitting sources are exceedingly difficult to obtain by bottom-up methods and are usually highly uncertain; however, they are important to know because they can represent a sizeable fraction of total primary emissions and are known to play a highly significant role in atmospheric chemistry. They also contribute in important ways to the ambient concentrations of many primary and secondary species in the atmosphere. Satellite measurements have so far proven valuable in application to a number of types of natural sources: biogenic NMVOC, volcanic $\mathrm{SO}_{2}$ and $\mathrm{PM}$, wetlands $\mathrm{CH}_{4}$, biomass burning $\mathrm{CO}$ and $\mathrm{PM}$, soil and lightning $\mathrm{NO}_{x}$, etc. To the extent that information about these emitting sources is necessary for modeling their contributions to ambient concentrations, they are a necessary part of the information portfolios of air quality managers, and the benefit of space-based observations has not yet been fully realized.

Satellite detection of aerosol speciation is an important future need from the public health perspective. A clear understanding of the spatial trend and temporal variation of PM species is crucial for U.S. EPA to design cost-effective emission control policies, as well as 
Table 2

Summary of the 2008 NEI by sector, key species, and sources of data.

\begin{tabular}{|c|c|c|}
\hline Sector & Species & Sources of data \\
\hline Agriculture & $\mathrm{NH}_{3}, \mathrm{PM}_{10}, \mathrm{PM}_{2.5}$ & $\begin{array}{l}\text { Nonpoint with minor point-source contributions by a few states who submit farms as point sources. Blend of } \\
\text { state and EPA data, with about } 75 \% \text { EPA estimates. } \mathrm{NH}_{3} \text { emission rate improvements pending ongoing NAEMS } \\
\text { study. Ambient data suggest dust emissions are too high. In addition to emission rates, sources of uncertainty } \\
\text { include: (1) the timing of animal waste operations, which impact the emission rates in combination with } \\
\text { meteorological influences, (2) the location of animal operations, ( } 3 \text { ) the timing of tilling operations, (4) which } \\
\text { fields are tilled in a given year, (5) the timing of fertilizer application, and (6) which fields are fertilized in a } \\
\text { given year. }\end{array}$ \\
\hline $\begin{array}{l}\text { Dust - Construction, paved, } \\
\text { and unpaved road dust }\end{array}$ & $\mathrm{PM}_{10}, \mathrm{PM}_{2.5}$ & $\begin{array}{l}\text { Nonpoint with very minor point-source contributions from industrial sites. Mostly EPA estimates, generally } \\
\text { about } 70 \% \text {. Meteorological adjustments applied at monthly resolution to consider moisture. Ambient data } \\
\text { suggest dust emissions are too high. Paved roads emission rates updated in } 2008 \mathrm{NEI} \text { based on latest data. }\end{array}$ \\
\hline Fires & $\begin{array}{l}\text { CO, VOC, } \mathrm{PM}_{2.5} \\
\mathrm{PM}_{10}, \mathrm{HAPs}\end{array}$ & $\begin{array}{l}\text { Satellite-based fires estimates from SMARTFIRE version 2, including allocation of all fires to wildfires, } \\
\text { prescribed burning, and agricultural fires. Emissions are both spatially and temporally resolved by day. } \\
\text { Emissions rates may be out of date, but documented. HAP emission rates do not vary spatially. Satellite-based } \\
\text { methods are known to both overestimate and underestimate areas burned. Sources of uncertainty include the } \\
\text { assessment of available fuel, fuel consumption, quantification of smoldering, extent of a burn, and the type } \\
\text { of the fire (a wildfire or a prescribed fire). }\end{array}$ \\
\hline $\begin{array}{l}\text { Fuel Combustion - Electric } \\
\text { Generation }\end{array}$ & $\begin{array}{l}\mathrm{NO}_{x}, \mathrm{SO}_{2}, \mathrm{PM}_{2.5} \\
\mathrm{Hg}, \mathrm{HAPs}\end{array}$ & $\begin{array}{l}\text { Data are largely based on data from continuous emissions monitors (especially in the Eastern US), which } \\
\text { measure } \mathrm{SO}_{2} \text { and } \mathrm{NO}_{x} \text { (and in few cases } \mathrm{Hg} \text { ) emissions. These data and heat input data are readily available } \\
\text { from the EPA and are used by states whose data submissions make up nearly } 100 \% \text { of the inventory for } \\
\mathrm{NO}_{x}, \mathrm{SO}_{2} \text {. Other species from both EPA and states, with EPA data from the Mercury and Air Toxics Standard } \\
\text { being used for most EGUs for Hg, other metals, and acid gases. Sources of uncertainty include emissions from } \\
\text { sources that do not have continuous emissions monitors. }\end{array}$ \\
\hline $\begin{array}{l}\text { Fuel Combustion - Industrial, } \\
\text { Commercial, and } \\
\text { Institutional }\end{array}$ & $\begin{array}{l}\mathrm{NO}_{x}, \mathrm{SO}_{2}, \mathrm{PM}_{2.5} \\
\mathrm{Hg}, \text { other HAPs }\end{array}$ & $\begin{array}{l}\text { Includes a broad mixture of point and nonpoint data, state and EPA data, which makes generalizations about } \\
\text { the data sources difficult. While nonpoint estimates generated by EPA are based on fuel consumption data } \\
\text { from the Department of Energy, fuel consumed by sources reported by states as point sources needs to be } \\
\text { subtracted from the nonpoint calculations. While states were responsible for this step in } 2008 \text { NEI, we do } \\
\text { not know if this was always done and suspect it was not in some cases. Some states may have double } \\
\text { counted, while other states may have left out nonpoint emissions. Emission rates are outdated in some cases } \\
\left.\text { (particularly for PM } \mathrm{P}_{2.5}\right) \text { with new methods now available (but not for } 2008 \mathrm{NEI)} \mathrm{for} \mathrm{condensible} \mathrm{PM} \\
2.5 \\
\text { emissions. Some }(\sim 15 \%) \text { HAP emissions from industry reporting to the EPA Toxics Release Inventory. }\end{array}$ \\
\hline Fuel Combustion - residential & $\begin{array}{l}\mathrm{CO}, \mathrm{NO}_{x}, \mathrm{PM}_{2.5} \\
\mathrm{PM}_{10}, \mathrm{HAPs}\end{array}$ & $\begin{array}{l}\text { Data are largely a nonpoint estimate that can be reasonably estimated based on fuel use and emission } \\
\text { factors. Natural gas heating important for } \mathrm{NO}_{x} \text { and is about } 80 \% \text { reported by states and } 20 \% \text { EPA estimates. } \\
\text { Wood heating is important for } \mathrm{PM}_{2.5} \text { and is about } 55 \% \text { reported by states. Urban area wood combustion } \\
\text { estimates have been called into question with overestimates apparent as compared to ambient data. } \\
\text { Methodologies and default emission factors revised by state/EPA and improved for } 2008 \text {. }\end{array}$ \\
\hline Industrial Processes & $\begin{array}{l}\mathrm{NO}_{x}, \mathrm{VOC}, \mathrm{SO}_{2} \\
\mathrm{PM}_{2.5}, \mathrm{HAPs}\end{array}$ & $\begin{array}{l}\text { Almost all data provided by states as point sources. Quality varies greatly depending on the source of the } \\
\text { information provided to EPA, which is generally not possible to assess because the origin of the data is usually } \\
\text { not provided. For HAPs, EPA augments with TRI data submitted by industry to EPA, but this is 10-30\% } \\
\text { depending on the industry. }\end{array}$ \\
\hline Onroad mobile & $\begin{array}{l}\mathrm{CO}, \mathrm{NO}_{x}, \mathrm{VOC}, \\
\text { HAPs }\end{array}$ & $\begin{array}{l}\text { Estimated by the onroad emissions model called the Motor Vehicle Emissions Simulator (MOVES), based on } \\
\text { modeled hourly temperatures using a 12-km gridded modeling resolution. California emissions provided by } \\
\text { that state. For MOVES-based emissions, data are computed hourly and summed up for the year. Many states } \\
\text { did not have state-specific inputs available because of the newness of the model. Activity data are based on } \\
\text { Federal Highway traffic count data at the state level and apportioned to counties, road types, and vehicles. }\end{array}$ \\
\hline Nonroad mobile equipment & $\begin{array}{l}\mathrm{CO}, \mathrm{NO}_{x}, \mathrm{VOC} \\
\text { HAPs }\end{array}$ & $\begin{array}{l}\text { Estimated by the NONROAD model, except in California. Some known problems with double counting of } \\
\text { emissions in a few states, though this is atypical for this sector. EPA keeps emission rates updated with the } \\
\text { latest emission rates and equipment populations and activity estimates. }\end{array}$ \\
\hline $\begin{array}{l}\text { Nonroad mobile aircraft, } \\
\text { railroad, and marine }\end{array}$ & $\begin{array}{l}\mathrm{Pb}, \text { (aircraft), } \\
\mathrm{CO}, \mathrm{NO}_{x}, \mathrm{SO}_{2}\end{array}$ & $\begin{array}{l}\text { Primarily EPA data for key species, with a relatively high contribution of state-submitted data for } \mathrm{NO}_{x} \text { from } \\
\text { aircraft of } 15 \% \text {. EPA data are estimated at a national resolution and apportioned to counties, rail lines, ports, } \\
\text { shipping lanes, and airports using methods developed in collaboration with many states. Emission factors } \\
\text { are updated regularly by EPA, but apportioning approaches for category } 1 \& 2 \text { marine vessels, which have in } \\
\text { some cases overestimated emissions in ports in some demonstrated cases as compared to ambient data. }\end{array}$ \\
\hline Solvents & VOC, HAPs & $\begin{array}{l}100 \% \text { state data for most solvent categories, with EPA not augmenting these sectors due to overlap between } \\
\text { point and nonpoint emissions that the states are expected to resolve. Have confirmed cases where states did } \\
\text { not submit VOC HAPs but did submit VOC and EPA did not compute or add HAP VOC. Methodologies and } \\
\text { default emission factors revised by state/EPA and improved for } 2008 \text {. Emission factors for HAPs out of date } \\
\text { and not consistent with new product formulations and technology changes. Methods updated for } 2008 \text { with } \\
\text { activity data on solvent use used from Freedonia, though not for calendar year } 2008 \text {. }\end{array}$ \\
\hline
\end{tabular}

to update NAAQS species and HAPS that have different primary emission sources and different toxicity levels. EPA's PM mass monitoring network has 1200 sites, covering less than $25 \%$ of the 3100 counties in the continental U.S. In addition, EPA's Chemical Speciation Network and IMPROVE network together have only $\sim 500$ sites. This number is unlikely to increase given current budgetary constraints. Satellite instruments such as MISR and OMI have shown promising signs of ability to differentiate boundarylayer fine PM components such as sulfate and black carbon. However, new algorithms or new sensors are needed to achieve the level of retrieval accuracy and spatial resolution that would be useful for air quality applications. For example, given the lower tropospheric lifetime of fine PM (a couple of days to a week), a satellite must be able to achieve a return frequency of $1-2$ days in order to study air pollution episodes related to wildfires, dust storms, and heavy haze. The large spatial gradient of black carbon requires the sensor to have a spatial resolution of $1-2 \mathrm{~km}$.

As data from the current generation of satellites are used more and more in tropospheric pollution applications, it is becoming apparent that more intensive validation efforts are required. Two major factors limiting our confidence in inversion studies are uncharacterized model errors, which are addressed in Section 4.1, 
and systematic errors in the satellite retrievals. Typically, we only assume the presence of a 0th order systematic error (bias) in the satellite products. However, satellite retrieval errors can be correlated with other geophysical quantities, such as temperature, water vapor, surface reflectance, and cloud properties. To properly diagnose these potential systematic errors, we need coincident observations of both the species retrieved and any geophysical quantities that could cause systematic errors in the retrieval. At a fundamental level, when we assimilate observations in an inverse modeling framework, we want to be confident that the noise in the observations is truly random.

All air quality observations from space so far have been from low Earth orbit (LEO). These provide return times for observation of at most once per day at a specific time of day. Because of clouds and retrieval noise, useful data may therefore be obtainable only with weekly or monthly temporal resolution. Observation from geostationary Earth orbit (GEO) would be of considerable value for air quality investigations by providing continuous mapping on a continental scale with hourly resolution and on the order of $4 \mathrm{~km} \times 4 \mathrm{~km}$ spatial resolution. As mentioned in Section 2, GEOCAPE and TEMPO are planned geostationary missions to observe tropospheric air pollution over North America. However, with current launch dates for both these missions likely to be 20172020 or later, acceleration of the schedules would greatly benefit the U.S. air quality management community in a number of ways. Continuous atmospheric composition from GEO measurements would provide for the first time the data density required for a comprehensive investigation of pollution events, pollution transport, and atmospheric processes at different altitudes and across fine spatial and temporal scales. In particular, such data would permit inversion of emissions at the high spatial and temporal resolution necessary to characterize diurnal variations. Observational errors for the inversion could be effectively decreased through the averaging of a large number of retrievals collected for a given scene during integration times of an hour or less. The high spatial and temporal resolution achievable in inversions would lend insights into the causes of bottom-up and top-down inconsistencies and potential errors in current emission inventories. They would also provide a unique ability to constrain transient and episodic sources such as wildfires and industrial chemical releases.

To quantify and separate the influences on chemical distributions of varying emissions, photochemistry, and dynamical processes, it is desirable to provide improved vertical profile information from satellite observations, especially in the lowermost troposphere. This has been demonstrated from LEO for CO (Worden et al., 2010) and $\mathrm{O}_{3}$ (Fu et al., 2013) through the use of multispectral retrieval techniques. Similar measurements are proposed for the GEO-CAPE mission, and an independent estimate of concentrations in the lowest $2 \mathrm{~km}$ should significantly improve the capability to constrain surface emissions.

In his eulogy for the loss of SCIAMACHY (IGAC News, August 2012), John Burrows reminded us that "we cannot manage what we can't measure." Reflecting on this adage is a useful way to conclude this article. U.S. air quality managers must continually manage air quality, even in the face of measurement shortcomings. Emission factors are measured for a few sources and then extrapolated to the array of real-world devices; emission rates are measured at the stack for those sources deemed large enough to warrant it; activity levels are inferred from surveys of the number of sources and their expected patterns of operation; and, in a few cases, monitors are set up in the field and source emissions determined by modeling. The situation is far from ideal, but managers have no choice but to accept the methodological limitations and acknowledge the levels of uncertainty that result. Perhaps it would be more appropriate to say that "what we can't measure well, we cannot manage effectively." The lure of satellite observations is that, given the right conditions, we might one day be able to measure the actual emissions from many sources at the same time, all of the time.

\section{Acknowledgments}

Nine of the co-authors of this article (DGS, GRC, BdF, RRD, BND, DPE, DKH, DJJ, and YL) are members of the NASA Air Quality Applied Sciences Team (AQAST) and acknowledge funding support from this program. They wish to express their gratitude to the present (John Haynes) and former (Lawrence Friedl) NASA program managers. Argonne National Laboratory is operated by UChicago Argonne, LLC, under Contract No. DE-AC02-06CH11357 with the US Department of Energy.

\section{References}

Allen, D.J., Pickering, K.E., Pinder, R.W., Henderson, B.H., Appel, K.W., Prados, A., 2012. Impact of lightning-NO on eastern United States photochemistry during the summer of 2006 as determined using the CMAQ model. Atmospheric Chemistry and Physics 12, 1737-1758.

Angelbratt, J., Mellqvist, J., Simpson, D., Jonson, J.E., Blumenstock, T., Borsdorff, T., Duchatelet, P., Forster, F., Hase, F., Mahieu, E., De Mazière, M., Notholt, J., Petersen, A.K., Raffalski, U., Servais, C., Sussmann, R., Warneke, T., Vigouroux, C., 2011. Carbon monoxide $(\mathrm{CO})$ and ethane $\left(\mathrm{C}_{2} \mathrm{H}_{6}\right)$ trends from ground-based solar FTIR measurements at six European stations, comparison and sensitivity analysis with the EMEP model. Atmospheric Chemistry and Physics 11, 9253-9269.

Arellano, A.F., Hess, P.G., 2006. Sensitivity of top-down estimates of CO sources to GCTM transport. Geophysical Research Letters 33, L21807.

Aumann, H.H., Chahine, M.T., Gautier, C., Goldberg, M.D., Kalnay, E., McMillin, L.M., Revercomb, H., Rosenkranz, P.W., Smith, W.L., Staelin, D.H., Strow, L.L., Susskind, J., 2003. AIRS/AMSU/HSB on the aqua mission: design, science objectives, data products, and processing systems. IEEE Transactions on Geoscience and Remote Sensing 41, 253-264.

Baker, D.F., Bösch, H., Doney, S.C., O’Brien, D., Schimel, D.S., 2010. Carbon source/sink information provided by column $\mathrm{CO}_{2}$ measurements from the orbiting carbon observatory. Atmospheric Chemistry and Physics 10, 4145-4165.

Barkley, M.P., Palmer, P.I., Kuhn, U., Kesselmeier, J., Chance, K., Kurosu, T.P., Martin, R.V., Helmig, D., Guenther, A., 2008. Net ecosystem fluxes of isoprene over tropical South America inferred from Global Ozone Monitoring Experiment (GOME) observations of HCHO columns. Journal of Geophysical Research 113, D20304.

Barnes, W.L., Pagano, T.S., Salomonson, V.V., 1998. Prelaunch characteristics of the moderate resolution imaging spectroradiometer (MODIS) on EOS-AM1. IEEE Transactions on Geoscience and Remote Sensing 36, 1088-1100.

Bechle, M.J., Millet, D.B., Marshall, J.D., 2011. Effects of income and urban form on urban $\mathrm{NO}_{2}$ : global evidence from satellites. Environmental Science \& Technology $45,4914-4919$.

Beer, R., Glavich, T.A., Rider, D.M., 2001. Tropospheric emission spectrometer for the earth observing system's aura satellite. Applied Optics 40, 2356-2367.

Beer, R., Shephard, M.W., Kulawik, S.S., Clough, S.A., Eldering, A., Bowman, K.W., Sander, S.P., Fisher, B.M., Payne, V.H., Luo, M., Osterman, G.B., Worden, J.R., 2008. First satellite observations of lower tropospheric ammonia and methanol. Geophysical Research Letters 35, L09801.

Beirle, S., Boersma, K.F., Platt, U., Lawrence, M.G., Wagner, T., 2011. Megacity emissions and lifetimes of nitrogen oxides probed from space. Science 333, 1737-1739.

Beirle, S., Huntrieser, H., Wagner, T., 2010. Direct satellite observation of lightningproduced $\mathrm{NO}_{x}$. Atmospheric Chemistry and Physics 10, 10965-10986.

Beirle, S., Platt, U., von Glasow, R., Wenig, M., Wagner, T., 2004a. Estimate of nitrogen oxide emissions from shipping by satellite remote sensing. Geophysical Research Letters 31, L18102.

Beirle, S., Platt, U., Wenig, M., Wagner, T., 2003. Weekly cycle of $\mathrm{NO}_{2}$ by GOME measurements: a signature of anthropogenic sources. Atmospheric Chemistry and Physics 3, 2225-2232.

Beirle, S., Platt, U., Wenig, M., Wagner, T., 2004b. Highly resolved global distribution of tropospheric $\mathrm{NO}_{2}$ using GOME narrow swath mode data. Atmospheric Chemistry and Physics 4, 1913-1924.

Beirle, S., Platt, U., Wenig, M., Wagner, T., 2004c. $\mathrm{NO}_{x}$ production by lightning estimated with GOME. Advances in Space Research 34, 793-797.

Beirle, S., Salzmann, M., Lawrence, M.G., Wagner, T., 2009. Sensitivity of satellite observations for freshly produced lightning $\mathrm{NO}_{x}$. Atmospheric Chemistry and Physics 9, 1077-1094.

Bergamaschi, P., Frankenberg, C., Meirink, J.F., Krol, M., Dentener, F., Wagner, T., Platt, U., Kaplan, J.O., Körner, S., Heimann, M., Dlugokencky, E.J., Goede, A., 2007. Satellite chartography of atmospheric methane from SCIAMACHY on board ENVISAT: 2. Evaluation based on inverse model simulations. Journal of Geophysical Research 112, D02304.

Bergamaschi, P., Frankenberg, C., Meirink, J.F., Krol, M., Villani, M.G., Houweling, S., Dentener, F., Dlugokencky, E.J., Miller, J.B., Gatti, L.V., Engel, A., Levin, I., 2009. 
Inverse modeling of global and regional $\mathrm{CH}_{4}$ emissions using SCIAMACHY satellite retrievals. Journal of Geophysical Research 114, D22301.

Bertram, T.H., Heckel, A., Richter, A., Burrows, J.P., Cohen, R.C., 2005. Satellite measurements of daily variations in soil $\mathrm{NO}_{x}$ emissions. Geophysical Research Letters 32, L24812.

Blond, N., Boersma, K.F., Eskes, H.J., van der, A.,R.J., Van Roozendael, M., De Smedt, I. Bergametti, G., Vautard, R., 2007. Intercomparison of SCIAMACHY nitrogen dioxide observations, in situ measurements and air quality modeling results over Western Europe. Journal of Geophysical Research 112, D10311.

Bloom, A.A., Palmer, P.I., Fraser, A., Reay, D.S., Frankenberg, C., 2010. Large-scale controls of methanogenesis inferred from methane and gravity spaceborne data. Science 327, 322-325.

Boersma, K.F., Eskes, H.J., Dirksen, R.J., van der, A.,R.J., Veefkind, J.P., Stammes, P., Huijnen, V., Kleipool, Q.L., Sneep, M., Claas, J., Leitão, J., Richter, A., Zhou, Y., Brunner, D., 2011. An improved tropospheric $\mathrm{NO}_{2}$ column retrieval algorithm for the ozone monitoring instrument. Atmospheric Measurement Techniques 4, 1905-1928.

Boersma, K.F., Eskes, H.J., Meijer, E.W., Kelder, H.M., 2005. Estimates of lightning $\mathrm{NO}_{x}$ production from GOME satellite observations. Atmospheric Chemistry and Physics 5, 1-21.

Boersma, K.F., Jacob, D.J., Bucsela, E.J., Perring, A.E., Dirksen, R., van der, A.,R.J., Yantosca, R.M., Park, R.J., Wenig, M.O., Bertram, T.H., Cohen, R.C., 2008a. Validation of OMI tropospheric $\mathrm{NO}_{2}$ observations during INTEX-B and application to constrain $\mathrm{NO}_{x}$ emissions over the eastern United States and Mexico. Atmospheric Environment 42, 4480-4497.

Boersma, K.F., Jacob, D.J., Eskes, H.J., Pinder, R.W., Wang, J., van der, A.,R.J., 2008b. Intercomparison of SCIAMACHY and OMI tropospheric $\mathrm{NO}_{2}$ columns: observing the diurnal evolution of chemistry and emissions from space. Journal of Geophysical Research 113, D16S26.

Bond, D.W., Steiger, S., Zhang, R., Tie, X., Orville, R.E., 2002. The importance of $\mathrm{NO}_{x}$ production by lightning in the tropics. Atmospheric Environment 36, 15091519.

Borrell, P., Burrows, J.P., Richter, A., Platt, U., Wagner, T., 2003. New Directions: new developments in satellite capabilities for probing the chemistry of the troposphere. Atmospheric Environment 37, 2567-2570.

Bovensmann, H., Buchwitz, M., Burrows, J.P., Reuter, M., Krings, T., Gerilowski, K., Schneising, O., Heymann, J., Tretner, A., Erzinger, J., 2010. A remote sensing technique for global monitoring of power plant $\mathrm{CO}_{2}$ emissions from space and related applications. Atmospheric Measurement Techniques 3, 781-811.

Bovensmann, H., Burrows, J.P., Buchwitz, M., Frerick, J., Noël, S., Rozanov, V.V., Chance, K.V., Goede, A.P.H., 1999. SCIAMACHY: mission objectives and measurement modes. Journal of the Atmospheric Sciences 56, 127-150.

Buchwitz, M., de Beek, R., Noël, S., Burrows, J.P., Bovensmann, H., Schneising, O., Khlystova, I., Bruns, M., Bremer, H., Bergamaschi, P., Körner, S., Heimann, M. 2006. Atmospheric carbon gases retrieved from SCIAMACHY by WFM-DOAS: version $0.5 \mathrm{CO}$ and $\mathrm{CH}_{4}$ and impact of calibration improvements on $\mathrm{CO}_{2} \mathrm{re}$ trieval. Atmospheric Chemistry and Physics 6, 2727-2751.

Buchwitz, M., Schneising, O., Burrows, J.P., Bovensmann, H., Reuter, M., Notholt, J., 2007. First direct observation of the atmospheric $\mathrm{CO}_{2}$ year-to-year increase from space. Atmospheric Chemistry and Physics 7, 4249-4256.

Bucsela, E.J., Perring, A.E., Cohen, R.C., Boersma, K.F., Celarier, E.A., Gleason, J.F., Wenig, M.O., Bertram, T.H., Wooldridge, P.J., Dirksen, R., Veefkind, J.P., 2008. Comparison of tropospheric $\mathrm{NO}_{2}$ from in situ aircraft measurements with nearreal-time and standard product data from OMI. Journal of Geophysical Research 113, D16S31.

Bucsela, E.J., Pickering, K.E., Huntemann, T.L., Cohen, R.C., Perring, A., Gleason, J.F., Blakeslee, R.J., Albrecht, R.I., Holzworth, R., Cipriani, J.P., Vargas-Navarro, D., Mora-Segura, I., Pacheco-Hernández, A., Laporte-Molina, S., 2010. Lightninggenerated $\mathrm{NO}_{\mathrm{x}}$ seen by the ozone monitoring instrument during NASA's tropical composition, cloud and climate coupling experiment $\left(\mathrm{TC}^{4}\right)$. Journal of Geophysical Research 115, D00J10.

Bucsela, E.J., Krotkov, N.A., Celarier, E.A., Lamsal, L.N., Swartz, W.H., Bhartia, P.K., Boersma, K.F., Veefkind, J.P., Gleason, J.F., Pickering, K.E., 2013. A new stratospheric and tropospheric $\mathrm{NO}_{2}$ retrieval algorithm for nadir-viewing satellite instruments: applications to OMI. Atmospheric Measurement Techniques Discussions 6, 1361-1407.

Burrows, J.P., Weber, M., Buchwitz, M., Rozanov, V., Ladstätter-Weißenmayer, A., Richter, A., DeBeek, R., Hoogen, R., Bramstedt, K., Eichmann, K.-U. Eisinger, M., 1999. The global ozone monitoring experiment (GOME): mission concept and first scientific results. Journal of the Atmospheric Sciences 56, 151-175.

Butz, A., Guerlet, S., Hasekamp, O., Schepers, D., Galli, A., Aben, I., Frankenberg, C., Hartmann, J.-M., Tran, H., Kuze, A., Keppel-Aleks, G., Toon, G., Wunch, D., Wennberg, P., Deutscher, N., Griffith, D., Macatangay, R., Messerschmidt, J., Notholt, J., Warneke, T., 2011. Toward accurate $\mathrm{CO}_{2}$ and $\mathrm{CH}_{4}$ observations from GOSAT. Geophysical Research Letters 38, L14812.

Cady-Pereira, K.E., Shephard, M.W., Millet, D.B., Luo, M., Wells, K.C., Xiao, Y., Payne, V.H., Worden, J., 2012. Methanol from TES global observations: retrieval algorithm and seasonal and spatial variability. Atmospheric Chemistry and Physics 12, 8189-8203.

Callies, J., Corpaccioli, E., Eisinger, M., Hahne, A., Lefebvre, A., 2000. GOME-2 Metop's second-generation sensor for operational ozone monitoring. European Space Agency Bulletin 102, 28-36.

Carboni, E., Grainger, R., Walker, J., Dudhia, A., Siddans, R., 2012. A new scheme for sulphur dioxide retrieval from IASI measurements: application to the
Eyjafjallajökull eruption of april and may 2010. Atmospheric Chemistry and Physics 12, 11417-11434.

Carmichael, G.R., Sandu, A., Chai, T., Daescu, D.N., Constantinescu, E.M., Tang, Y., 2008. Predicting air quality: improvements through advanced methods to integrate models and measurements. Journal of Computational Physics 227, 3540-3571.

Carn, S.A., Krueger, A.J., Krotkov, N.A., Gray, M.A., 2004. Fire at Iraqi sulfur plant emits $\mathrm{SO}_{2}$ clouds detected by earth probe TOMS. Geophysical Research Letters 31, L19105.

Carn, S.A., Krueger, A.J., Krotkov, N.A., Yang, K., Levelt, P.F., 2007. Sulfur dioxide emissions from Peruvian copper smelters detected by the ozone monitoring instrument. Geophysical Research Letters 34, L09801.

Carn, S.A., Prata, F.J., 2010. Satellite-based constraints on explosive $\mathrm{SO}_{2}$ release from Soufrière Hills Volcano, Montserrat. Geophysical Research Letters 37, L00E22.

Castellanos, P., Boersma, K.F., 2012. Reductions in nitrogen oxides over Europe driven by environmental policy and economic recession. Scientific Reports 2, 265.

Castellanos, P., Marufu, L.T., Doddridge, B.G., Taubman, B.F., Schwab, J.J., Hains, J.C., Ehrman, S.H., Dickerson, R.R., 2011. Ozone, oxides of nitrogen, and carbon monoxide during pollution events over the eastern United States: an evaluation of emissions and vertical mixing. Journal of Geophysical Research 116, D16307.

Celarier, E.A., Brinksma, E.J., Gleason, J.F., Veefkind, J.P., Cede, A., Herman, J.R. Ionov, D., Goutail, F., Pommereau, J.-P., Lambert, J.-C., van Roozendael, M. Pinardi, G., Wittrock, F., Schönhardt, A., Richter, A., Ibrahim, O.W., Wagner, T., Bojkov, B., Mount, G., Spinei, E., Chen, C.M., Pongetti, T.J., Sander, S.P. Bucsela, E.J., Wenig, M.O., Swart, D.P.J., Volten, H., Kroon, M., Levelt, P.F., 2008 Validation of ozone monitoring instrument nitrogen dioxide columns. Journal of Geophysical Research 113, D15S15.

Cermak, J., Knutti, R., 2009. Beijing olympics as an aerosol field experiment Geophysical Research Letters 36, L10806.

Chance, K., Palmer, P.I., Spurr, R.J.D., Martin, R.V., Kurosu, T.P., Jacob, D.J., 2000 Satellite observations of formaldehyde over North America from GOME. Geophysical Research Letters 27, 3461-3464.

Chance, K.V., Spurr, R.J.D., 1997. Ring effect studies: Rayleigh scattering, including molecular parameters for rotational Raman scattering, and the Fraunhofer spectrum. Applied Optics 36, 5224-5230.

Chevallier, F., Bréon, F.-M., Rayner, P.J., 2007. Contribution of the orbiting carbon observatory to the estimation of $\mathrm{CO}_{2}$ sources and sinks: theoretical study in a variational data assimilation framework. Journal of Geophysical Research 112, D09307.

Chevallier, F., Maksyutov, S., Bousquet, P., Bréon, F.-M., Saito, R., Yoshida, Y., Yokota, T., 2009. On the accuracy of the $\mathrm{CO}_{2}$ surface fluxes to be estimated from the GOSAT observations. Geophysical Research Letters 36, L19807.

Chu, D.A., Kaufman, Y.J., Zibordi, G., Chern, J.D., Mao, J., Li, C., Holben, B.N., 2003. Global monitoring of air pollution over land from the Earth observing systemterra moderate resolution imaging Spectroradiometer (MODIS). Journal of Geophysical Research 108, 4661.

Clarisse, L., Clerbaux, C., Dentener, F., Hurtmans, D., Coheur, P.-F., 2009. Global ammonia distribution derived from infrared satellite observations. Nature Geoscience 2, 479-483.

Clarisse, L., Coheur, P.F., Chefdeville, S., Lacour, J.-L., Hurtmans, D., Clerbaux, C., 2011a. Infrared satellite observations of hydrogen sulfide in the volcanic plume of the august 2008 kasatochi eruption. Geophysical Research Letters 38, L10804

Clarisse, L., Coheur, P.F., Prata, A.J., Hurtmans, D., Razavi, A., Phulpin, T., HadjiLazaro, J., Clerbaux, C., 2008. Tracking and quantifying volcanic $\mathrm{SO}_{2}$ with IASI, the september 2007 eruption at Jebel at Tair. Atmospheric Chemistry and Physics 8, 7723-7734.

Clarisse, L., R'Honi, Y., Coheur, P.-F., Hurtmans, D., Clerbaux, C., 2011b. Thermal infrared nadir observations of 24 atmospheric gases. Geophysical Research Letters 38, L10802.

Clarisse, L., Shephard, M.W., Dentener, F., Hurtmans, D., Cady-Pereira, K. Karagulian, F., Van Damme, M., Clerbaux, C., Coheur, P.-F., 2010. Satellite monitoring of ammonia: a case study of the San Joaquin Valley. Journal of Geophysical Research 115, D13302.

Clarmann, T. v., Glatthor, N., Koukouli, M.E., Stiller, G.P., Funke, B., Grabowski, U., Höpfner, M., Kellmann, S., Linden, A., Milz, M., Steck, T., Fischer, H., 2007. MIPAS measurements of upper tropospheric $\mathrm{C}_{2} \mathrm{H}_{6}$ and $\mathrm{O}_{3}$ during the southern hemispheric biomass burning season in 2003. Atmospheric Chemistry and Physics 7, 5861-5872.

Clerbaux, C., Boynard, A., Clarisse, L., George, M., Hadji-Lazaro, J., Herbin, H. Hurtmans, D., Pommier, M., Razavi, A., Turquety, S., Wespes, C., Coheur, P.-F. 2009. Monitoring of atmospheric composition using the thermal infrared IASI/ MetOp sounder. Atmospheric Chemistry and Physics 9, 6041-6054.

Clerbaux, C., Crevoisier, C., 2013. New directions: infrared remote sensing of the troposphere from satellite: less, but better. Atmospheric Environment 72, 24-26.

Clerbaux, C., Edwards, D.P., Deeter, M., Emmons, L., Lamarque, J.-F., Tie, X.X., Massie, S.T., Gille, J., 2008. Carbon monoxide pollution from cities and urban areas observed by the Terra/MOPITT mission. Geophysical Research Letters 35, L03817.

Cogan, A.J., Boesch, H., Parker, R.J., Feng, L., Palmer, P.I., Blavier, J.-F.L., Deutscher, N.M., Macatangay, R., Notholt, J., Roehl, C., Warneke, T., Wunch, D., 2012. Atmospheric carbon dioxide retrieved from the Greenhouse gases Observing SATellite (GOSAT): comparison with ground-based TCCON observations and GEOS-Chem model calculations. Journal of Geophysical Research 117, D21301.

Coheur, P.-F., Clarisse, L., Turquety, S., Hurtmans, D., Clerbaux, C., 2009. IASI measurements of reactive trace species in biomass burning plumes. Atmospheric Chemistry and Physics 9, 5655-5667. 
Crevoisier, C., Nobileau, D., Fiore, A.M., Armante, R., Chédin, A., Scott, N.A., 2009 Tropospheric methane in the tropics - first year from IASI hyperspectral infrared observations. Atmospheric Chemistry and Physics 9, 6337-6350.

Curci, G., Palmer, P.I., Kurosu, T.P., Chance, K., Visconti, G., 2010. Estimating European volatile organic compound emissions using satellite observations of formaldehyde from the ozone monitoring instrument. Atmospheric Chemistry and Physics 10, 11501-11517.

de Foy, B., Krotkov, N.A., Bei, N., Herndon, S.C., Huey, L.G., Martinez, A.-P., RuizSuárez, L.G., Wood, E.C., Zavala, M., Molina, L.T., 2009. Hit from both sides: tracking industrial and volcanic plumes in Mexico City with surface measurements and $\mathrm{OMI} \mathrm{SO}_{2}$ retrievals during the MILAGRO field campaign. Atmospheric Chemistry and Physics 9, 9599-9617.

de Ruyter de Wildt, M., Eskes, H., Boersma, K.F., 2012. The global economic cycle and satellite-derived $\mathrm{NO}_{2}$ trends over shipping lanes. Geophysical Research Letters 39, L01802.

De Smedt, I., Müller, J.-F., Stavrakou, T., van der, A.,R., Eskes, H., Van Roozendael, M. 2008. Twelve years of global observations of formaldehyde in the troposphere using GOME and SCIAMACHY sensors. Atmospheric Chemistry and Physics 8 4947-4963.

Deeter, M.N., Edwards, D.P., Gille, J.C., Drummond, J.R., 2009. CO retrievals based on MOPITT near-infrared observations. Journal of Geophysical Research 114 D04303.

Deeter, M.N., Edwards, D.P., Gille, J.C., Emmons, L.K., Francis, G., Ho, S.-P., Mao, D. Masters, D., Worden, H., Drummond, J.R., Novelli, P.C., 2010. The MOPITT version 4 CO product: algorithm enhancements, validation, and long-term stability. Journal of Geophysical Research 115, D07306.

Deeter, M.N., Emmons, L.K., Edwards, D.P., Gille, J.C., Drummond, J.R., 2004. Vertical resolution and information content of $\mathrm{CO}$ profiles retrieved by MOPITT. Geophysical Research Letters 31, L15112.

Deeter, M.N., Emmons, L.K., Francis, G.L., Edwards, D.P., Gille, J.C., Warner, J.X Khattatov, B., Ziskin, D., Lamarque, J.-F., Ho, S.-P., Yudin, V., Attié, J.-L., Packman, D., Chen, J., Mao, D., Drummond, J.R., 2003. Operational carbon monoxide retrieval algorithm and selected results for the MOPITT instrument. Journal of Geophysical Research 108, 4399.

Deeter, M.N., Worden, H.M., Edwards, D.P., Gille, J.C., Andrews, A.E., 2012. Evaluation of MOPITT retrievals of lower-tropospheric carbon monoxide over the United States. Journal of Geophysical Research 117, D13306.

Dickerson, R.R., Li, C., Li, Z., Marufu, L.T., Stehr, J.W., McClure, B., Krotkov, N., Chen, H., Wang, P., Xia, X., Ban, X., Gong, F., Yuan, J., Yang, J., 2007. Aircraf observations of dust and pollutants over northeast China: insight into the meteorological mechanisms of transport. Journal of Geophysical Research 112, D24S90.

Diner, D.J., Beckert, J.C., Reilly, T.H., Bruegge, C.J., Conel, J.E., Kahn, R.A., Martonchik, J.V., Ackerman, T.P., Davies, R., Gerstl, S.A.W., Gordon, H.R., Muller, J.-P., Myneni, R.B. Sellers, P.J., Pinty, B., Verstraete, M.M., 1998. Multi-angle Imaging SpectroRadiometer (MISR) instrument description and experiment overview. IEEE Transactions on Geoscience and Remote Sensing 36, 1072-1087.

Dlugokencky, E.J., Nisbet, E.G., Fisher, R., Lowry, D., 2011. Global atmospheric methane: budget, changes and dangers. Philosophical Transactions of the Royal Society A 369, 2058-2072.

Drummond, J.R. 1992. Measurements of Pollution in the Troposphere (MOPITT). In: Gille, J.C., Visconti, G. (Eds.), The Use of EOS for Studies of Atmospheric Physics, pp. 77-101. North-Holland, New York, NY, USA

Dubovik, O., Lapyonok, T., Kaufman, Y.J., Chin, M., Ginoux, P., Kahn, R.A., Sinyuk, A. 2008. Retrieving global aerosol sources from satellites using inverse modeling. Atmospheric Chemistry and Physics 8, 209-250.

Dufour, G., Boone, C.D., Rinsland, C.P., Bernath, P.F., 2006. First space-borne measurements of methanol inside aged southern tropical to mid-latitude biomass burning plumes using the ACE-FTS instrument. Atmospheric Chemistry and Physics 6, 3463-3470.

Dufour, G., Szopa, S., Hauglustaine, D.A., Boone, C.D., Rinsland, C.P., Bernath, P.F. 2007. The influence of biogenic emissions on upper-tropospheric methanol as revealed from space. Atmospheric Chemistry and Physics 7, 6119-6129.

Edwards, D.P., Emmons, L.K., Hauglustaine, D.A., Chu, D.A., Gille, J.C., Kaufman, Y.J. Pétron, G., Yurganov, L.N., Giglio, L., Deeter, M.N., Yudin, V., Ziskin, D.C., Warner, J., Lamarque, J.-F., Francis, G.L., Ho, S.P., Mao, D., Chen, J., Grechko, E.I., Drummond, J.R., 2004. Observations of carbon monoxide and aerosols from the Terra satellite: Northern Hemisphere variability. Journal of Geophysica Research 109, D24202.

Edwards, D.P., Halvorson, C.M., Gille, J.C., 1999. Radiative transfer modeling for the EOS Terra satellite Measurement of Pollution in the Troposphere (MOPITT) instrument. Journal of Geophysical Research 104, 16755-16775.

Eisinger, M., Burrows, J.P., 1998. Tropospheric sulfur dioxide observed by the ERS-2 GOME instrument. Geophysical Research Letters 25, 4177-4180

Elbern, H., Schmidt, H., Talagrand, O., Ebel, A., 2000. 4D-variational data assimilation with an adjoint air quality model for emission analysis. Environmental Modelling \& Software 15, 539-548.

Environmental Protection Agency (EPA), 2013a. 2008 National Emissions Inventory. Version 2 Technical Support Document. http://www.epa.gov/ttn/chief/net/ 2008neiv2/2008_neiv2_tsd_draft.pdf (accessed March 2013.).

Environmental Protection Agency (EPA), 2013b. Trends in $\mathrm{NO}_{2}, \mathrm{CO}$, and $\mathrm{SO}_{2}$ Concentrations (accessed March 2013.). http://www.epa.gov/airtrends/2011/.

Evensen, G., 1994. Sequential data assimilation with a nonlinear quasi-geostrophic model using Monte Carlo methods to forecast error statistics. Journal of Geophysical Research 99 (C5), 10143-10162.
Fioletov, V.E., McLinden, C.A., Krotkov, N., Moran, M.D., Yang, K., 2011. Estimation of $\mathrm{SO}_{2}$ emissions using OMI retrievals. Geophysical Research Letters 38, L21811.

Fiore, A.M., Jacob, D.J., Field, B.D., Streets, D.G., Fernandes, S.D., Jang, C., 2002. Linking ozone pollution and climate change: the case for controlling methane. Geophysical Research Letters 29, 1919.

Fischer, E.V., Hsu, N.C., Jaffe, D.A., Jeong, M.-J., Gong, S.L., 2009. A decade of dust: Asian dust and springtime aerosol load in the U.S. Pacific Northwest. Geophysical Research Letters 36, L03821.

Fisher, J.A., Jacob, D.J., Purdy, M.T., Kopacz, M., Le Sager, P., Carouge, C., Holmes, C.D., Yantosca, R.M., Batchelor, R.L., Strong, K., Diskin, G.S., Fuelberg, H.E., Holloway, J.S., Hyer, E.J., McMillan, W.W., Warner, J., Streets, D.G., Zhang, Q., Wang, Y., Wu, S., 2010. Source attribution and interannual variability of Arctic pollution in spring constrained by aircraft (ARCTAS, ARCPAC) and satellite (AIRS) observations of carbon monoxide. Atmospheric Chemistry and Physics 10, 977-996.

Fishman, J., Iraci, L.T., Al-Saadi, J., Chance, K., Chavez, F., Chin, M., Coble, P., Davis, C., DiGiacomo, P.M., Edwards, D., Eldering, A., Goes, J., Herman, J., Hu, C., Jacob, D.J., Jordan, C., Kawa, S.R., Key, R., Liu, X., Lohrenz, S., Mannino, A., Natraj, V., Neil, D., Neu, J., Newchurch, M., Pickering, K., Salisbury, J., Sosik, H., Subramaniam, A., Tzortziou, M., Wang, J., Wang, M., 2012. The United States' next generation of atmospheric composition and coastal ecosystem measurements: NASA's Geostationary Coastal and Air Pollution Events (GEO-CAPE) mission. Bulletin of the American Meteorological Society 93, 1547-1566.

Fortems-Cheiney, A., Chevallier, F., Pison, I., Bousquet, P., Carouge, C., Clerbaux, C., Coheur, P.-F., George, M., Hurtmans, D., Szopa, S., 2009. On the capability of IASI measurements to inform about CO surface emissions. Atmospheric Chemistry and Physics 9, 8735-8743.

Fortems-Cheiney, A., Chevallier, F., Pison, I., Bousquet, P., Szopa, S., Deeter, M.N., Clerbaux, C., 2011. Ten years of CO emissions as seen from measurements of pollution in the troposphere (MOPITT). Journal of Geophysical Research 116, D05304.

Franke, K., Richter, A., Bovensmann, H., Eyring, V., Jöckel, P., Hoor, P., Burrows, J.P., 2009. Ship emitted $\mathrm{NO}_{2}$ in the Indian Ocean: comparison of model results with satellite data. Atmospheric Chemistry and Physics 9, 7289-7301.

Frankenberg, C., Aben, I., Bergamaschi, P., Dlugokencky, E.J., van Hees, R., Houweling, S., van der Meer, P., Snel, R., Tol, P., 2011. Global column-averaged methane mixing ratios from 2003 to 2009 as derived from SCIAMACHY: trends and variability. Journal of Geophysical Research 116, D04302.

Frankenberg, C., Meirink, J.F., van Weele, M., Platt, U., Wagner, T., 2005. Assessing methane emissions from global space-borne observations. Science 308, 1010-1014.

Fu, D., Worden, J.R., Liu, X., Kulawik, S.S., Bowman, K.W., Natraj, V., 2013. Characterization of ozone profiles derived from Aura TES and OMI radiances. Atmospheric Chemistry and Physics 13, 3445-3462.

Fu, T.-Z., Jacob, D.J., Palmer, P.I., Chance, K., Wang, Y.X., Barletta, B., Blake, D.R., Stanton, J.C., Pilling, M.J., 2007. Space-based formaldehyde measurements as constraints on volatile organic compound emissions in east and south Asia and implications for ozone. Journal of Geophysical Research 112, D06312.

Fu, T.-Z., Jacob, D.J., Wittrock, F., Burrows, J.P., Vrekoussis, M., Henze, D.K. 2008. Global budgets of atmospheric glyoxal and methylglyoxal, and implications for formation of secondary organic aerosols. Journal of Geophysical Research 113, D15303.

Galloway, J.N., Aber, J.D., Erisman, J.W., Seitzinger, S.P., Howarth, R.W., Cowling, E.B., Cosby, B.J., 2003. The nitrogen cascade. BioScience 53, 341-356.

George, M., Clerbaux, C., Hurtmans, D., Turquety, S., Coheur, P.-F., Pommier, M., Hadji-Lazaro, J., Edwards, D.P., Worden, H., Luo, M., Rinsland, C., McMillan, W., 2009. Carbon monoxide distributions from the IASI/METOP mission: evaluation with other space-borne remote sensors. Atmospheric Chemistry and Physics 9 , $8317-8330$

Glatthor, N., von Clarmann, T., Stiller, G.P., Funke, B., Koukouli, M.E., Fischer, H., Grabowski, U., Höpfner, M., Kellmann, S., Linden, A., 2009. Large-scale upper tropospheric pollution observed by MIPAS HCN and $\mathrm{C}_{2} \mathrm{H}_{6}$ global distributions. Atmospheric Chemistry and Physics 9, 9619-9634.

Ghude, S.D., Fadnavis, S., Beig, G., Polade, S.D., van der, A.,R.J., 2008. Detection of surface emission hot spots, trends, and seasonal cycle from satellite-retrieved $\mathrm{NO}_{2}$ over India. Journal of Geophysical Research 113, D20305.

Ghude, S.D., Kulkarni, S.H., Jena, C., Pfister, G.G., Beig, G., Fadnavis, S., van der, A.,R.J., 2013. Application of satellite observations for identifying regions of dominant sources of nitrogen oxides over the Indian Subcontinent. Journal of Geophysical Research 118, 1075-1089.

Ghude, S.D., Lal, D.M., Beig, G., van der, A.,R., Sable, D., 2010. Rain-induced soil $\mathrm{NO}_{\mathrm{x}}$ emission from India during the onset of the summer monsoon: a satellite perspective. Journal of Geophysical Research 115, D16304.

González Abad, G., Allen, N.D.C., Bernath, P.F., Boone, C.D., McLeod, S.D., Manney, G.L., Toon, G.C., Carouge, C., Wang, Y., Wu, S., Barkley, M.P., Palmer, P.I., Xiao, Y., Fu, T.M., 2011. Ethane, ethyne and carbon monoxide concentrations in the upper troposphere and lower stratosphere from ACE and GEOS-Chem: a comparison study. Atmospheric Chemistry and Physics 11, 9927-9941.

Grutter, M., Glatthor, N., Stiller, G.P., Fischer, H., Grabowski, U., Höpfner, M., Kellmann, S., Linden, A., von Clarmann, T., 2010. Global distribution and variability of formic acid as observed by MIPAS-ENVISAT. Journal of Geophysical Research 115, D10303.

Hains, J.C., Boersma, K.F., Kroon, M., Dirksen, R.J., Cohen, R.C., Perring, A.E., Bucsela, E., Volten, H., Swart, D.P.J., Richter, A., Wittrock, F., Schoenhardt, A., Wagner, T., Ibrahim, O.W., van Roozendael, M., Pinardi, G., Gleason, J.F., Veefkind, J.P., Levelt, P., 2010. Testing and improving OMI DOMINO tropospheric 
$\mathrm{NO}_{2}$ using observations from the DANDELIONS and INTEX-B validation campaigns. Journal of Geophysical Research 115, D05301.

Hains, J.C., Taubman, B.F., Thompson, A.M., Stehr, J.W., Marufu, L.T., Doddridge, B.G. Dickerson, R.R., 2008. Origins of chemical pollution from Mid-Atlantic aircraft profiles using a clustering technique. Atmospheric Environment 42, 1727-1741.

Hammerling, D.M., Michalak, A.M., O’Dell, C., Kawa, S.R., 2012. Global $\mathrm{CO}_{2}$ distributions over land from the Greenhouse Gases Observing Satellite (GOSAT). Geophysical Research Letters 39, L008804.

Hao, N., Valks, P., Loyola, D., Cheng, Y.F., Zimmer, W., 2011. Space-based measurements of air quality during the World Expo 2010 in Shanghai. Environmental Research Letters 6, 044004.

He, H., Li, C., Loughner, C.P., Li, Z., Krotkov, N.A., Yang, K., Wang, L., Zheng, Y., Bao, X., Zhao, G., Dickerson, R.R., 2012. $\mathrm{SO}_{2}$ over central China: measurements, numerical simulations and the tropospheric sulfur budget. Journal of Geophysical Research 117, D00K37.

Heald, C.L., Collett, J.L., Lee, T., Benedict, K.B., Schwandner, F.M., Li, Y., Clarisse, L., Hurtmans, D.R., Van Damme, M., Clerbaux, C., Coheur, P.-F., Philip, S. Martin, R.V., Pye, H.O.T., 2012. Atmospheric ammonia and particulate inorganic nitrogen over the United States. Atmospheric Chemistry and Physics 12, 1029510312.

Heald, C.L., Jacob, D.J., Jones, D.B.A., Palmer, P.I., Logan, J.A., Streets, D.G., Sachse, G.W., Gille, J.C., Hoffman, R.N., Nehrkorn, T., 2004. Comparative inverse analysis of satellite (MOPITT) and aircraft (TRACE-P) observations to estimate Asian sources of carbon monoxide. Journal of Geophysical Research 109, D23306.

Heckel, A., Kim, S.-W., Frost, G.J., Richter, A., Trainer, M., Burrows, J.P., 2011. Influence of low spatial resolution a priori data on tropospheric $\mathrm{NO}_{2}$ satellite retrievals. Atmospheric Measurement Techniques 4, 1805-1820.

Heimann, M., 2011. Enigma of the recent methane budget. Nature 476, 157-158.

Hennigan, C.J., Sandholm, S., Kim, S., Stickel, R.E., Huey, L.G., Weber, R.J., 2006. Influence of Ohio River valley emissions on fine particle sulfate measured from aircraft over large regions of the eastern United States and Canada during INTEX-NA. Journal of Geophysical Research 111, D24S04.

Herbin, H., Hurtmans, D., Clarisse, L., Turquety, S., Clerbaux, C., Rinsland, C.P., Boone, C., Bernath, P.F., Coheur, P.-F., 2009. Distributions and seasonal variations of tropospheric ethene $\left(\mathrm{C}_{2} \mathrm{H}_{4}\right)$ from Atmospheric Chemistry Experiment (ACEFTS) solar occultation spectra. Geophysical Research Letters 36, L04801.

Heue, K.-P., Brenninkmeijer, C.A.M., Wagner, T., Mies, K., Dix, B., Frieß, U. Martinsson, B.G., Slemr, F., van Velthoven, P.F.J., 2010. Observations of the 2008 Kasatochi volcanic $\mathrm{SO}_{2}$ plume by CARIBIC aircraft DOAS and the GOME-2 satellite. Atmospheric Chemistry and Physics 10, 4699-4713.

Hoff, R.M., Christopher, S.A., 2009. Remote sensing of particulate pollution from space: have we reached the promised land? Journal of the Air \& Waste Management Association 59, 645-675.

Hooghiemstra, P.B., Krol, M.C., Bergamaschi, P., de Laat, A.T.J., van der Werf, G.R., Novelli, P.C., Deeter, M.N., Aben, I., Röckmann, T., 2012. Comparing optimized CO emission estimates using MOPITT or NOAA surface network observations. Journal of Geophysical Research 117, D06309.

Houweling, S., Breon, F.-M., Aben, I., Rödenbeck, C., Gloor, M., Heimann, M., Ciais, P., 2004. Inverse modeling of $\mathrm{CO}_{2}$ sources and sinks using satellite data: a synthetic inter-comparison of measurement techniques and their performance as a function of space and time. Atmospheric Chemistry and Physics 4, 523-538.

Hsu, N.C., Tsay, S.-C., King, M.D., Herman, J.R., 2004. Aerosol properties over brightreflecting source regions. IEEE Transactions on Geoscience and Remote Sensing 42, 557-569.

Hsu, N.C., Tsay, S.-C., King, M.D., Herman, J.R., 2006. Deep Blue retrievals of Asian aerosol properties during ACE-Asia. IEEE Transactions on Geoscience and Remote Sensing 44, 3180-3195.

Hudman, R.C., Moore, N.E., Mebust, A.K., Martin, R.V., Russell, A.R., Valin, L.C., Cohen, R.C., 2012. Steps towards a mechanistic model of global soil nitric oxide emissions: implementation and space-based constraints. Atmospheric Chemistry and Physics 12, 7779-7795.

Hudman, R.C., Murray, L.T., Jacob, D.J., Millet, D.B., Turquety, S., Wu, S., Blake, D.R., Goldstein, A.H., Holloway, J., Sachse, G.W., 2008. Biogenic versus anthropogenic sources of CO in the United States. Geophysical Research Letters 35, L04801.

Hudman, R.C., Russell, A.R., Valin, L.C., Cohen, R.C., 2010. Interannual variability in soil nitric oxide emissions over the United States as viewed from space. Atmospheric Chemistry and Physics 10, 9943-9952.

Huijnen, V., Eskes, H.J., Poupkou, A., Elbern, H., Boersma, K.F., Foret, G., Sofiev, M. Valdebenito, A., Flemming, J., Stein, O., Gross, A., Robertson, L., D’Isidoro, M., Kioutsioukis, I., Friese, E., Amstrup, B., Bergstrom, R., Strunk, A., Vira, J., Zyryanov, D., Maurizi, A., Melas, D., Peuch, V.-H., Zerefos, C., 2010. Comparison of OMI $\mathrm{NO}_{2}$ tropospheric columns with an ensemble of global and European regional air quality models. Atmospheric Chemistry and Physics 10, 3273-3296.

Huneeus, N., Chevallier, F., Boucher, O., 2012. Estimating aerosol emissions by assimilating observed aerosol optical depth in a global aerosol model. Atmospheric Chemistry and Physics 12, 4585-4606.

Ichoku, C., Remer, L.A., Eck, T.F., 2005. Quantitative evaluation and intercomparison of morning and afternoon Moderate Resolution Imaging Spectroradiometer (MODIS) aerosol measurements from Terra and Aqua. Journal of Geophysical Research 110, D10S03.

IGAC News, Issue No. 47, August 2012. The End of the Envisat Mission. Editorial by John P. Burrows, pp. 3-4.

IPCC, 2007. In: Solomon, S., Qin, D., Manning, M., Chen, Z., Marquis, M., Averyt, K.B., Tignor, M., Miller, H.L. (Eds.), Climate Change 2007: the Physical Science Basis,
Contribution of Working Group I to the Fourth Assessment Report of the Intergovernmental Panel on Climate Change. Cambridge University Press, Cambridge, United Kingdom and New York, NY, USA, p. 996.

Jaeglé, L., Martin, R.V., Chance, K., Steinberger, L., Kurosu, T.P., Jacob, D.J., Modi, A.I. Yaboué, V., Sigha-Nkamdjou, L., Galy-Lacaux, C., 2004. Satellite mapping of raininduced nitric oxide emissions from soils. Journal of Geophysical Research 109, D21310.

JASON, 2011. Methods for Remote Determination of $\mathrm{CO}_{2}$ Emissions. Technical report JSR-10-300. The MITRE Corporation, McLean, Virginia, p. 198.

Jiang, J., Zha, Y., Gao, J., Jiang, J., 2012. Monitoring of $\mathrm{SO}_{2}$ column concentration change over China from Aura OMI data. International Journal of Remote Sensing 33, 1934-1942.

Jiang, Z., Jones, D.B.A., Kopacz, M., Liu, J., Henze, D.K., Heald, C., 2011. Quantifying the impact of model errors on top-down estimates of carbon monoxide emissions using satellite observations. Journal of Geophysical Research 116, D15306.

Jiang, Z., Jones, D.B.A., Worden, H.M., Deeter, M.N., Henze, D.K., Worden, J., Bowman, K.W., Brenninkmeijer, C.A.M., Schuck, T.J., 2013. Impact of model errors in convective transport on CO source estimates inferred from MOPITT CO retrievals. Journal of Geophysical Research 118, 2073-2083.

Jones, D.B.A., Bowman, K.W., Logan, J.A., Heald, C.L., Liu, J., Luo, M., Worden, J. Drummond, J., 2009. The zonal structure of tropical $\mathrm{O}_{3}$ and $\mathrm{CO}$ as observed by the Tropospheric Emission Spectrometer in November 2004 - Part 1: Inverse modeling of $\mathrm{CO}$ emissions. Atmospheric Chemistry and Physics 9, 3547-3562.

Kahn, R.A., Chen, Y., Nelson, D.L., Leung, F.-Y., Li, Q., Diner, D.J., Logan, J.A., 2008 Wildfire smoke injection heights: two perspectives from space. Geophysical Research Letters 35, L04809.

Kanakidou, M., Mihalopoulos, N., Kindap, T., Im, U., Vrekoussis, M., Gerasopoulos, E. Dermitzaki, E., Unal, A., Koçak, M., Markakis, K., Melas, D., Kouvarakis, G., Youssef, A.F., Richter, A., Hatzianastassiou, N., Hilboll, A., Ebojie, F., Wittrock, F., von Savigny, C., Burrows, J.P., Ladstaetter-Weissenmayer, A., Moubasher, H. 2011. Megacities as hot spots of air pollution in the East Mediterranean. Atmospheric Environment 45, 1223-1235.

Kar, J., Fishman, J., Creilson, J.K., Richter, A., Ziemke, J., Chandra, S., 2010. Are there urban signatures in the tropospheric ozone column products derived from satellite measurements? Atmospheric Chemistry and Physics 10, 52135222.

Kaynak, B., Hu, Y., Martin, R.V., Sioris, C.E., Russell, A.G., 2009. Comparison of weekly cycle of $\mathrm{NO}_{2}$ satellite retrievals and $\mathrm{NO}_{\mathrm{x}}$ emission inventories for the continental United States. Journal of Geophysical Research 114, D05302.

Kearney, C., Watson, I.M., Bluth, G.J.S., Carn, S., Realmuto, V.J., 2009. A comparison of thermal infrared and ultraviolet retrievals of $\mathrm{SO}_{2}$ in the cloud produced by the 2003 Al-Mishraq State sulfur plant fire. Geophysical Research Letters 36, L10807.

Khokhar, M.F., Frankenberg, C., Van Roozendael, M., Beirle, S., Kühl, S., Richter, A. Platt, U., Wagner, T., 2005. Satellite observations of atmospheric $\mathrm{SO}_{2}$ from volcanic eruptions during the time-period of 1996-2002. Advances in Space Research 36, 879-887.

Khokhar, M.F., Platt, U., Wagner, T., 2008. Temporal trends of anthropogenic $\mathrm{SO}_{2}$ emitted by non-ferrous metal smelters in Peru and Russia estimated from satellite observations. Atmospheric Chemistry and Physics Discussions 8 17393-17422.

Kim, S.-W., Heckel, A., Frost, G.J., Richter, A., Gleason, J., Burrows, J.P., McKeen, S., Hsie, E.-Y., Granier, C., Trainer, M., 2009. $\mathrm{NO}_{2}$ columns in the western United States observed from space and simulated by a regional chemistry model and their implications for $\mathrm{NO}_{\mathrm{x}}$ emissions. Journal of Geophysical Research 114, D11301.

Kim, S.-W., Heckel, A., McKeen, S.A., Frost, G.J., Hsie, E.-Y., Trainer, M.K., Richter, A. Burrows, J.P., Peckham, S.E., Grell, G.A., 2006. Satellite-observed U.S. power plant $\mathrm{NO}_{\mathrm{x}}$ emission reductions and their impact on air quality. Geophysical Research Letters 33, L22812.

Kloog, I., Koutrakis, P., Coull, B.A., Lee, H.J., Schwartz, J., 2011. Assessing temporally and spatially resolved $\mathrm{PM}_{2.5}$ exposures for epidemiological studies using satellite aerosol optical depth measurements. Atmospheric Environment 45, 6267-6275.

Konovalov, I.B., Beekmann, M., Richter, A., Burrows, J.P., 2006. Inverse modelling of the spatial distribution of $\mathrm{NO}_{\mathrm{x}}$ emissions on a continental scale using satellite data. Atmospheric Chemistry and Physics 6, 1747-1770.

Konovalov, I.B., Beekmann, M., Richter, A., Burrows, J.P., Hilboll, A., 2010. Multiannual changes of $\mathrm{NO}_{\mathrm{x}}$ emissions in megacity regions: nonlinear trend analysis of satellite measurement based estimates. Atmospheric Chemistry and Physics $10,8481-8498$.

Kopacz, M., Jacob, D.J., Fisher, J.A., Logan, J.A., Zhang, L., Megretskaia, I.A. Yantosca, R.M., Singh, K., Henze, D.K., Burrows, J.P., Buchwitz, M., Khlystova, I, McMillan, W.W., Gille, J.C., Edwards, D.P., Eldering, A., Thouret, V., Nedelec, P., 2010. Global estimates of CO sources with high resolution by adjoint inversion of multiple satellite datasets (MOPITT, AIRS, SCIAMACHY, TES). Atmospheric Chemistry and Physics 10, 855-876.

Kopacz, M., Jacob, D.J., Henze, D.K., Heald, C.L., Streets, D.G., Zhang, Q., 2009 Comparison of adjoint and analytical Bayesian inversion methods for constraining Asian sources of carbon monoxide using satellite (MOPITT) measurements of CO columns. Journal of Geophysical Research 114, D04305.

Kort, E.A., Frankenberg, C., Miller, C.E., Oda, T., 2012. Space-based observations of megacity carbon dioxide. Geophysical Research Letters 39, L17806.

Krotkov, N.A., Carn, S.A., Krueger, A.J., Bhartia, P.K., Yang, K., 2006. Band residual difference algorithm for retrieval of $\mathrm{SO}_{2}$ from the Aura Ozone Monitoring 
Instrument (OMI). IEEE Transactions on Geoscience and Remote Sensing 44, $1259-1266$.

Krotkov, N.A., McClure, B., Dickerson, R.R., Carn, S.A., Li, C., Bhartia, P.K., Yang, K., Krueger, A.J., Li, Z., Levelt, P.F., Chen, H., Wang, P., Lu, D., 2008. Validation of $\mathrm{SO}_{2}$ retrievals from the Ozone Monitoring Instrument over NE China. Journal of Geophysical Research 113, D16S40.

Krotkov, N.A., Schoeberl, M.R., Morris, G.A., Carn, S., Yang, K., 2010. Dispersion and lifetime of the $\mathrm{SO}_{2}$ cloud from the August 2008 Kasatochi eruption. Journal of Geophysical Research 115, D00L20.

Krueger, A.J., 1983. Sighting of El Chichón sulfur dioxide clouds with the Nimbus 7 total ozone mapping spectrometer. Science 220, 1377-1379.

Krueger, A.J., Krotkov, N.A., Yang, K., Carn, S., Vicente, G., Schroeder, W., 2009. Applications of satellite-based sulfur dioxide monitoring. IEEE Journal of Selected Topics in Applied Earth Observations and Remote Sensing 2, 293-298.

Kuai, L., Worden, J., Kulawik, S., Bowman, K., Lee, M., Biraud, S.C., Abshire, J.B., Wofsy, S.C., Natraj, V., Frankenberg, C., Wunch, D., Connor, B., Miller, C., Roehl, C. Shia, R.-L., Yung, Y., 2013. Profiling tropospheric $\mathrm{CO}_{2}$ using Aura TES and TCCON instruments. Atmospheric Measurement Techniques 6, 63-79.

Kulawik, S.S., Jones, D.B.A., Nassar, R., Irion, F.W., Worden, J.R., Bowman, K.W., Machida, T., Matsueda, H., Sawa, Y., Biraud, S.C., Fischer, M.L., Jacobson, A.R., 2010. Characterization of Tropospheric Emission Spectrometer (TES) $\mathrm{CO}_{2}$ for carbon cycle science. Atmospheric Chemistry and Physics 10, 5601-5623.

Kuze, A., Suto, H., Nakajima, M., Hamazaki, T., 2009. Thermal and near infrared sensor for carbon observation Fourier-transform spectrometer on the Greenhouse Gases Observing Satellite for greenhouse gases monitoring. Applied Optics 48, 6716-6733.

Lamsal, L.N., Martin, R.V., Padmanabhan, A., van Donkelaar, A., Zhang, Q., Sioris, C.E., Chance, K., Kurosu, T.P., Newchurch, M.J., 2011. Application of satellite observations for timely updates to global anthropogenic $\mathrm{NO}_{\mathrm{x}}$ emission inventories. Geophysical Research Letters 28, L05810.

Lamsal, L.N., Martin, R.V., van Donkelaar, A., Celarier, E.A., Bucsela, E.J., Boersma, K.F., Dirksen, R., Luo, C., Wang, Y., 2010. Indirect validation of tropospheric nitrogen dioxide retrieved from the OMI satellite instrument: insight into the seasonal variation of nitrogen oxides at northern midlatitudes. Journal of Geophysical Research 115, D05302.

Lamsal, L.N., Martin, R.V., van Donkelaar, A., Steinbacher, M., Celarier, E.A., Bucsela, E., Dunlea, E.J., Pinto, J.P., 2008. Ground-level nitrogen dioxide concentrations inferred from the satellite-borne Ozone Monitoring Instrument. Journal of Geophysical Research 113, D16308.

Lauvaux, T., Pannekoucke, O., Sarrat, C., Chevallier, F., Ciais, P., Noilhan, J., Rayner, P.J., 2009. Structure of the transport uncertainty in mesoscale inversions of $\mathrm{CO}_{2}$ sources and sinks using ensemble model simulations. Biogeosciences 6 , 1089-1102.

Lee, C., Martin, R.V., van Donkelaar, A., Lee, H., Dickerson, R.R., Hains, J.C., Krotkov, N., Richter, A., Vinnikov, K., Schwab, J.J., 2011a. $\mathrm{SO}_{2}$ emissions and lifetimes: estimates from inverse modeling using in situ and global, space-based (SCIAMACHY and OMI) observations. Journal of Geophysical Research 116, D06305.

Lee, C., Martin, R.V., van Donkelaar, A., O’Byrne, G., Krotkov, N., Richter, A., Huey, L.G., Holloway, J.S., 2009. Retrieval of vertical columns of sulfur dioxide from SCIAMACHY and OMI: air mass factor algorithm development, validation, and error analysis. Journal of Geophysical Research 114, D22303.

Lee, C., Richter, A., Lee, H., Kim, Y.J., Burrows, J.P., Lee, Y.G., Choi, B.C., 2008a. Impact of transport of sulfur dioxide from the Asian continent on the air quality over Korea during may 2005. Atmospheric Environment 42, 1461-1475.

Lee, C., Richter, A., Weber, M., Burrows, J.P., 2008b. $\mathrm{SO}_{2}$ retrieval from SCIAMACHY using the Weighting Function DOAS (WFDOAS) technique: comparison with Standard DOAS retrieval. Atmospheric Chemistry and Physics 8, 6137-6145.

Lee, C.J., Brook, J.R., Evans, G.J., Martin, R.V., Mihele, C., 2011b. Novel application of satellite and in-situ measurements to map surface-level $\mathrm{NO}_{2}$ in the Great Lakes region. Atmospheric Chemistry and Physics 11, 11761-11775.

Lee, H.J., Liu, Y., Coull, B.A., Schwartz, J., Koutrakis, P., 2011c. A novel calibration approach of MODIS AOD data to predict $\mathrm{PM}_{2.5}$ concentrations. Atmospheric Chemistry and Physics 11, 7991-8002.

Levelt, P.F., van den Oord, G.H.J., Dobber, M.R., Mälkki, A., Visser, H., de Vries, J., Stammes, P., Lundell, J.O.V., Saari, H., 2006. The ozone monitoring instrument. IEEE Transactions on Geoscience and Remote Sensing 44, 1093-1101.

Levy, R.C., Mattoo, S., Munchak, L.A., Remer, L.A., Sayer, A.M., Hsu, N.C., 2013. The Collection 6 MODIS aerosol products over land and ocean. Atmospheric Measurement Techniques Discussions 6, 159-259.

Li, C., Krotkov, N.A., Dickerson, R.R., Li, Z., Yang, K., Chin, M., 2010a. Transport and evolution of a pollutant plume from northern China: a satellite-based case study. Journal of Geophysical Research 115, D00K03.

Li, C., Zhang, Q., Krotkov, N.A., Streets, D.G., He, K., Tsay, S.-C., Gleason, J.F., 2010b. Recent large reductions in sulfur dioxide emissions from Chinese power plants observed by the ozone monitoring instrument. Geophysical Research Letters 37, L08807.

Li, Z., Chen, H., Cribb, M., Dickerson, R., Holben, B., Li, C., Lu, D., Luo, Y., Maring, H., Shi, G., Tsay, S.-C., Wang, P., Wang, Y., Xia, X., Zheng, Y., Yuan, T., Zhao, F., 2007. Preface to special section on east Asian studies of tropospheric aerosols: an international regional experiment (EAST-AIRE). Journal of Geophysical Research 112, D22S00.

Li, Z., Li, C., Chen, H., Tsay, S.-C., Holben, B., Huang, J., Li, B., Maring, H., Qian, Y., Shi, G., Xia, X., Yin, Y., Zheng, Y., Zhuang, G., 2011. East Asian studies of tropospheric aerosols and their impact on regional climate (EAST-AIRC): an overview. Journal of Geophysical Research 116, D00K34.
Lin, J., Nielsen, C.P., Zhao, Y., Lei, Y., Liu, Y., McElroy, M.B., 2010a. Recent changes in particulate air pollution over China observed from space and the ground: effectiveness of emission control. Environmental Science \& Technology 44, $7771-7776$.

Lin, J.-T., Liu, Z., Zhang, Q., Liu, H., Mao, J., Zhuang, G., 2012. Modeling uncertainties for tropospheric nitrogen dioxide columns affecting satellite-based inverse modeling of nitrogen oxides emissions. Atmospheric Chemistry and Physics 12, 12255-12275.

Lin, J.-T., McElroy, M.B., 2010. Impacts of boundary layer mixing on pollutant vertical profiles in the lower troposphere: implications to satellite remote sensing. Atmospheric Environment 44, 1726-1739.

Lin, J.-T., McElroy, M.B., 2011. Detection from space of a reduction in anthropogenic emissions of nitrogen oxides during the Chinese economic downturn. Atmospheric Chemistry and Physics 11, 8171-8188.

Lin, J.-T., McElroy, M.B., Boersma, K.F., 2010b. Constraint of anthropogenic $\mathrm{NO}_{\mathrm{x}}$ emissions in China from different sectors: a new methodology using multiple satellite retrievals. Atmospheric Chemistry and Physics 10, 63-78.

Liu, Y., Franklin, M., Kahn, R., Koutrakis, P., 2007. Using aerosol optical thickness to predict ground-level $\mathrm{PM}_{2.5}$ concentrations in the St. Louis area: a comparison between MISR and MODIS. Remote Sensing of Environment 107, 33-44.

Liu, Y., He, K., Li, S., Wang, Z., Christiani, D.C., Koutrakis, P., 2012a. A statistical model to evaluate the effectiveness of $\mathrm{PM}_{2.5}$ emissions control during the Beijing 2008 Olympic Games. Environment International 44, 100-105.

Liu, Y., Sarnat, J.A., Kilaru, V., Jacob, D.J., Koutrakis, P., 2005. Estimating ground-level $\mathrm{PM}_{2.5}$ in the eastern United States using satellite remote sensing. Environmental Science \& Technology 39, 3269-3278.

Liu, Z., Wang, Y., Vrekoussis, M., Richter, A., Wittrock, F., Burrows, J.P., Shao, M., Chang, C.-C., Liu, S.-C., Wang, H., Chen, C., 2012b. Exploring the missing source of glyoxal (CHOCHO) over China. Geophysical Research Letters 39, L0812.

Loughner, C.P., Allen, D.J., Pickering, K.E., Zhang, D.-L., Shou, Y.-X., Dickerson, R.R., 2011. Impact of fair-weather cumulus clouds and the Chesapeake Bay breeze on pollutant transport and transformation. Atmospheric Environment 45, 40604072.

Loyola, D., van Geffen, J., Valks, P., Erbertseder, T., Van Roozendael, M., Thomas, W., Zimmer, W., Wißkirchen, K., 2008. Satellite-based detection of volcanic sulphur dioxide from recent eruptions in Central and South America. Advances in Geosciences 14, 35-40.

Lu, Z., Streets, D.G., 2012. Increase in $\mathrm{NO}_{\mathrm{x}}$ emissions from Indian thermal power plants during 1996-2010: unit-based inventories and multi-satellite observations. Environmental Science \& Technology 46, 7463-7470.

Marais, E.A., Jacob, D.J., Kurosu, T.P., Chance, K., Murphy, J.G., Reeves, C., Mills, G., Casadio, S., Millet, D.B., Barkley, M.P., Paulot, F., Mao, J., 2012. Isoprene emissions in Africa inferred from OMI observations of formaldehyde columns. Atmospheric Chemistry and Physics 12, 6219-6235.

Marbach, T., Beirle, S., Platt, U., Hoor, P., Wittrock, F., Richter, A., Vrekoussis, M., Grzegorski, M., Burrows, J.P., Wagner, T., 2009. Satellite measurements of formaldehyde linked to shipping emissions. Atmospheric Chemistry and Physics 9, 8223-8234.

Martin, R.V., 2008. Satellite remote sensing of surface air quality. Atmospheric Environment 42, 7823-7843.

Martin, R.V., Chance, K., Jacob, D.J., Kurosu, T.P., Spurr, R.J.D., Bucsela, E., Gleason, J.F., Palmer, P.I., Bey, I., Fiore, A.M., Li, Q., Yantosca, R.M., Koelemeijer, R.B.A., 2002. An improved retrieval of tropospheric nitrogen dioxide from GOME. Journal of Geophysical Research 107, 4437.

Martin, R.V., Jacob, D.J., Chance, K., Kurosu, T.P., Palmer, P.I., Evans, M.J., 2003. Global inventory of nitrogen oxide emissions constrained by space-based observations of $\mathrm{NO}_{2}$ columns. Journal of Geophysical Research 108, 4537.

Martin, R.V., Sauvage, B., Folkins, I., Sioris, C.E., Boone, C., Bernath, P., Ziemke, J. 2007. Space-based constraints on the production of nitric oxide by lightning. Journal of Geophysical Research 112, D09309.

Martínez-Alonso, S., Deeter, M.N., Worden, H.M., Clerbaux, C., Mao, D., Gille, J.C., 2012. First satellite identification of volcanic carbon monoxide. Geophysical Research Letters 39, L21809.

Martonchik, J.V., Diner, D.J., Kahn, R.A., Ackerman, T.P., Verstraete, M.M., Pinty, B., Gordon, H.R., 1998. Techniques for the retrieval of aerosol properties over land and ocean using multiangle imaging. IEEE Transactions on Geoscience and Remote Sensing 36, 1212-1227.

Marufu, L.T., Taubman, B.F., Bloomer, B., Piety, C.A., Doddridge, B.G., Stehr, J.W., Dickerson, R.R., 2004. The 2003 North American electrical blackout: an accidental experiment in atmospheric chemistry. Geophysical Research Letters 31, L13106.

McKain, K., Wofsy, S.C., Nehrkorn, T., Eluszkiewicz, J., Ehleringer, J.R., Stephens, B.B., 2012. Assessment of ground-based atmospheric observations for verification of greenhouse gas emissions from an urban region. Proceedings of the National Academy of Sciences of the United States 109, 8423-8428.

McLinden, C.A., Fioletov, V., Boersma, K.F., Krotkov, N., Sioris, C.E., Veefkind, J.P., Yang, K., 2012. Air quality over the Canadian oil sands: a first assessment using satellite observations. Geophysical Research Letters 39, L04804.

McMillan, W.W., Barnet, C., Strow, L., Chahine, M.T., McCourt, M.L., Warner, J.X., Novelli, P.C., Korontzi, S., Maddy, E.S., Datta, S., 2005. Daily global maps of carbon monoxide from NASA's Atmospheric Infrared Sounder. Geophysical Research Letters 32, L11801.

Meirink, J.F., Bergamaschi, P., Krol, M.C., 2008. Four-dimensional variational data assimilation for inverse modelling of atmospheric methane emissions: method and comparison with synthesis inversion. Atmospheric Chemistry and Physics 8, 6341-6353. 
Meirink, J.F., Eskes, H.J., Goede, A.P.H., 2006. Sensitivity analysis of methane emissions derived from SCIAMACHY observations through inverse modelling. Atmospheric Chemistry and Physics 6, 1275-1292.

Mijling, B., van der, A.,R.J., 2012. Using daily satellite observations to estimate emissions of short-lived air pollutants on a mesoscopic scale. Journal of Geophysical Research 117, D17302.

Mijling, B., van der, A.,R.J., Boersma, K.F., Van Roozendael, M., De Smedt, I., Kelder, H.M., 2009. Reductions of $\mathrm{NO}_{2}$ detected from space during the 2008 Beijing Olympic Games. Geophysical Research Letters 36, L13801.

Miller, C.E., Crisp, D., DeCola, P.L., Olsen, S.C., Randerson, J.T., Michalak, A.M., Alkhaled, A., Rayner, P., Jacob, D.J., Suntharalingam, P., Jones, D.B.A., Denning, A.S., Nicholls, M.E., Doney, S.C., Pawson, S., Boesch, H., Connor, B.J., Fung, I.Y., O’Brien, D., Salawitch, R.J., Sander, S.P., Sen, B., Tans, P., Toon, G.C. Wennberg, P.O., Wofsy, S.C., Yung, Y.L., Law, R.M., 2007. Precision requirements for space-based $X_{\mathrm{CO} 2}$ data. Journal of Geophysical Research 112, D10314.

Miller, S.M., Matross, D.M., Andrews, A.E., Millet, D.B., Longo, M., Gottlieb, E.W., Hirsch, A.I., Gerbig, C., Lin, J.C., Daube, B.C., Hudman, R.C., Dias, P.L.S., Chow, V.Y. Wofsy, S.C., 2008. Sources of carbon monoxide and formaldehyde in North America determined from high-resolution atmospheric data. Atmospheric Chemistry and Physics 8, 7673-7696.

Millet, D.B., Jacob, D.J., Boersma, K.F., Fu, T.-M., Kurosu, T.P., Chance, K., Heald, C.L., Guenther, A., 2008. Spatial distribution of isoprene emissions from North America derived from formaldehyde column measurements by the OMI satellite sensor. Journal of Geophysical Research 113, D02307.

Millet, D.B., Jacob, D.J., Turquety, S., Hudman, R.C., Wu, S., Fried, A., Walega, J., Heikes, B.G., Blake, D.R., Singh, H.B., Anderson, B.E., Clarke, A.D., 2006. Formaldehyde distribution over North America: implications for satellite retrievals of formaldehyde columns and isoprene emission. Journal of Geophysical Research 111, D24S02.

Miyazaki, K., Eskes, H.J., Sudo, K., 2012a. Global $\mathrm{NO}_{\mathrm{x}}$ emission estimates derived from an assimilation of OMI tropospheric $\mathrm{NO}_{2}$ columns. Atmospheric Chemistry and Physics 12, 2263-2288.

Miyazaki, K., Eskes, H.J., Sudo, K., Takigawa, M., van Weele, M., Boersma, K.F., 2012b. Simultaneous assimilation of satellite $\mathrm{NO}_{2}, \mathrm{O}_{3}, \mathrm{CO}$, and $\mathrm{HNO}_{3}$ data for the analysis of tropospheric chemical composition and emissions. Atmospheric Chemistry and Physics 12, 9545-9579.

Molina, L.T., Madronich, S., Gaffney, J.S., Apel, E., de Foy, B., Fast, J., Ferrare, R., Herndon, S., Jimenez, J.L., Lamb, B., Osornio-Vargas, A.R., Russell, P., Schauer, J.J., Stevens, P.S., Volkamer, R., Zavala, M., 2010. An overview of the MILAGRO 2006 Campaign: Mexico City emissions and their transport and transformation. Atmospheric Chemistry and Physics 10, 8697-8760.

Moore, D.P., Remedios, J.J., Waterfall, A.M., 2012. Global distributions of acetone in the upper troposphere from MIPAS spectra. Atmospheric Chemistry and Physics $12,757-768$.

Müller, J.-F., Stavrakou, T., 2005. Inversion of $\mathrm{CO}$ and $\mathrm{NO}_{\mathrm{x}}$ emissions using the adjoint of the IMAGES model. Atmospheric Chemistry and Physics 5, 1157-1186.

Myriokefalitakis, S., Vrekoussis, M., Tsigaridis, K., Wittrock, F., Richter, A., Brühl, C. Volkamer, R., Burrows, J.P., Kanakidou, M., 2008. The influence of natural and anthropogenic secondary sources on the glyoxal global distribution. Atmospheric Chemistry and Physics 8, 4965-4981.

Napelenok, S.L., Pinder, R.W., Gilliland, A.B., Martin, R.V., 2008. A method for evaluating spatially-resolved $\mathrm{NO}_{\mathrm{x}}$ emissions using Kalman filter inversion, direct sensitivities, and space-based $\mathrm{NO}_{2}$ observations. Atmospheric Chemistry and Physics 8, 5603-5614.

Nassar, R., Jones, D.B.A., Kulawik, S.S., Worden, J.R., Bowman, K.W., Andres, R.J., Suntharalingam, P., Chen, J.M., Brenninkmeijer, C.A.M., Schuck, T.J., Conway, T.J., Worthy, D.E., 2011. Inverse modeling of $\mathrm{CO}_{2}$ sources and sinks using satellite observations of $\mathrm{CO}_{2}$ from TES and surface flask measurements. Atmospheric Chemistry and Physics 11, 6029-6047.

National Aeronautics and Space Administration (NASA), 2013a. Air Quality Applied Sciences Team (AQAST). Website. http://www.aqast.org (accessed March 2013.).

National Aeronautics and Space Administration (NASA), 2013b. TEMPO News Release (accessed March 2013.). http://www.nasa.gov/home/hqnews/2012/nov/ HQ_12-390_TEMPO_Instrument.html.

Novotny, E.V., Bechle, M.J., Millet, D.B., Marshall, J.D., 2011. National satellite-based land-use regression: $\mathrm{NO}_{2}$ in the United States. Environmental Science \& Technology 45, 4407-4414.

Nowlan, C.R., Liu, X., Chance, K., Cai, Z., Kurosu, T.P., Lee, C., Martin, R.V., 2011. Retrievals of sulfur dioxide from the Global Ozone Monitoring Experiment 2 (GOME-2) using an optimal estimation approach: algorithm and initial validation. Journal of Geophysical Research 116, D18301.

Oshchepkov, S., Bril, A., Yokota, T., Morino, I., Yoshida, Y., Matsunaga, T., Belikov, D., Wunch, D., Wennberg, P., Toon, G., O'Dell, C., Butz, A., Guerlet, S., Cogan, A., Boesch, H., Eguchi, N., Deutscher, N., Griffith, D., Macatangay, R., Notholt, J., Sussmann, R., Rettinger, M., Sherlock, V., Robinson, J., Kyrö, E., Heikkinen, P., Feist, D.G., Nagahama, T., Kadygrov, N., Maksyutov, S., Uchino, O., Watanabe, H. 2012. Effects of atmospheric light scattering on spectroscopic observations of greenhouse gases from space: validation of PPDF-based $\mathrm{CO}_{2}$ retrievals from GOSAT. Journal of Geophysical Research 117, D12305.

Paciorek, C.J., Liu, Y., Moreno-Macias, H., Kondragunta, S., 2008. Spatiotemporal associations between GOES aerosol optical depth retrievals and ground-level $\mathrm{PM}_{2.5}$. Environmental Science \& Technology 42, 5800-5806.

Palmer, P.I., 2008. Quantifying sources and sinks of trace gases using space-borne measurements: current and future science. Philosophical Transactions of the Royal Society A 366, 4509-4528.
Palmer, P.I., Abbot, D.S., Fu, T.-M., Jacob, D.J., Chance, K., Kurosu, T.P., Guenther, A., Wiedinmyer, C., Stanton, J.C., Pilling, M.J., Pressley, S.N., Lamb, B., Sumner, A.L., 2006. Quantifying the seasonal and interannual variability of North American isoprene emissions using satellite observations of the formaldehyde column. Journal of Geophysical Research 111, D12315.

Palmer, P.I., Jacob, D.J., Fiore, A.M., Martin, R.V., Chance, K., Kurosu, T.P., 2003. Mapping isoprene emissions over North America using formaldehyde column observations from space. Journal of Geophysical Research 108, 4180.

Parker, R., Boesch, H., Cogan, A., Fraser, A., Feng, L., Palmer, P.I., Messerschmidt, J., Deutscher, N., Griffith, D.W.T., Notholt, J., Wennberg, P.O., Wunch, D., 2011 Methane observations from the Greenhouse Gases Observing SATellite: comparison to ground-based TCCON data and model calculations. Geophysical Research Letters 38, L15807.

Parrish, D.D., 2006. Critical evaluation of US on-road vehicle emission inventories. Atmospheric Environment 40, 2288-2300.

Pétron, G., Granier, C., Khattatov, B., Yudin, V., Lamarque, J.-F., Emmons, L., Gille, J. Edwards, D.P., 2004. Monthly CO surface sources inventory based on the 20002001 MOPITT satellite data. Geophysical Research Letters 31, L21107.

Pickett-Heaps, C.A., Jacob, D.J., Wecht, K.J., Kort, E.A., Wofsy, S.C., Diskin, G.S. Worthy, D.E.J., Kaplan, J.O., Bey, I., Drevet, J., 2011. Magnitude and seasonality of wetland methane emissions from the Hudson Bay Lowlands (Canada). Atmospheric Chemistry and Physics 11, 3773-3779.

Pillai, D., Gerbig, C., Marshall, J., Ahmadov, R., Kretschmer, R., Koch, T., Karstens, U. 2010. High resolution modeling of $\mathrm{CO}_{2}$ over Europe: implications for representation errors of satellite retrievals. Atmospheric Chemistry and Physics 10, 83-94

Pinder, R.W., Walker, J.T., Bash, J.O., Cady-Pereira, K.E., Henze, D.K., Luo, M., Osterman, G.B., Shephard, M.W., 2011. Quantifying spatial and seasonal variability in atmospheric ammonia with in situ and space-based observations. Geophysical Research Letters 38, L04802.

Prados, A.I., Kondragunta, S., Ciren, P., Knapp, K.R., 2007. GOES Aerosol/Smoke product (GASP) over North America: comparisons to AERONET and MODIS observations. Journal of Geophysical Research 112, D15201.

Prasad, A.K., Singh, R.P., Kafatos, M., 2012. Influence of coal-based thermal power plants on the spatial-temporal variability of tropospheric $\mathrm{NO}_{2}$ column over India. Environmental Monitoring and Assessment 184, 1891-1907.

Razavi, A., Clerbaux, C., Wespes, C., Clarisse, L., Hurtmans, D., Payan, S., CamyPeyret, C., Coheur, P.F., 2009. Characterization of methane retrievals from the IASI space-borne sounder. Atmospheric Chemistry and Physics 9, 7889-7899.

Razavi, A., Karagulian, F., Clarisse, L., Hurtmans, D., Coheur, P.F., Clerbaux, C. Müller, J.F., Stavrakou, T., 2011. Global distributions of methanol and formic acid retrieved for the first time from the IASI/MetOp thermal infrared sounder. Atmospheric Chemistry and Physics 11, 857-872.

Remer, L.A., Kaufman, Y.J., Tanré, D., Mattoo, S., Chu, D.A., Martins, J.V., Li, R.-R., Ichoku, C., Levy, R.C., Kleidman, R.G., Eck, T.F., Vermote, E., Holben, B.N., 2005. The MODIS aerosol algorithm, products, and validation. Journal of the Atmospheric Sciences 62, 947-973.

Reuter, M., Bovensmann, H., Buchwitz, M., Burrows, J.P., Connor, B.J. Deutscher, N.M., Griffith, D.W.T. Heymann, J. Keppel-Aleks, G. Messerschmidt, J., Notholt, J., Petri, C., Robinson, J., Schneising, O., Sherlock, V. Velazco, V., Warneke, T., Wennberg, P.O., Wunch, D., 2011. Retrieval of atmospheric $\mathrm{CO}_{2}$ with enhanced accuracy and precision from SCIAMACHY: validation with FTS measurements and comparison with model results. Journal of Geophysical Research 116, D04301.

Richter, A., Burrows, J.P., Nüß, H., Granier, C., Niemeier, U., 2005. Increase in tropospheric nitrogen dioxide over China observed from space. Nature 437, 129-132.

Richter, A., Eyring, V., Burrows, J.P., Bovensmann, H., Lauer, A., Sierk, B., Crutzen, P.J., 2004. Satellite measurements of $\mathrm{NO}_{2}$ from international shipping emissions. Geophysical Research Letters 31, L23110.

Rinsland, C.P., Boone, C.D., Bernath, P.F., Mahieu, E., Zander, R., Dufour, G., Clerbaux, C., Turquety, S., Chiou, L., McConnell, J.C., Neary, L., Kaminski, J.W. 2006a. First space-based observations of formic acid $(\mathrm{HCOOH})$ : atmospheric chemistry experiment austral spring 2004 and 2005 Southern Hemisphere tropical-mid-latitude upper tropospheric measurements. Geophysical Research Letters 33, L23804.

Rinsland, C.P., Luo, M., Logan, J.A., Beer, R., Worden, H., Kulawik, S.S., Rider, D., Osterman, G., Gunson, M., Eldering, A., Goldman, A., Shephard, M., Clough, S.A., Rodgers, C., Lampel, M., Chiou, L., 2006b. Nadir measurements of carbon monoxide distributions by the Tropospheric Emission Spectrometer instrument onboard the Aura Spacecraft: overview of analysis approach and examples of initial results. Geophysical Research Letters 33, L22806.

Rinsland, C.P., Dufour, G., Boone, C.D., Bernath, P.F., Chiou, L., 2005. Atmospheric Chemistry Experiment (ACE) measurements of elevated Southern Hemisphere upper tropospheric $\mathrm{CO}, \mathrm{C}_{2} \mathrm{H}_{6}, \mathrm{HCN}$, and $\mathrm{C}_{2} \mathrm{H}_{2}$ mixing ratios from biomass burning emissions and long-range transport. Geophysical Research Letters 32 , L20803.

Rinsland, C.P., Dufour, G., Boone, C.D., Bernath, P.F., Chiou, L., Coheur, P.-F. Turquety, S., Clerbaux, C., 2007. Satellite boreal measurements over Alaska and Canada during June-July 2004: simultaneous measurements of upper tropospheric $\mathrm{CO}, \mathrm{C}_{2} \mathrm{H}_{6}, \mathrm{HCN}, \mathrm{CH}_{3} \mathrm{Cl}, \mathrm{CH}_{4}, \mathrm{C}_{2} \mathrm{H}_{2}, \mathrm{CH}_{3} \mathrm{OH}, \mathrm{HCOOH}, \mathrm{OCS}$, and $\mathrm{SF}_{6}$ mixing ratios. Global Biogeochemical Cycles 21, GB3008.

Rix, M., Valks, P., Hao, N., Loyola, D., Schlager, H., Huntrieser, H., Flemming, J., Koehler, U., Schumann, U., Inness, A., 2012. Volcanic $\mathrm{SO}_{2}$, BrO and plume height estimations using GOME-2 satellite measurements during the eruption of Eyjafjallajökull in May 2010. Journal of Geophysical Research 117, D00U19. 
Rodgers, C.D., 2000. Inverse Methods for Atmospheric Sounding. World Scientific Publishing Co., Hackensack, NJ.

Russell, A.R., Perring, A.E., Valin, L.C., Bucsela, E.J., Browne, E.C., Min, K.-E., Wooldridge, P.J., Cohen, R.C., 2011. A high spatial resolution retrieval of $\mathrm{NO}_{2}$ column densities from OMI: method and evaluation. Atmospheric Chemistry and Physics 11, 8543-8554.

Russell, A.R., Valin, L.C., Bucsela, E.J., Wenig, M.O., Cohen, R.C., 2010. Space-based constraints on spatial and temporal patterns of $\mathrm{NO}_{\mathrm{x}}$ emissions in California, 2005-2008. Environmental Science \& Technology 44, 3608-3615.

Russell, A.R., Valin, L.C., Cohen, R.C., 2012. Trends in OMI NO 2 observations over the United States: effects of emission control technology and the economic recession. Atmospheric Chemistry and Physics 12, 12197-12209.

Sandu, A., Chai, T., 2011. Chemical data assimilation-an overview. Atmosphere 2 426-463.

Schneider, P., van der, A.,R.J., 2012. A global single-sensor analysis of 2002-2011 tropospheric nitrogen dioxide trends observed from space. Journal of Geophysical Research 117, D16309.

Schneising, O., Heymann, J., Buchwitz, M., Reuter, M., Bovensmann, H., Burrows, J.P., 2013. Anthropogenic carbon dioxide source areas observed from space: assessment of regional enhancements and trends. Atmospheric Chemistry and Physics 13, 2445-2454

Schumann, U., Huntrieser, H., 2007. The global lightning-induced nitrogen oxides source. Atmospheric Chemistry and Physics 7, 3823-3907.

Shephard, M.W., Cady-Pereira, K.E., Luo, M., Henze, D.K., Pinder, R.W., Walker, J.T., Rinsland, C.P., Bash, J.O., Zhu, L., Payne, V.H., Clarisse, L., 2011. TES ammonia retrieval strategy and global observations of the spatial and seasonal variability of ammonia. Atmospheric Chemistry and Physics 11, 10743-10763.

Shim, C., Li, Q., Luo, M., Kulawik, S., Worden, H., Worden, J., Eldering, A., Diskin, G., Sachse, G., Weinheimer, A., Knapp, D., Montzca, D., Campos, T., 2009. Satellite observations of Mexico City pollution outflow from the Tropospheric Emissions Spectrometer (TES). Atmospheric Environment 43, 1540-1547.

Shim, C., Wang, Y., Choi, Y., Palmer, P.I., Abbot, D.S., Chance, K., 2005. Constraining global isoprene emissions with Global Ozone Monitoring Experiment (GOME) formaldehyde column measurements. Journal of Geophysical Research 110 D24301.

Stavrakou, T., Guenther, A., Razavi, A., Clarisse, L., Clerbaux, C., Coheur, P.-F., Hurtmans, D., Karagulian, F., De Mazière, M., Vigouroux, C., Amelynck, C., Schoon, N., Laffineur, Q., Heinesch, B., Aubinet, M., Rinsland, C., Müller, J.-F., 2011a. First space-based derivation of the global atmospheric methanol emission fluxes. Atmospheric Chemistry and Physics 11, 4873-4898.

Stavrakou, T., Müller, J.-F., 2006. Grid-based versus big region approach for inverting $\mathrm{CO}$ emissions using Measurement of Pollution in the Troposphere (MOPITT) data. Journal of Geophysical Research 111, D15304.

Stavrakou, T., Müller, J.-F., De Smedt, I., Van Roozendael, M., Kanakidou, M. Vrekoussis, M., Wittrock, F., Richter, A., Burrows, J.P., 2009a. The continental source of glyoxal estimated by the synergistic use of spaceborne measurements and inverse modelling. Atmospheric Chemistry and Physics 9, 8431-8446.

Stavrakou, T. Müller, J.-F., De Smedt, I., Van Roozendael, M., van der Werf, G.R., Giglio, L., Guenther, A., 2009b. Evaluating the performance of pyrogenic and biogenic emission inventories against one decade of space-based formaldehyde columns. Atmospheric Chemistry and Physics 9, 1037-1060.

Stavrakou, T., Müller, J.-F., De Smedt, I., Van Roozendael, M., van der Werf, G.R Giglio, L., Guenther, A., 2009c. Global emissions of non-methane hydrocarbons deduced from SCIAMACHY formaldehyde columns through 2003-2006. Atmospheric Chemistry and Physics 9, 3663-3679.

Stavrakou, T., Müller, J.-F., Peeters, J., Razavi, A., Clarisse, L., Clerbaux, C., Coheur, P.-F., Hurtmans, D., De Mazière, M., Vigouroux, C., Deutscher, N.M., Griffith, D.W.T. Jones, N., Paton-Welsh, C., 2011b. Satellite evidence for a large source of formic acid from boreal and tropical forests. Nature Geoscience 5, 26-30.

Taubman, B.F., Hains, J.C., Thompson, A.M., Marufu, L.T., Doddridge, B.G., Stehr, J.W. Piety, C.A., Dickerson, R.R., 2006. Aircraft vertical profiles of trace gas and aerosol pollution over the mid-Atlantic United States: statistics and meteorological cluster analysis. Journal of Geophysical Research 111, D10S07.

Thomas, H.E., Watson, I.M., 2010. Observations of volcanic emissions from space: current and future perspectives. Natural Hazards 54, 323-354.

Toenges-Schuller, N., Stein, O., Rohrer, F., Wahner, A., Richter, A., Burrows, J.P. Beirle, S., Wagner, T., Platt, U., Elvidge, C.D., 2006. Global distribution pattern of anthropogenic nitrogen oxide emissions: correlation analysis of satellite measurements and model calculations. Journal of Geophysical Research 111, D05312.

Turner, A.J., Henze, D.K., Martin, R.V., Hakami, A., 2012. The spatial extent of source influences on modeled column concentrations of short-lived species. Geophysical Research Letters 39, L12806.

Urbanski, S.P., Hao, W.M., Nordgren, B., 2011. The wildland fire emission inventory: western United States emission estimates and an evaluation of uncertainty. Atmospheric Chemistry and Physics 11, 12973-13000.

Valin, L.C., Russell, A.R., Hudman, R.C., Cohen, R.C., 2011. Effects of model resolution on the interpretation of satellite $\mathrm{NO}_{2}$ observations. Atmospheric Chemistry and Physics 11, 11647-11655.

Vandaele, A.C., Hermans, C., Simon, P.C., Carleer, M., Colin, R., Fally, S., Mérienne, M.F. Jenouvrier, A., Coquart, B., 1998. Measurements of the $\mathrm{NO}_{2}$ absorption crosssection from $42000 \mathrm{~cm}^{-1}$ to $10000 \mathrm{~cm}^{-1}(238-1000 \mathrm{~nm})$ at $220 \mathrm{~K}$ and 294 K. Journal of Quantitative Spectroscopy and Radiative Transfer 59, 171-184.

van den Oord, G.H.J., Rozemeijer, N.C., Schenkelaars, V., Levelt, P.F., Dobber, M.R. Voors, R.H.M., Claas, J., de Vries, J., ter Linden, M., De Haan, C., van de Berg, T.,
2006. OMI Level 0 to $1 \mathrm{~b}$ processing and operational aspects. IEEE Transactions on Geoscience and Remote Sensing 44, 1380-1397.

van der, A.,R.J., Eskes, H.J., Boersma, K.F., van Noije, T.P.C., Van Roozendael, M., De Smedt, I., Peters, D.H.M.U., Meijer, E.W., 2008. Trends, seasonal variability and dominant $\mathrm{NO}_{\mathrm{x}}$ source derived from a ten year record of $\mathrm{NO}_{2}$ measured from space. Journal of Geophysical Research 113, D04302.

van der, A.,R.J., Peters, D.H.M.U., Eskes, H., Boersma, K.F., Van Roozendael, M., De Smedt, I., Kelder, H.M., 2006. Detection of the trend and seasonal variation in tropospheric $\mathrm{NO}_{2}$ over China. Journal of Geophysical Research 111, D12317.

van der Werf, G.R., Randerson, J.T., Giglio, L., Collatz, G.J., Mu, M., Kasibhatla, P.S., Morton, D.C., DeFries, R.S., Jin, Y., van Leeuwen, T.T., 2010. Global fire emissions and the contribution of deforestation, savanna, forest, agricultural, and peat fires (1997-2009). Atmospheric Chemistry and Physics 10, 11707-11735.

van Donkelaar, A., Martin, R.V., Brauer, M., Kahn, R., Levy, R., Verduzco, C., Villeneuve, P.J., 2010. Global estimates of ambient fine particulate matter concentrations from satellite-based aerosol optical depth: development and application. Environmental Health Perspectives 118, 847-855.

von Bobrutzki, K., Braban, C.F., Famulari, D., Jones, S.K., Blackall, T., Smith, T.E.L., Blom, M., Coe, H., Gallagher, M., Ghalaieny, M., McGillen, M.R., Percival, C.J., Whitehead, J.D., Ellis, R., Murphy, J., Mohacsi, A., Pogany, A., Junninen, H., Rantanen, S., Sutton, M.A., Nemitz, E., 2010. Field inter-comparison of eleven atmospheric ammonia measurement techniques. Atmospheric Measurement Techniques 3, 91-112.

Vrekoussis, M., Wittrock, F., Richter, A., Burrows, J.P., 2009. Temporal and spatial variability of glyoxal as observed from space. Atmospheric Chemistry and Physics 9, 4485-4504.

Vrekoussis, M., Wittrock, F., Richter, A., Burrows, J.P., 2010. GOME-2 observations of oxygenated VOCs: what can we learn from the ratio glyoxal to formaldehyde on a global scale? Atmospheric Chemistry and Physics 10, 10145-10160.

Vrekoussis, M., Richter, A., Hilboll, A., Burrows, J.P., Gerasopoulos, E., Lelieveld, J., Barrie, L., Zerefos, C., Mihalopoulos, N., 2013. Economic crisis detected from space: air quality observations over Athens/Greece. Geophysical Research Letters $40,458-463$.

Walter, D, Heue, K.-P., Rauthe-Schöch, A, Brenninkmeijer, C.A.M, Lamsal, LN. Krotkov, N.A., Platt, U., 2012. Flux calculation using CARIBIC DOAS air craft measurements: $\mathrm{SO}_{2}$ emission of Norilsk. Journal of Geophysical Research 117, D11305.

Wang J. Christopher, S.A. 2003. Intercomparison between satellite-derived aerosol optical thickness and $\mathrm{PM}_{2.5}$ mass: implications for air quality studies. Geophysical Research Letters 30, 2095.

Wang, S., Streets, D.G., Zhang, Q., He, K., Chen, D., Kang, S., Lu, Z., Wang, Y., 2010. Satellite detection and model verification of $\mathrm{NO}_{\mathrm{x}}$ emissions from power plants in northern China. Environmental Research Letters 5, 044007.

Wang, S., Zhang, Q., Streets, D.G., He, K.B., Martin, R.V., Lamsal, L.N., Chen, D., Lei, Y., Lu, Z., 2012. Growth in $\mathrm{NO}_{\mathrm{x}}$ emissions from power plants in China: bottom-up estimates and satellite observations. Atmospheric Chemistry and Physics 12 4429-4447.

Wang, Y., McElroy, M.B., Boersma, K.F., Eskes, H.J., Veefkind, J.P., 2007. Traffic restrictions associated with the Sino-African summit: reductions of $\mathrm{NO}_{\mathrm{x}}$ detected from space. Geophysical Research Letters 34, L08814.

Wecht, K.J., Jacob, D.J., Wofsy, S.C., Kort, E.A., Worden, J.R., Kulawik, S.S., Henze, D.K., Kopacz, M., Payne, V.H., 2012. Validation of TES methane with HIPPO aircraft observations: implications for inverse modeling of methane sources. Atmospheric Chemistry and Physics 12, 1823-1832.

Wells, K.C., Millet, D.B., Hu, L., Cady-Pereira, K.E., Xiao, Y., Shephard, M.W., Clerbaux, C.L., Clarisse, L., Coheur, P.-F., Apel, E.C., de Gouw, J., Warneke, C., Singh, H.B., Goldstein, A.H., Sive, B.C., 2012. Tropospheric methanol observations from space: retrieval evaluation and constraints on the seasonality of biogenic emissions. Atmospheric Chemistry and Physics 12, 5897-5912.

Wiedinmyer, C., Akagi, S.K., Yokelson, R.J., Emmons, L.K., Al-Saadi, J.A., Orlando, J.J., Soja, A.J., 2011. The Fire INventory from NCAR (FINN): a high resolution global model to estimate the emissions from open burning. Geoscientific Model Development 4, 625-641.

Wiegele, A., Glatthor, N., Höpfner, M., Grabowski, U., Kellmann, S., Linden, A., Stiller, G., von Clarmann, T., 2012. Global distributions of $\mathrm{C}_{2} \mathrm{H}_{6}, \mathrm{C}_{2} \mathrm{H}_{2}, \mathrm{HCN}$, and PAN retrieved from MIPAS reduced spectral resolution measurements. Atmospheric Measurement Techniques 5, 723-734.

Winker, D.M., Hunt, W.H., McGill, M.J., 2007. Initial performance assessment of CALIOP. Geophysical Research Letters 34, L19803.

Witte, J.C. Schoeberl, M.R., Douglass, A.R., Gleason, J.F., Krotkov, N.A., Gille, J.C., Pickering, K.E., Livesey, N., 2009. Satellite observations of changes in air quality during the 2008 Beijing Olympics and Paralympics. Geophysical Research Letters 36, L17803.

Wittrock, F., Richter, A., Oetjen, H., Burrows, J.P., Kanakidou, M., Myriokefalitakis, S., Volkamer, R., Beirle, S., Platt, U., Wagner, T., 2006. Simultaneous global observations of glyoxal and formaldehyde from space. Geophysical Research Letters 33, L16804.

Worden, H.M., Chang, Y., Pfister, G., Carmichael, G.R., Zhang, Q., Streets, D.G., Deeter, M., Edwards, D.P., Gille, J.C., Worden, J.R., 2012a. Satellite-based estimates of reduced $\mathrm{CO}$ and $\mathrm{CO}_{2}$ emissions due to traffic restrictions during the 2008 Beijing Olympics. Geophysical Research Letters 39, L14802.

Worden, H.M., Deeter, M.N., Edwards, D.P., Gille, J.C., Drummond, J.R., Nédélec, P., 2010. Observations of near-surface carbon monoxide from space using MOPITT multispectral retrievals. Journal of Geophysical Research 115, D18314.

Worden, H.M., Deeter, M.N., Frankenberg, C., George, M., Nichitiu, F., Worden, J., Aben, I., Bowman, K.W., Clerbaux, C., Coheur, P.F., de Laat, A.T.J., Detweiler, R., 
Drummond, J.R., Edwards, D.P., Gille, J.C., Hurtmans, D., Luo, M., MartínezAlonso, S., Massie, S., Pfister, G., Warner, J.X., 2013. Decadal record of satellite carbon monoxide observations. Atmospheric Chemistry and Physics 13, 837-850.

Worden, J., Kulawik, S., Frankenberg, C., Payne, V., Bowman, K., Cady-Peirara, K., Wecht, K., Lee, J.-E., Noone, D., 2012b. Profiles of $\mathrm{CH}_{4}, \mathrm{HDO}, \mathrm{H}_{2} \mathrm{O}$, and $\mathrm{N}_{2} \mathrm{O}$ with improved lower tropospheric vertical resolution from Aura TES radiances. Atmospheric Measurement Techniques 5, 397-411.

Xia, X., Eck, T.F., Holben, B.N., Phillippe, G., Chen, H., 2008. Analysis of the weekly cycle of aerosol optical depth using AERONET and MODIS data. Journal of Geophysical Research 113, D14217.

Xiong, X., Barnet, C., Maddy, E., Wei, J., Liu, X., Pagano, T.S., 2010. Seven years' observation of mid-upper tropospheric methane from Atmospheric Infrared Sounder. Remote Sensing 2, 2509-2530.

Xiong, X., Houweling, S., Wei, J., Maddy, E., Sun, F., Barnet, C., 2009. Methane plume over south Asia during the monsoon season: satellite observation and model simulation. Atmospheric Chemistry and Physics 9, 783-794.

Yang, K., Krotkov, N.A., Krueger, A.J., Carn, S.A., Bhartia, P.K., Levelt, P.F., 2007. Retrieval of large volcanic $\mathrm{SO}_{2}$ columns from the Aura Ozone Monitoring Instrument: Comparison and limitations. Journal of Geophysical Research 112 , D24S43.

Yang, K., Liu, X., Bhartia, P.K., Krotkov, N.A., Carn, S.A., Hughes, E.J., Krueger, A.J., Spurr, R.J.D., Trahan, S.G., 2010. Direct retrieval of sulfur dioxide amount and altitude from spaceborne hyperspectral UV measurements: theory and application. Journal of Geophysical Research 115, D00L09.

Yokota, T., Yoshida, Y., Eguchi, N., Ota, Y., Tanaka, T., Watanabe, H., Maksyutov, S., 2009. Global concentrations of $\mathrm{CO}_{2}$ and $\mathrm{CH}_{4}$ retrieved from GOSAT: first preliminary results. Scientific Online Letters on the Atmosphere 5, 160-163.

Yoshida, Y., Duncan, B.N., Retscher, C., Pickering, K.E., Celarier, E.A., Joiner, J., Boersma, K.F., Veefkind, J.P., 2010. The impact of the 2005 Gulf hurricanes on pollution emissions as inferred from Ozone Monitoring Instrument (OMI) nitrogen dioxide. Atmospheric Environment 44, 1443-1448.

Zellweger, C., Hüglin, C., Klausen, J., Steinbacher, M., Vollmer, M., Buchmann, B., 2009. Inter-comparison of four different carbon monoxide measurement techniques and evaluation of the long-term carbon monoxide time series of Jungfraujoch. Atmospheric Chemistry and Physics 9, 3491-3503.

Zhang, L., Constantinescu, E.M., Sandu, A., Tang, Y., Chai, T., Carmichael, G.R., Byun, D. Olaguer, E., 2008. An adjoint sensitivity analysis and 4D-Var data assimilation study of Texas air quality. Atmospheric Environment 42, 5787-5804.

Zhang, Q., Geng, G., Wang, S., Richter, A., He, K., 2012. Satellite remote sensing of changes in $\mathrm{NO}_{\mathrm{x}}$ emissions over China during 1996-2010. Chinese Science Bulletin 57, 2857-2864.

Zhang, Q., Streets, D.G., He, K., 2009a. Satellite observations of recent power plant construction in Inner Mongolia, China. Geophysical Research Letters 36, L15809.

Zhang, Q., Streets, D.G., He, K., Wang, Y., Richter, A., Burrows, J.P., Uno, I., Jang, C.J., Chen, D., Yao, Z., Lei, Y., 2007. $\mathrm{NO}_{\mathrm{x}}$ emission trends for China, 1995-2004: the view from the ground and the view from space. Journal of Geophysical Research 112, D22306.

Zhang, X.Y., Wang, Y.Q., Lin, W.L., Zhang, Y.M., Zhang, X.C., Gong, S., Zhao, P., Yang, Y.Q., Wang, J.Z., Hou, Q., Zhang, X.L., Che, H.Z., Guo, J.P., Li, Y., 2009b. Changes of atmospheric composition and optical properties over Beijing-2008 Olympic monitoring campaign. Bulletin of the American Meteorological Society $90,1633-1651$

Zhao, C., Wang, Y., 2009. Assimilated inversion of $\mathrm{NO}_{\mathrm{x}}$ emissions over east Asia using OMI $\mathrm{NO}_{2}$ column measurements. Geophysical Research Letters 36 L06805.

Zhou, Y., Brunner, D., Hueglin, C., Henne, S., Staehelin, J., 2012. Changes in OMI tropospheric $\mathrm{NO}_{2}$ columns over Europe from 2004 to 2009 and the influence of meteorological variability. Atmospheric Environment 46, 482-495.

Zhu, L., Henze, D.K., Cady-Pereira, K.E., Shephard, M.W., Luo, M., Pinder, R.W. Bash, J.O., Jeong, G.-R., 2013. Constraining U.S. ammonia emissions using TES remote sensing observations and the GEOS-Chem adjoint model. Journal of Geophysical Research 118, 3355-3368.

Zyrichidou, I., Koukouli, M.E., Balis, D.S., Katragkou, E., Melas, D., Poupkou, A Kioutsioukis, I., van der, A.,R., Boersma, F.K., van Roozendael, M., Richter, A., 2009. Satellite observations and model simulations of tropospheric $\mathrm{NO}_{2}$ columns over south-eastern Europe. Atmospheric Chemistry and Physics 9, 6119-6134. 